Portland State University

PDXScholar

$1-1-2011$

\title{
Storytelling as Loving Praxis in Critical Peace Education: A Grounded Theory Study of Postsecondary Social Justice Educators
}

Amanda Smith Byron

Portland State University

Follow this and additional works at: https://pdxscholar.library.pdx.edu/open_access_etds

Part of the Curriculum and Instruction Commons, and the Curriculum and Social Inquiry Commons Let us know how access to this document benefits you.

Recommended Citation

Byron, Amanda Smith, "Storytelling as Loving Praxis in Critical Peace Education: A Grounded Theory Study of Postsecondary Social Justice Educators" (2011). Dissertations and Theses. Paper 245.

https://doi.org/10.15760/etd.245

This Dissertation is brought to you for free and open access. It has been accepted for inclusion in Dissertations and Theses by an authorized administrator of PDXScholar. Please contact us if we can make this document more accessible: pdxscholar@pdx.edu. 
Storytelling as Loving Praxis in Critical Peace Education: A Grounded Theory Study of Postsecondary Social Justice Educators

by

Amanda Smith Byron

A dissertation submitted in partial fulfillment of the requirements for the degree of

Doctor of Education

in

Educational Leadership: Curriculum and Instruction

Dissertation Committee:

Ramin Farahmandpur, Chair

Samuel Henry

Swapna Mukhopadhyay

Candyce Reynolds

Yves Labissiere

Portland State University

(C)2011 


\begin{abstract}
Looking through the philosophical lens of love, this study seeks a deeper understanding and appreciation of how postsecondary social justice educators use storytelling, in the context of critical peace education, to create social change. This research explores the guiding question of how storytelling is used to encourage social change and to inspire action toward the goal of greater social justice. The argument for the importance of this research is located within the crisis of neoliberalism, where the very tenets of democratic education are being challenged by an educational agenda that favors standards-based learning and employment training over the critical and analytical thinking skills required for democracy to flourish. The results of this study identify storytelling as a method of ideology critique, and locate it within a larger process of loving praxis. A theoretical model of loving praxis is offered to explain how postsecondary social justice educators engage story as an action that leads to the goal of social justice. The steps in the model describe how valuing the common good motivates social justice educators to take action through storytelling, toward the outcome of building transformation, voice, and agency within students as a means to build greater social justice. The sense of possibility that is cultivated in this process re-engages the cycle by validating the value of and hope for the common good.
\end{abstract}




\section{Dedication}

To "all of those who, whether known or unknown to the world, have held aloft the light of Truth through the darkness of human ignorance."

(Prayer from Universal Worship Service, Hazrat Inayat Khan)

This paper is dedicated to social justice educators throughout the world, whether they know themselves by this designation or not, who have opened people's eyes to the presence of injustice and who, using their own pedagogies of love, have inspired action toward change.

This paper is offered with reverence to the living presence of Mevlana Jelaluddin Rumi, a thirteenth-century Persian Sufi, who has invited the contemporary world into a passionate and inherently radical discourse of love through the gift of his mystical poetry. May we all be so blessed, with adequate words and swift agency, to express our love for humanity in our decisive actions toward greater social justice. 


\section{Acknowledgments}

I believe that success only happens with the love of family, friends, and colleagues, and with a strong vote of confidence from the universe at large. Without the breath-taking surge of support from all of the people who helped me with this project, and the myriad and rock-star opportunities that facilitated its completion, I would still be waiting to set sail. So, thank you all for your help in reaching this goal.

I would first like to acknowledge Isbel Ingham, my friend and mentor, who provided praise and encouragement on this seemingly Sisyphean journey. Without Isbel's continued kindness and brilliance, I would have abandoned ship many times over. My chair, Ramin Farahmandpur, was patient and unrelenting in his determination to keep me anchored in the strong tradition of critical theory, and (I think) kept me from slipping into the squishy nether regions of the new age. Candyce Reynolds provided much-needed insight and feedback, and selflessly kept me well occupied with online scrabble whenever I needed a break from writing. Samuel Henry, Yves Labissiere, and Swapna Mukhopadhyay graciously weighed in when asked, and shared their wealth of experience and expertise in the design and direction of this paper.

Andy, Elijah, and Sydney, my wonderful family, allowed me the time and space to work on this project, and kept me well schooled in the praxis of love. Whenever I would lose direction, they readily reminded me that I was good enough, I was smart enough, and gosh darn it, people liked me. They worked very hard to help me keep an even keel, and picked up the pieces when I occasionally and dramatically capsized. I look 
forward to having more time to adventure with you all, and to supporting you to write your own dissertations in time.

A heart-felt thank you to all of the respondents who shared their time, wisdom, and experience as part of this study. Thanks to Roberta Hunte, Amy Juve, Zafreen Jaffery, Jan Carpenter, Janelle Voegele, and Jolina Kwong Caputo, whose camaraderie in this task has carried me through the last six years. Thanks to my friend and colleague Rachel Hardesty, who shared her precious time each week as I developed the parameters of the study. Thanks to Jelehla Ziemba, my lifelong friend and perfectly persnickety editor. Thanks to Laurie Regan for so many delightful, refreshing, and fully distracting coffee breaks at the "Makery." Last, but certainly not least, I want to thank Robert Jarvis Gould, without whom I never would have embarked on this journey. My life as an accidental academic started because of our collegial rapport, and this accomplishment is very much the result of his unflagging encouragement, support, and insistence.

Thank you, and I wish you all the satisfaction of realizing your hearts' desires. 


\section{Table of Contents}

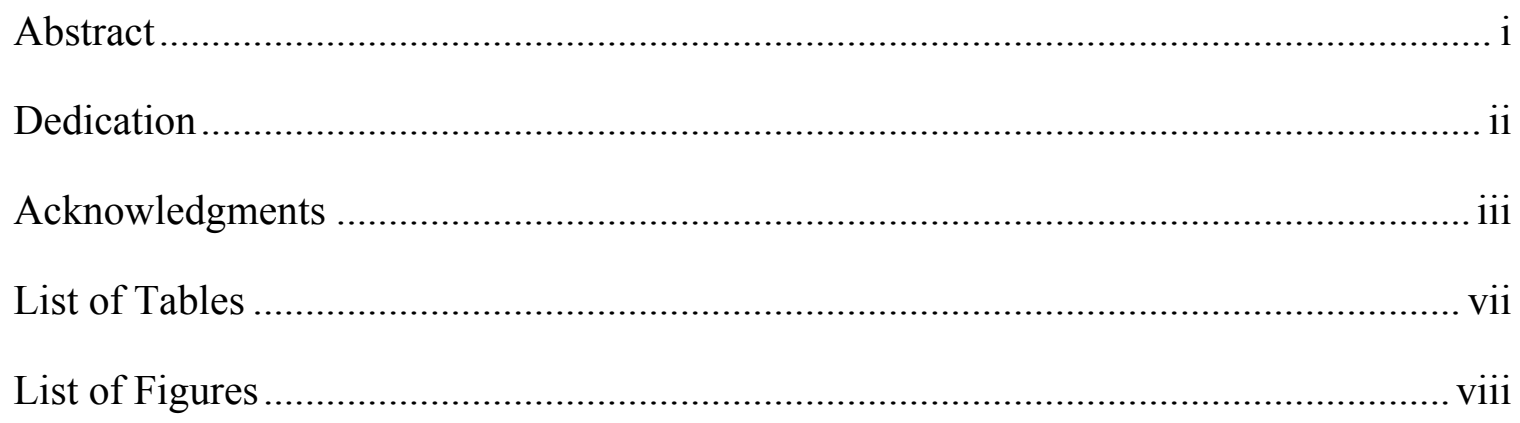

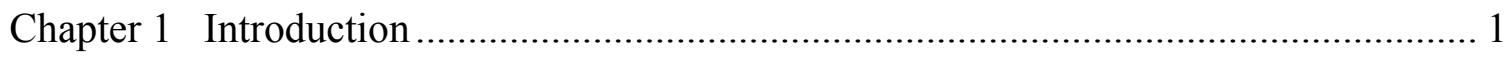

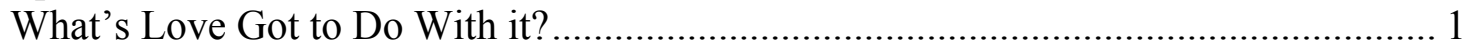

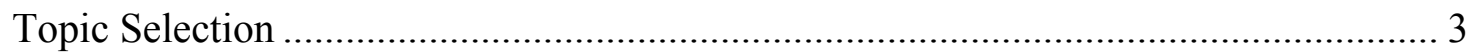

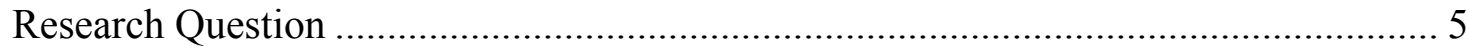

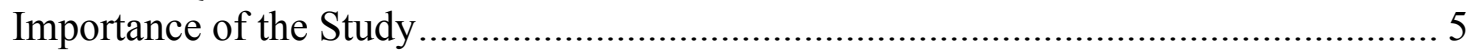

Social Justice as a Value: A Caveat................................................................... 10

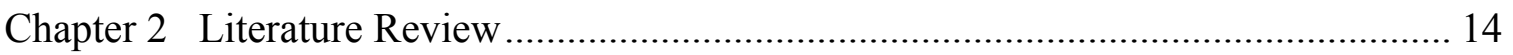

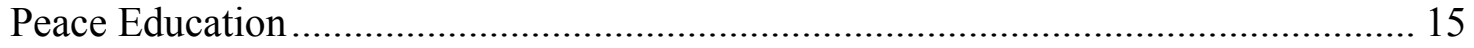

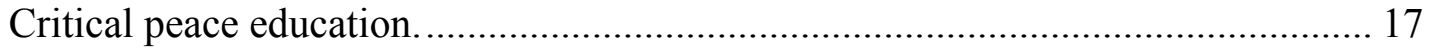

Critical pedagogy and social justice education.................................................... 19

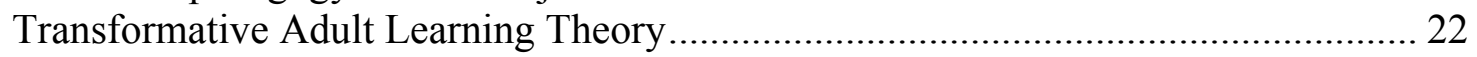

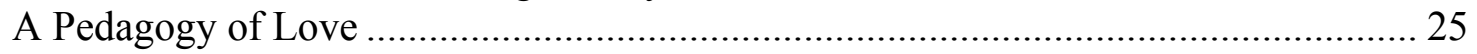

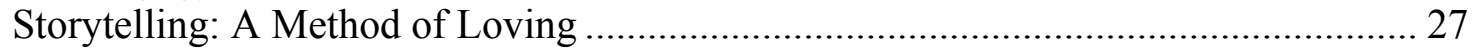

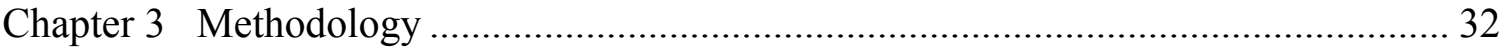

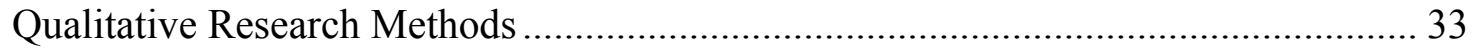

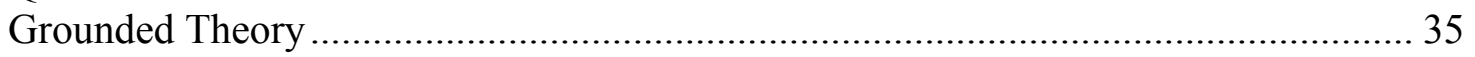

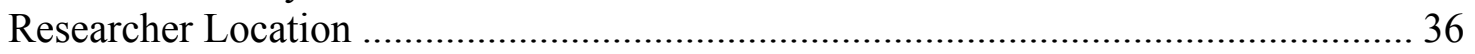

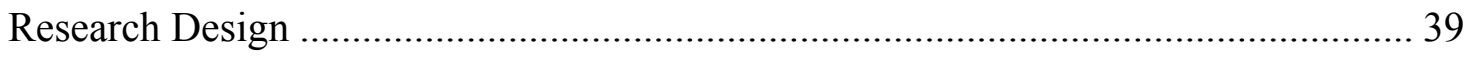

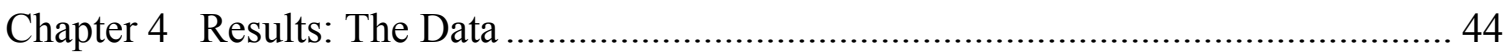

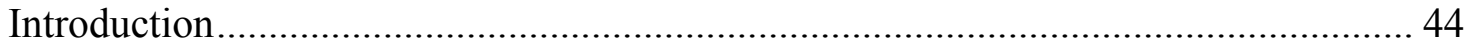

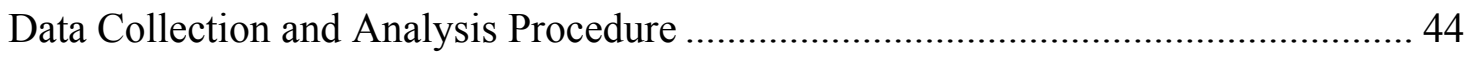

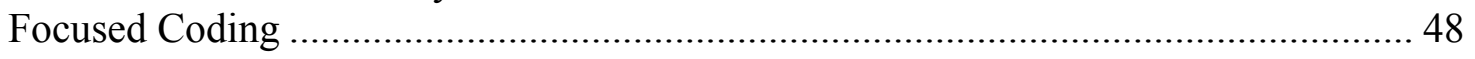

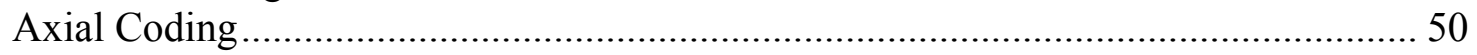

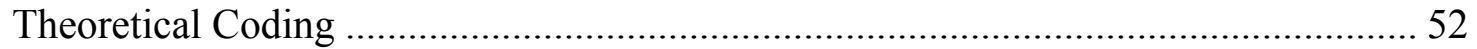

Analysis of Conceptual Categories ........................................................................... 53

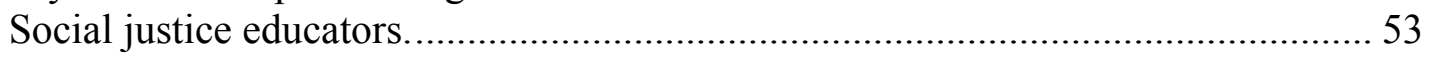

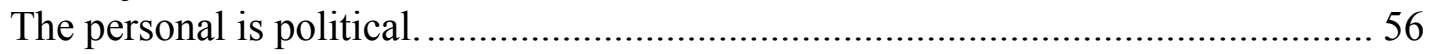

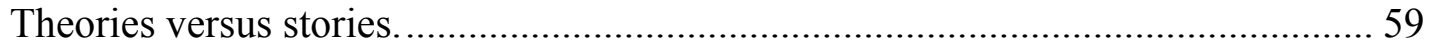

Relationship building through story sharing............................................................. 63 


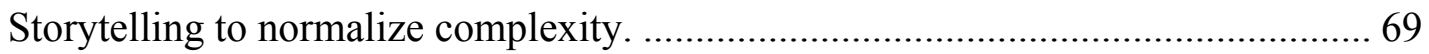

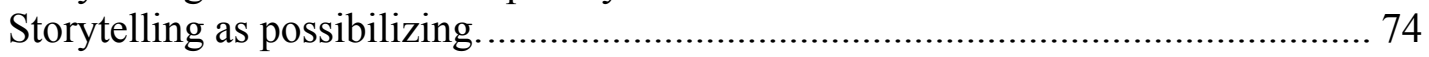

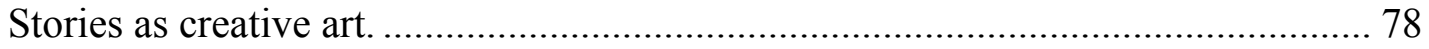

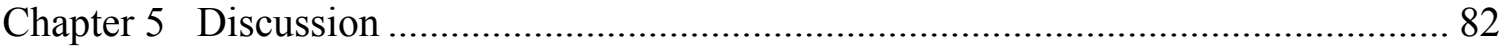

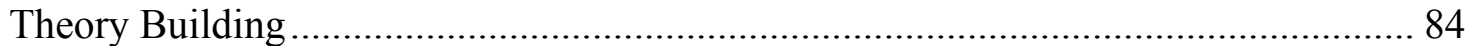

My Theory of Loving Praxis: Storytelling as Ideology Critique ............................... 86

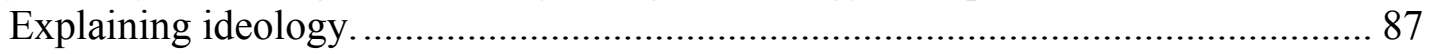

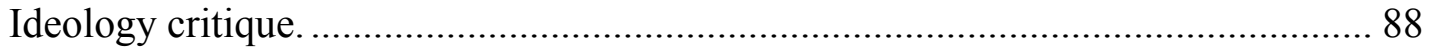

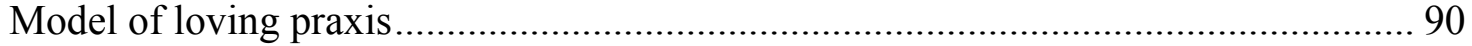

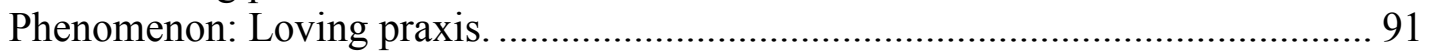

Motivation: Common good/goodness sake........................................................ 92

Actors: Postsecondary social justice educators. ............................................... 94

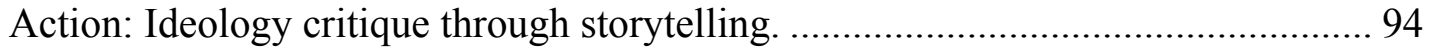

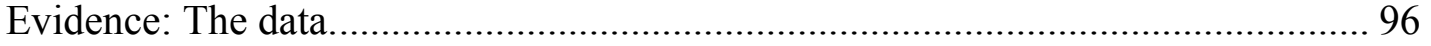

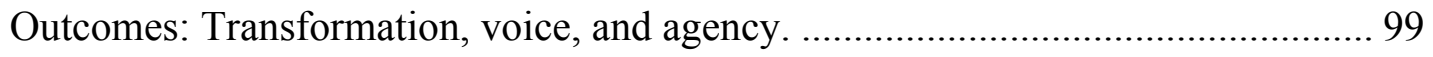

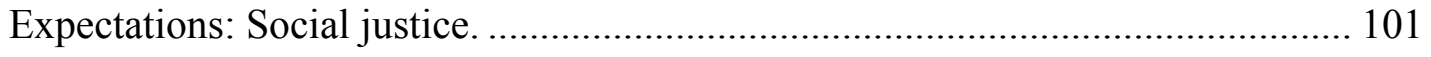

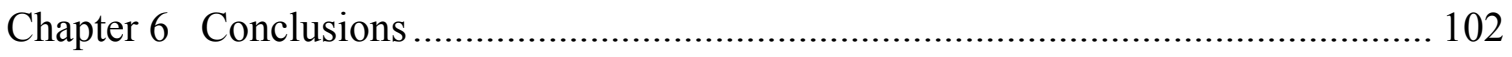

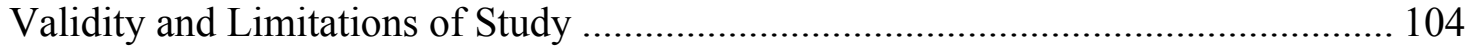

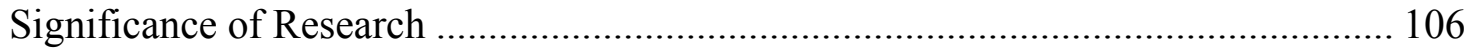

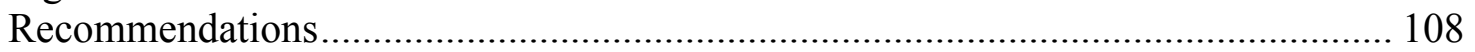

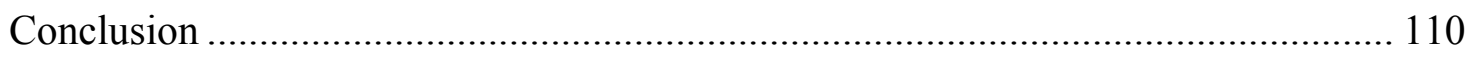

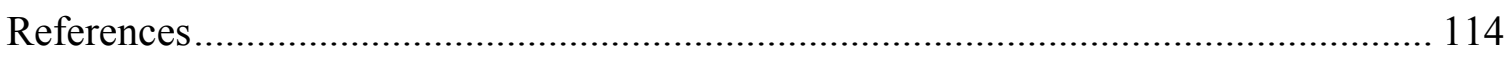

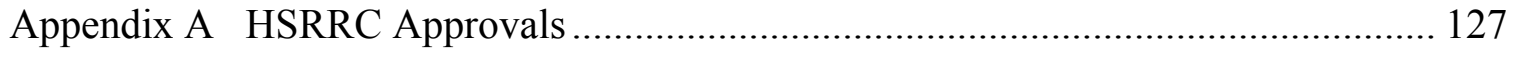

Appendix B HSRRC Application Proposal ...................................................... 130

Appendix C Description of Study Participants................................................... 139 


\section{List of Tables}

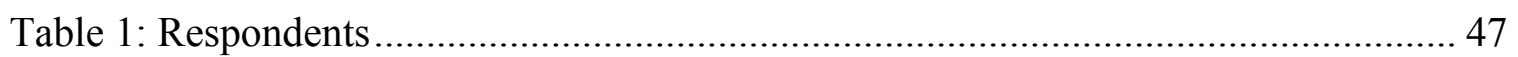

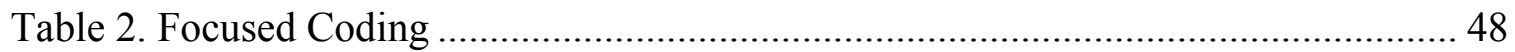

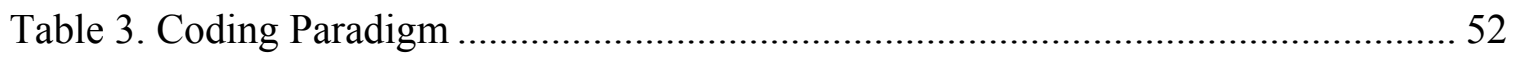




\section{List of Figures}

Figure 1. Conceptual Framework for Dissertation Research........................................... 83

Figure 2. Schema of Loving Praxis as Theoretical Model .............................................. 91

Figure 3. The Storytelling Project Model: Creating Counter-Storytelling ....................... 96

Figure 4. Focused Codes as Consistent with Bell's Storytelling Project Model to

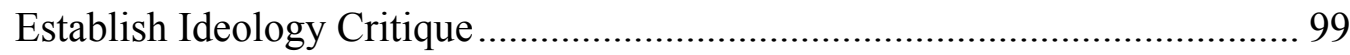




\section{Chapter 1}

\section{Introduction}

\section{What's Love Got to Do With it?}

Love is not a new topic for academic exploration. Historically, love has been of great interest within philosophical inquiry and, over time, the study of love has gained currency across multiple academic disciplines. The start of the last century witnessed the Frankfurt School instigating a conversation about love as a form of revolutionary praxis that provides a vital counter-discourse to the capitalistic values of dominant culture. Erich Fromm encouraged further consideration of love in his well-known publication, The Art of Loving (1956); others have subsequently picked up the thread from different perspectives, and in service to a number of diverse ideologies. Nel Noddings (1984), for example, built on the concept of love to introduce the importance of ethical caring within the field of education, and many others have followed that line of inquiry (Darder, 2002; hooks, 2000; Liston \& Garrison, 2004; Rossiter, 2006).

In popular culture, love is presented as a panacea for social problems. The corporate media ${ }^{1}$ reinforces a one-dimensional face of love where it is, at best, sentimentalized - love is all you need — and, at worst, commodified — long-term happiness comes from the short-term action of purchasing something. The New York Times heralds love as the current and ubiquitous sure thing in advertising (Newman, 2009) - you'll love this car, that bank, and any number of other things guaranteed to

\footnotetext{
1 "The corporate media" is not difficult to generalize because of the wholesale deregulation of media ownership that has taken place in recent history, and also as a result of the heterogeneous nature of the six "imperialist, white-supremacist, capitalist, patriarchal" (hooks, 1989, p. 50) media giants who own (and shape) the corporate media.
} 
satisfy your quest for meaning in life. This popular conceptualization of love as resulting from material gain adeptly illustrates how human emotions can be commodified to benefit capitalist interests. Yet, the love of material things does not deliver the promise of enduring satisfaction, nor does it provide a deeper meaning to life. It is a one-sided phenomenon that shortchanges the lover by denying her the byproduct of love: connection. As consumers become disillusioned by the superficial nature of a commodified love, their idea of love itself can become correspondingly tarnished.

Love has continuously been a subject of great interest within the domains of philosophy and mysticism, drawing from the suggestion of metaphor instead of relying upon a concrete description for absolute meaning. The philosophic and transcendent nature of love makes it particularly difficult to define, which might explain our susceptibility to the incomplete emotional renderings of the advertising industry, and the corporate media as a whole. A deeper consideration of love provides an opportunity for greater understanding, and offers the possibility of polishing the tarnish left by popular culture's illusory definitions. Poetry is a ready tool for articulating the nuances of love and loving, using words to shape an awareness of that which is known and unknown, experienced or longed for. The creative arts as a whole can be directed toward a similar task, recounting a story that extends beyond words. Creative expressions depend largely upon the process of experiencing the art to be able to decipher and interpret the story at hand.

When love is simplified and trivialized, it is deprived of its power to deliver the promise of satisfaction, let alone its potential for transformation. This paper offers a radical reinterpretation of love by moving beyond the limitations of its objectification in 
popular culture and embracing the transformative action of loving as praxis in education. Loving, in this sense, is a social and political activity, working toward the transcendent qualities of love: affection, compassion, empathy, connection, and justice. Praxis is commonly understood as the process of situating theoretical knowledge inside of actual practice. In Pedagogy of the Oppressed, Freire (1970) identifies praxis as, "reflection and action upon the world in order to transform it" (p. 33). This definition captures the key essence of praxis as a mechanism for creating action toward change.

\section{Topic Selection}

The topic of this dissertation is the outcome of my experiences as a postsecondary educator working in the field of social justice education. I had been teaching in a graduate program in conflict resolution for close to a decade before I finally decided to pursue a doctoral degree in education. Because I understood the nature of conflict resolution to be intrinsically interdisciplinary, I knew I would have to evaluate which aspect of conflict resolution was of particular interest to me in order to decide upon an appropriate discipline for doctoral study.

Through this process of evaluation I recognized that my passion as an educator was in observing how the study of conflict resolution invites students to transform their understanding of themselves and of the world around them. I was especially fascinated and heartened by students' increased understanding of the dialectical nature of complex social conflicts, their ability to experience compassion for the people impacted by those conflicts, and their increased capacity to contribute to social change, all of which seemed to result from this increased understanding. I recognized that this transformation happened as a result of their successful engagement in a process of critical and dialectical 
thinking. As an educator, and from my many years of experience as a student, I also understood that educators play a large role in creating the space for this transformation to occur — both ideologically and logistically. I came to the conclusion that my interest in conflict resolution fit best within the discipline of education, and made the decision to pursue doctoral study within this field.

The research topic I selected to best articulate my interest was roughly worded as the study of love as a pedagogical strategy for social change. As I pursued coursework in educational theory and continued in my role as an educator in a conflict resolution program, I reflected further on my responsibility to create the educational space to invite transformation, and began to pay attention to how that transformation was best facilitated. I became increasingly aware of my conscious and unconscious decisions as an educator, and noticed how those decisions have been and continue to be shaped by my beliefs, values, and worldviews.

I also noticed, in informal conversation and in formal evaluation, that many of my students felt that my style of teaching had an impact on their increased understandings and personal discoveries. While I consciously employed the practice of engaged pedagogy in my classes (hooks, 1994), I became curious about how my presence and choices as an educator facilitated reflection by and empowerment for my students. I became interested in understanding myself as an educator, and through that process of self-reflection became even more interested in exploring how other social justice educators engage their students in the transformational process that inspires action toward social change. 
Research Question

The overarching concern of this paper is to better understand how storytelling, framed within a pedagogy of love, can provide a means toward the goal of critical peace education - which is to create greater social justice (Bajaj, 2008; Darder, 2002). Using grounded theory as a research methodology, I anticipated that theoretical constructs will emerge to define and explain the nature of a loving pedagogy of storytelling for social change, and that those constructs will articulate its capacity to create awareness and movement toward greater social justice.

The specific question I pose is how postsecondary educators use storytelling to address issues of social change, and to inspire action toward social justice. Through the collection of educator narratives, I examine postsecondary educators' use of storytelling as a means to work toward social justice. I am particularly curious about how educators use storytelling to humanize the struggle of oppressed groups, and how that understanding can and does engage learner empathy and mobilize learner action toward change. The sharing of transformative story, and the alchemy of disequilibrium that is created through telling powerful stories, will be explained and explored as an integral part of the revolutionary praxis of loving.

\section{Importance of the Study}

In an effort to justify the need for critical peace education, and its ultimate goal of social justice, the problem statement is framed within the limitations of the neoliberal trend in public education. While the economic stature of the United States was historically perceived as responsible for driving the quality of public education, the National Commission on Excellence in Education published a report in 1983 (A Nation at 
Risk) that turned the location of responsibility 180 degrees, wherein public education was suddenly viewed as being responsible for the economic strength of the United States. At the time of the report, the United States was losing economic cachet in the global arena, and the shortcomings in public education were identified as the cause of the United States' loss of competitive edge. The reorientation of blame away from (the lack of) economic support for education and toward education itself fuelled the fire of support for the neoliberal agenda and the attack on the public sector in general. Giroux recalls that, "education became one of the first targets of neoliberals, neoconservatives, religious extremists, and fundamentalists advocating market interest over social needs and democratic values" (2009, p. 14).

Historically, one of the many goals of public education has been to prepare students to meet the needs of the marketplace; over the last decade, however, the emphasis on economic goals has overshadowed a focus on learning. Educational reform, educational policy, and educational practice in the United States increasingly reflect the neoliberal goals of preparing students to compete in a globalized workforce, insinuating the competition of the marketplace within the educational process, and privatizing what has historically been public education (Hursh, 2004). The original goal of education as a means to prepare students to think critically, evaluate their lives and world within their complex historic contexts, and contribute to the civic engagement that underlies democracy has fallen out of favor.

As public funding for colleges and universities declines, the privatization of postsecondary education has created a new category of for-profit colleges and universities. At these for-profit enterprises, competitive market forces drive curricular 
choice as a means for post-graduation employment (Roosevelt, 2006). The University of Phoenix, which has 200 campuses worldwide, is a prime example of such an institution. Its singular goal is to train students for future employment. These enterprises operate as businesses, making administrative and curricular decisions based on forecasted profit. They solicit input from employers to determine how best to educate students for future employment, and that input is then used to dictate course content and degree design (A. Job, personal communication, 2001). Public colleges and universities have felt the need to rise to the competition posed by the private sector and, in response, have adopted similarly market-driven agendas.

This commercialization of learning in higher education has had far-reaching implications, not the least of which has been a decreased emphasis on the development of the critical and analytical thinking skills central to classical education, in favor of increased emphasis on pre-employment training. Giroux (2009) explains that the "language of market fundamentalism and the emerging corporate university radically altered the vocabulary available for appraising the meaning of citizenship, agency, and civic virtue" (p. 16). While there are compelling arguments for making higher education relevant to students and valuable to society, emphasizing individual employability over the goal of creating a citizenry capable of analyzing complex social issues and judging political decisions has impacted our ability to participate in democracy — and has, therefore, impacted the efficacy of our democracy itself.

The efficacy of democracy is dependent upon an engaged citizenry. If the government is truly by the people, then the people need to be involved and paying close attention. Without adequately developed critical reflection and thinking skills, civic 
participation declines; there are fewer people interested in or willing to commit to democratic processes, which results in a marginalized form of democracy. The literature shows a direct relationship between exposure to critical-thinking skills in secondary and postsecondary education and long-term participation in public life, which is a key indicator of a functional democracy (Abilock, 2005; Gates, 2006; Roosevelt, 2006). Higher public education, where academic freedom is designed to protect critical debate on even the most controversial topics, is perhaps the last bastion of hope that there will continue to be critical debate on controversial topics in an otherwise civically disengaged landscape (O’Neil, 2005).

While history provides rich examples of the symbiotic relationship between education and democracy, that relationship is not supported by current trends in education. Saltman (2009) describes the neoliberal thrust of privatized education as being at cross-purposes with democracy. He argues that neoliberal education does not encourage or teach the language and critical thinking skills that would enable students to develop rationally sound and effectively dissenting perspectives, and furthermore, he shows how democracy's principle of majority rule is regarded as a dangerous threat to the capitalistic creed of individual rights. This discrepancy in values needs to be acknowledged and addressed. Giroux (2009) suggests a concrete course of action that contests neoliberal influence, and supports the reclaiming of a functional democracy.

Making pedagogy and education central to the political task of reclaiming public space, rekindling the importance of public connectedness, and infusing civic life with the importance of a democratic worldly vision is at the heart of opposing the new authoritarianism. (Giroux, 2009, p. 20) 
This research draws attention to the crisis of neoliberalized education by investigating critical peace education as a possible antidote. Peace education, which can be identified as a hybrid of "diversity education, conflict resolution, civic and democratic education, and violence-prevention" (Mahrouse, 2006, p. 400), has the capacity to encourage development of the skills overlooked by the neoliberal agenda: reflective thinking, critical analysis, compassion for marginalized populations, civic participation, and action toward social justice.

When educators challenge students to think reflectively and critically, and provide students with engaging opportunities to challenge preexisting worldviews, students’ understanding of and concern for social issues correspondingly shifts. Hardiman and Jackson (1992) outline five stages of student development that can occur in the course of postsecondary education that speak to development toward one's sense of responsibility to contribute to social change. While Hardiman and Jackson's original work contextualizes the stages in terms of racial identity, they correspond with more generalizable aspects of social identity development and speak to the process of consciousness-raising inherent in a Freirian definition of praxis.

Hardiman and Jackson (1992) describe the developmental stages as moving progressively from the first to the fifth, with movement prompted by the student's recognition that a his or her "current worldview is either illogical or contradicted by new experience and information, detrimental to healthy self-concept or no longer serving some important self-interest” (p. 24). The stages are as follows: (1) Naïve: no consciousness of social identity; (2) Acceptance: accepting dominant opinions about relative status social identities; (3) Resistance: rejecting structural violence against 
marginalized populations, and recognizing relative privilege of dominant social identities;

(4) Redefinition: redeveloping understanding of a social identity of self (and other) that is outside of habitual oppression(s); and (5) Internalization: integrating redefinition into perceptions, actions, and agency.

My research seeks to investigate how a pedagogy of love fosters the goals of critical peace education, using storytelling as a means to transform students' relationships with social justice (and social injustice). This research intends to instigate a conversation about how postsecondary educators can and do work to deliberately reclaim the realm of public education as one that cultivates agency among learners, inspiring a deeper understanding of social identity and a greater sense of responsibility to act toward greater social justice.

\section{Social Justice as a Value: A Caveat}

It would be naive to believe that social justice is priority for all human beings who operate ethnically, or that, once introduced to the struggle of marginalized people, everyone will be automatically propelled toward remedying social inequity. As ongoing support for the neoliberal agenda has proven, and both personal and collective history have corroborated, whole factions of honorable people do not share the belief that social justice is a critical concern. To understand something about the diversity of perspectives about social justice, it can be viewed as a value that, while articulated as a goal in this paper and most certainly a motivating force for social justice educators, cannot be presumed to be a shared value.

In Poverty in America, John Iceland (2006) distinguishes between two prevailing and ostensibly opposing policy goals: that of minimizing inequality, versus that of 
encouraging economic growth (p. 134). While he does not directly attribute these preferences to particular political parties, they are consistent with the conflicting priorities of the two-party political structure within the United States (Fowler, 2004). Liberal ideology tends to prioritize issues pertaining to equality, while conservative ideology reliably supports economic growth. This dichotomy of values creates a veritable cross-cultural experience, with both sides left to wonder how the other side could miss the point so completely.

Lulofs and Cahn (2000) refer to conflicts between opposing ideologies as moral conflicts, where parties are unlikely to abandon one value-driven ideology in favor of another. In a best-case scenario, parties are able to develop respect for the conflicting ideology without necessarily subscribing to its values. This becomes significantly more complicated when considering policy, especially when majority rule can mean that the decisions made are based on values that are morally opposed by a significant percentage of society.

Despite ideological differences within the United States political spectrum, some basic commonalities in policy goal setting have been found (Iceland, 2006). Heclo (as cited in Iceland) proposes that policymaking in the United States is driven by three agreed-upon guidelines. The first is that the public is responsible for helping those who are lacking basic necessities. The second is that people should strive to become selfsupporting. The third is that people need to work toward a cure for poverty and welfare dependence. These commonly held beliefs provide a general framework for discerning how and if to get involved in particular issues of concern, and leave room to negotiate in favor or against particular policies and practices. 
To better understand the conflict surrounding the issue of social justice, Iceland (2006) proposes a fourth guideline that dictates existing policymaking processes, which is that any effort toward promoting equity should not interfere with economic productivity. This is a deceptively simple statement that, at face value, no one would disagree with, but with further examination could justify a lack of commitment to equity in the face of real or imagined economic drawbacks. For example, a conservative majority could rationalize a need to limit efforts toward equity because of the economic costs, and in doing so could use majority rule to control discourse and any resulting policy about the need for and importance of equity.

This conflict of values, and control of the discourse surrounding the underlying problems of inequity and its economic implications, is at the heart of social issues in Europe and the United States. Iceland (2006) cites the example of the economic crisis in Europe, where immigrant populations are being blamed for larger economic problems because of their alleged abuse of Europe's generous social welfare benefits. This same pattern can be seen throughout history in the United States, where marginalized populations are widely considered responsible for dragging the economy down with their habitual exploitation of public assistance (Kozol, 1992).

Based on the distinctions made by Iceland (2006), the ideological divide around addressing social inequity in the United States can be explained as a lack of communitarianism ${ }^{2}$, or concern for the common good. Iceland explains that, "in the absence of a collective feeling of fellowship and citizenship, efforts to alleviate poverty

\footnotetext{
${ }^{2}$ This is a term widely used in Australia, New Zealand, and Great Britain to refer to a community minded, collectivist ethos, complete with civic concern and civic participation, and I am avidly attempting to insinuate it into the American lexicon.
} 
LOVING PRAXIS

are bound to suffer" (p. 138-9). Whether the fight is against poverty, or other forms of injustice, those who have concern for the common good are likely to maintain a value for social justice. Those who are social justice educators are arguably in the position to make a case for the importance of this concern, and to engage others to work toward that goal. 


\section{Chapter 2}

\section{Literature Review}

While dissertation literature reviews typically innumerate existing research on their topic, this paper weaves together a relatively unique series of elements that have not previously been explored in relationship to one another. This literature review, therefore, provides foundational information to situate storytelling as intrinsic to loving pedagogy, and as a crucial aspect of critical peace education.

The literature review begins with an introduction to critical peace education, situated within the scholarship of education, cultural studies, and the interdisciplinary field of peace and conflict studies. Within that, I examine the literature on agency, since this is the goal of critical peace education — to inspire action toward social justice. Critical peace education is situated within the context of critical pedagogy, within which social justice education is explained. I then review the literature of transformative learning theory, as an element of adult learning theory, to provide a framework with which to consider relevant epistemological and andragogical questions. I review the literature on loving pedagogy, a revolutionary form of praxis that draws from the scholarship of education and philosophy, and conclude with a section on storytelling as a means toward social change and transformation. 


\section{Peace Education}

Peace education should lead not only to a greater awareness of problems but also to a sense of responsibility and an active involvement in efforts towards promoting equal rights, economic and social development, and mutual respect and understanding among nations. The power of informed public opinion, internationally, in influencing governments towards peace and disarmament should not be underestimated; therefore, greater attention in peace education needs to be given to identifying and overcoming the structural, conceptual and cultural obstacles to peace. (Nastase, 1983, p. 391)

Peace education is based on a belief that education can contribute to understandings of peace, and promote the achievement of peace in personal, social and political realms (Eisler \& Miller, 2004; Harris \& Morrisson, 2003). The practices of peace education include diverse applications that range from administrative protocols intended to create peaceful school culture, to curricula and resources designed to teach the history of peace. Peace education refers to many different types of philosophical and curricular elements that seek to educate about peace. With respect to the multiple interpretations and applications of peace education, and an acknowledgement of the need for all of them, this paper defines peace education as a qualitative shift away from competition and towards collaboration in the socialization process that is intrinsically and historically part of education (Eisler, 2004). This definition of peace education encompasses substantive change in the process as well as the content of education, and provides an overarching framework from which to consider different pathways toward peace.

The concept of peace can seem ambiguous without further explanation. Peace is most often defined in the context of the negative, describing what peace is not: it is not violence, war, or abuse. Bountiful metaphors represent subjective visions of peace, but 
concrete descriptions of positive peace, what peace actually is, are difficult to find or forge. The term passivist (connoting inactivity) is often mistaken as being synonymous with the term pacifist (from the Latin word for peace, pacem), because of the erroneous assumption that peace is something inactive. Throughout history, achieving peace has required great effort, courageous confrontation, and determined action. For the purposes of this paper, peace is defined as positive peace, which Johan Galtung (1969) defines as the absence of structural violence and the presence of democracy.

While peace education has historically been framed as war abatement, or negative peace, during the 1960s the women's movement drew attention to peace education's relational and transformative potential (Morrison, 2008). Feminists brought focus to the significance of personal consequences resulting from violence, and a recognition that peace cannot occur in the outer spheres without regard for the human impact of violence within the inner spheres. Elise Boulding (2000) is one such feminist who, through her scholarship and activism, has fought tirelessly to bring attention to the social realm of peace, and the role of education in contributing to a culture of peace.

The various approaches to peace education have taken many different forms, with many distinct purposes. To illustrate the breadth of these approaches, Haavelsrud (1981) offers four different branches of disarmament education to characterize the various orientations to peace education (Bajaj, 2008; Burns \& Aspelagh, 1983), and to provide a useful reference point: the idealistic concept, the scientific concept, the ideological concept, and politicization. The idealistic concept is exemplified by Unesco's Constitution, which states that wars start in the minds of people, suggesting a reliance on the human appeal for tolerance and acceptance on an individual level, but ignoring the 
underlying issues of structural inequality. The scientific concept advocates for developing an intellectual understanding of the issues through academic study of peace and conflict issues. While an intellectual understanding is certainly of value, there is no evidence that understanding the situation will result in effective strategies for action. The ideological concept uses a neo-Marxist critique of schooling to recognize the inevitability of formal education's reproduction of dominant culture's ideas and values, and suggests that true peace education can only happen outside the formal system of education. Politicization, the fourth approach, is influenced by the ideas of Johan Galtung and Paulo Freire. The thrust of politicization is to raise students' critical consciousness about systems of oppression, and to inspire research, education, and action toward peace and justice.

\section{Critical peace education.}

The ideological and politicization approaches to disarmament education, developed by Haavelsrud (1981) and applied to peace education by Bajaj (2008) and Burns and Aspelagh (1983), provide excellent starting points for understanding critical peace education, as distinct from the many other approaches. The neo-Marxist critique of dominant ideas and values that is central to the ideological concept of peace education is also central to the theoretical basis of critical peace education. Critical peace education draws from the strength of critical theory, and the work of the Frankfurt School of Social Research, to challenge the dominant ideologies that contribute to systems of oppression, and to encourage strategic action toward peace, which is understood within this context as greater social justice. Similarly, the politicization approaches to peace education and critical peace education share the goal of raising critical consciousness about systems of oppression, and mobilizing student action toward change. 
Bajaj (2008) distinguishes critical peace education from other definitions of peace education by attending to the role of, "issues of structural inequality and research aimed towards local understandings of how participants can cultivate a sense of transformative agency" (p. 135). Cultivating this agency is central to the task of critical peace educators, because while learning about injustice and peace are vitally important, agency is what liberates oppression. Giroux describes this task as linking

knowledge and learning to the performative and worldly space of action and engagement, energizing people not only to think critically about the world around them but also to use their capacities as social agents to intervene in the larger social order and confront the myriad forms of lives. $(2009$, p. 22)

Betty Reardon similarly articulates the importance of individual and collective agency as global action, which "refers to the skills and practices of active citizenship in global civil society, and actions taken to benefit the whole of human society, including unfamiliar and distant peoples" (1999, p. 16). The importance of encouraging concern for and righteous action toward social justice is central to critical peace education. Illustrating Maxine Greene's concept of possibilizing, Bajaj (2008) describes peace education as having a goal for learners to develop

[a] sense of possibility that enables them to become agents of social change. Freirean ideas on the necessity for educators to inspire a critical optimism among students that is aimed at promoting solidarity and diminishing the distance between social groups - whether they are stratified by race, ethnicity, religion, class, or any other ascriptive characteristic. (p. 3)

Since the institution of education not only mimics prevailing ideologies, but coconstructs the ideas and values that are disseminated, critical peace education recognizes the importance of acknowledging the vital role of the educational process in shaping the way democracy will work (or not) in the future. 
Critical pedagogy and social justice education.

Critical peace education draws heavily from the tradition of critical pedagogy, which Giroux (2010) describes as an, "educational movement, guided by passion and principle, to help students develop consciousness of freedom, recognize authoritarian tendencies, and connect knowledge to power and the ability to take constructive action" (p. B15). Giroux introduced the term critical pedagogy into the academic literature in 1983, to name the efforts of scholars and activists to emphasize the importance of democratic schooling in the United States (Darder, Baltodano, \& Torres, 2003). Critical pedagogy, however, is not a new invention, but stems from the "historical legacy of radical social thought and progressive educational movements that aspired to link the practice of schooling to democratic principles of society and to transformative social action in the interest of oppressed communities" (p. 3).

There is significant overlap between critical pedagogy and peace education, social justice education, human rights education, democratic education, anti-oppression education, and feminist pedagogy — which all emphasize the principles of democracy, and which are all committed to infusing formal and/or informal education with the active goal of working toward greater social justice. The literature on critical pedagogy is prolific and academic, particularly compared with the corresponding body of literature for other forms of social justice education, which emphasizes the practical tasks of creating social change. The literature on critical pedagogy focuses on the philosophic and theoretical underpinnings of working for social justice and, as such, is directed to the audience of educators and scholars. Fischman and McLaren (2005) go as far as suggesting that critical pedagogy is the responsibility of educators. In contrast, the 
literature on other forms of social justice education focuses attention on frameworks, systems, and applications - appealing more to an audience of activists and practitioners.

The highly philosophical nature of critical pedagogy, rooted firmly within the intellectual rigor of critical theory, causes it to be considered inaccessible by many and often controversial within the field of education. Critiques of critical pedagogy include objections to the amount of work required by the educator to facilitate it effectively within learning communities, the highly intellectual language used in its discourse and the elitism that such discourse represents and perpetuates, the lack of diverse voices in the discourse of critical pedagogy (Darder, Baltodano, \& Torres, 2003; Suarez, 2006). Rather than facilitating greater social justice, some educators believe the discourse of critical pedagogy reifies the very patterns of domination and subordination that it attempts to critique. From her experience as educator teaching a course on anti-racist pedagogies, Ellsworth (1989) shares that, "key assumptions, goals, and pedagogical practices fundamental to the literature on critical pedagogy ... are repressive myths that perpetuate relations of domination" (p. 298).

Rather than investigate different approaches to social justice education as discreet types of educational philosophies or interventions, I offer a few definitions from multiple traditions as a means to approximate a robust definition of social justice education, thereby illustrating the similarities that exist despite any real or perceived differences. Though there is merit in discussing how they differ, my purposes are best served by establishing the general scope of social justice education as a whole. Many definitions of social justice education build upon the work of Paolo Freire, particularly his work entitled, Pedagogy of the Oppressed, which introduces a critical and liberatory pedagogy 
for social change (Fischman \& McLaren, 2005). In the following quote, Weiler (1991)

describes feminist pedagogy in concert with Freire's foundational ideas.

Feminist pedagogy as it has developed in the United States provides a historically situated example of a critical pedagogy in practice. Feminist conceptions of education are similar to Freire's pedagogy in a variety of ways, and feminist educators often cite Freire as the educational theorist who comes closest to the approach and goals of feminist pedagogy. Both feminist pedagogy as it is usually defined and Freirean pedagogy rest upon visions of social transformation; underlying both are certain common assumptions concerning oppression, consciousness, and historical change. Both pedagogies assert the existence of oppression in people's material conditions of existence and as a part of consciousness; both rest on a view of consciousness as more than a sum of dominating discourses, but as containing within it a critical capacity — what Antonio Gramsci called "good sense"; and both thus see human beings as subjects and actors in history and hold a strong commitment to justice and a vision of a better world and of the potential for liberation. (Weiler, 1991, p. 449).

Kumashiro (2009) introduces anti-oppression education as a form of social justice education that also draws from the rich heritage of "many activist traditions, crafting links between feminist, critical, multicultural, queer, postcolonial, and other movements toward social justice" and recognizes that, "some approaches respond to and build on others, whereas other approaches critique or contradict others" (p. xxvi). He defines antioppression education in the following quote:

Anti-oppressive education constantly turns its lens of analysis inward as it explores way that its own perspectives and practices make certain changes possible but others, impossible; and it constantly turns its lens outwards to explore the insights made possible by perspectives on teaching and learning that have yet to be adequately addressed in the field of education. Anti-oppressive education is premised on the notion that its work is never done. (Kumashiro, 2009, p. xxvi)

Much of social justice education acknowledges this notion that the work is never done, and that social justice must persistently and actively be sought. This is particularly true with human rights education, which addresses the long-term necessity of changing the culture of post-conflict societies, and aspires to create a universal culture of human 
rights. Human rights education has been championed by the United Nations since 1953;

and in 1995, the United Nations launched the Decade for Human Rights Education. The

United Nations formally defines human rights education as

education, training and information aiming at building a universal culture of human rights through the sharing of knowledge, imparting of skills and molding of attitudes directed to: a) the strengthening of respect for human rights and fundamental freedoms; $b$ ) the full development of the human personality and the sense of its dignity; c) the promotion of understanding, tolerance, gender equality and friendship among all nations, indigenous peoples and racial, national, ethnic, religious and linguistic groups; $d$ ) the enabling of all persons to participate effectively in a free and democratic society governed by the rule of law; e) the building and maintenance of peace; and $f$ ) the promotion of people-centered sustainable development and social justice. (United Nations, 2006, p. 12)

The above definitions illustrate some of the consistent themes of social justice education, which can be applied in many diverse contexts, to meet different dimensions of the common goal to increase social justice. In summary, critical pedagogy might be considered as the intellectual exploration of argument for and theoretical justification of social justice education, and a variety of specific types of social justice education exist to operationalize the tenets of critical pedagogy, and to contribute to the shared goal of greater social justice.

\section{Transformative Adult Learning Theory}

To answer Bajaj's (2008) question of how best to cultivate a sense of transformative agency among students, an understanding of adult learning theory in general and transformative learning in particular, can provide some assistance. While there is no single definition of adult learning theory, Cranton (1994) regards it as "a process of being freed from the oppression of being illiterate, a means of gaining knowledge and skills, a way to satisfy learner needs, and a process of critical self- 
reflection that can lead to transformation" (p. 3). This theory of learning has been widely recognized as a means for empowering adult learners' sense of place in society, and stimulating adult learners' sense of agency.

Adult learning theory is based in the study of andragogy, a term coined in 1895 by Alexander Kapp as the process of engaging adult learners (Knowles, 1970). Knowles clarified that while pedagogy can be defined as the science of teaching, andragogy is the art of helping others to learn. Knowles built on Kapp's work by developing a distinct epistemic structure for adult learners, based on the following assumptions about adult learning: adults needs to know why something is important to learn, experience is the most effective way for adults to learn, adults need to be involved in the decisions about their education, adults are best able to engage with learning that is relevant to their lives, adults learn better with a problem-centered focus than with a content-centered focus, and adults respond better with internal motivators than external motivators.

Despite the lack of a standardized definition for adult learning, in Understanding and Facilitating Adult Learning, Brookfield (1986) introduces six principles of effective practice that facilitate adult learning. First, Brookfield states that adult participation in learning is voluntary, and the decision to learn is entirely the learner's. Second, effective practice is characterized by respect among participants for each other's self-worth. Third, facilitation is collaborative, and begs cooperative involvement in assessing needs, setting objectives, developing curriculum, choosing methodology, and evaluating success. Fourth, praxis is at the heart of effective facilitation. Fifth, facilitation aims to foster a spirit of critical reflection. Sixth, the aim is the nurturing of self-directed, empowered adults. The process of empowerment, through learning, encourages recognition of adult 
learners' proactive agency in personal relationships, work settings, and social circumstances overall.

Inspired by the work of Freire, bell hooks developed a similar concept of adult learning that she calls engaged pedagogy (hooks, 1994). Hooks applies the guiding principles of adult learning theory, steeped in Freire's concepts from Pedagogy of the Oppressed (1970), to introduce a system of learning that invites students into an engaged learning process intended to encourage empowerment, transformation, and agency toward social change.

While transformation is a widely used term with multiple meanings, the term transformative learning is most commonly associated with Mezirow's scholarship. Mezirow (1991) conducted research about how the perspectives of adult learners are transformed through education, about learning processes that encourage reflection on how we understand ourselves, and about how we perceive our relationship to the world around us. Drawing heavily from the work of Habermas, Mezirow proposed a theory of transformative learning that explains:

how adult learners make sense or meaning of their experiences, the nature of the structures that influence the way they construe experience, the dynamics involved in modifying meanings, and the way the structures of meaning themselves undergo changes when learners find them to be dysfunctional. (p. xii)

Looking specifically at how transformative learning theory applies to the field of conflict resolution, which underlies and overlaps critical peace education, the emphasis remains on the change of learner perspective more than the resolution of a particular conflict. Fetherson and Kelly (2007) explain that, 
from a transformation perspective, [conflict resolution] is less about the application of techniques or models for managing conflict, than a search for processes that can make possible myriad transformations of self, self-inrelationships, self-in-society, as well as transformations in the structural realm. (p. 264)

\section{A Pedagogy of Love}

I want to write abut a political and radicalized form of love that is never about absolute consensus, or unconditional acceptance, or unceasing words of sweetness, or endless streams of hugs and kisses. Instead, it is a love that I experienced as unconstricted, rooted in a committed willingness to struggle persistently with purpose in our life and to intimately connect that purpose with what [Freire] called our "true vocation" - to be human. (Darder, 2003, pp. 497498)

The idea of love as a political and radical social change agent is not a new one in their history of nonviolence in America, Lynd and Lynd (1966) define nonviolent action as the vision of love as an agent of social change. An exploration of the deeper meaning of love finds it to be "the most powerful antidote to the politics of domination" (hooks, 2006, p. 59), which makes it an ideal starting place from which to examine the forces that hold hegemony in place. The very exploration of love challenges the absolutism of positivistic logic and suggests value in considering the significance of more inclusive perspectives (Liston \& Garrison, 2004).

Romantic love, which is ubiquitous in popular culture, is typically sexualized and/or sentimentalized (Darder, 2003; Liston \& Garrison, 2004). Freire (1970), and subsequently Darder (2003) and Liston and Garrison (2004), offer alternative conceptualizations of romantic love as emerging from a history of insurgence, having an inclination toward passionate rebellion, and a transgressive reaction against dominance. This powerful and passionate face of love contributes to countervailing ideologies that 
incite change, but when it is relegated to the private sphere of sexual conduct, its capacity to leverage social change within the public sphere of political participation can be easily forgotten.

Education, and the socialization process that transpires in the relationships that develop in the process of education, model what is acceptable and what is not. As such, the educational experience is vital in the process of social change. The idea of love, beyond the sentimental and sexualized notions saturating popular culture, has the potential to foster the engagement of learners - be they students, teachers, parents, administrators or the extended community. In writing about a pedagogy of love, Darder (2002) articulates the common goal of critical pedagogy and critical peace education, and illustrates the emerging concept of loving as praxis:

Living a pedagogy of love in our classroom and our communities defies the prescriptive formulas and models of the past, calling for the "reinvention" of our radical vision not only of schooling but of American society - a vision of a society that is unquestionably shaped by a democratic commitment to human rights, social justice, and a radical redistribution of wealth and power. (Darder, 2002, pp. 30-31)

This idea of a pedagogy of love is central to the core constructs of engaged pedagogy, critical pedagogy, and critical peace education, which all value the importance of developing the thought, voice, agency, and action of the individual to contribute to social justice. This development is accomplished through cultivating relationships between the teacher and student, and among the learning community, that prepare students to be in relationship with society at large, contributing in an active and valued way. While cultivating a relationship with society could be regarded as a radical and/or 
revolutionary goal, it could also be regarded as simply serving the most basic objectives of democracy.

In examining loving as "reflection and action upon the world in order to transform it" (Freire, 1970, p. 33), the pedagogy of love can be ushered closer to the goal of creating movement toward social justice. Diaz Soto (2005) describes the vital task of critical peace education as relying upon "[1]ove as an inclusive alternate paradigm in solidarity transcending existing conditions and reality" (p. 96). This quote evokes a common theme in critical peace education, and echoes Reardon's description of global action to benefit all of humanity (Reardon, 1999).

\section{Storytelling: A Method of Loving}

The sense of disconnection and objectification that results from the standardsbased education intrinsic to neoliberalized education has inspired some educators to recognize storytelling's counter hegemonic role in creating connection, fostering imagination, and cultivating wisdom (Bell, 2010; Dale, 2004). Dale (2004) describes the function of stories as being to create, "a longing for what is not and an envisioning of what is absent in our schools, in our teaching, and in our learning" (p. 71). This longing and envisioning give strength to our capacity to possibilize (Greene, 2003) social justice - be it in the classroom, the community, or the world at large.

The literature on storytelling covers a wide swath of disciplines, audiences, applications, and purposes. While storytelling is used to draw out a diversity of voices and perspectives on a given topic (Bell, 2010; hooks, 1994; Palmer, 1998), it is also used to find connections that underlie superficial diversities and link "between past and future, between people and place, among people whose opinions diverge" (Cruikshank, 1998, p. 
2). There are numerous ways to define storytelling, and as many more treatises on how to operationalized it. Senehi (2009) offers a general definition of storytelling as "a universal way human beings deal with knowledge" (p. 203), and describes the process of telling and receiving stories as continually forming, reproducing, negotiating, resisting, and changing our view of the world (p. 202). Similarly, Michel de Certeau (1984) portrays storytelling as authorizing, founding, and settling in place the way people experience and understand the world.

In the field of education, many authors recognize the transformative role stories play in student learning, although some focus on the value of sharing personal stories of experience while others champion the importance of sharing stories from literature (Coles, 1998; Dale, 2004; Murdoch, 1971; Nussbaum, 1990; Williams, 1993). Whereas some scholars value stories from personal experience as well those from literature, Bernard Williams (1993) suggests that using stories from life instead of stories from literature simply creates bad literature. Nussbaum (1990) explains this sentiment further as she rationalizes,

in the activity of literary imagining we are led to imagine and describe with greater precision, focusing our attention on each word, feeling each even more keenly - whereas much of actual life goes by without that heightened awareness, and is thus, in a certain sense, not fully or thoroughly lived. (p. 47-48)

Maxine Green (2003) encourages the use of stories from literature and poetry because of their capacity to transform perspectives through the sharing of repressed truths. She shares the prose of Muriel Rukeyser (1973), "What would happen if one woman told the truth about her life? The world would split open." When stories of marginalization are shared, they have the power to rock the worlds of those who did not 
know, and of those who were either colluding with or complicit to, systems of domination and power (Cruikshank, 1998; Plummer, 1995; Senehi, 2009). This splitting open of worlds has the power to create new beginnings, and within that, extend the invitation for action toward change.

While teacher-told stories can impact the learning experience, student-told stories that are informal or experience-based, are also regarded as having a powerful role in contributing to connection and transformation in the classroom (Senehi, J., Flaherty, M., Kirupakaran, C., Kornelsen, L., Matenge, M., \& Skarlato, O., 2009). Student storytelling exemplifies the tenets of engaged pedagogy (hooks, 1994), where teachers and students share in the tasks of teaching and learning, and illustrates Parker Palmer's circle of truth (1998), representing the nonhierarchical web of relationships that can develop between all members of a learning community. By sharing their own stories, learners deepen their ability to critically think about their experience, and to analyze their experience in light of the theoretical knowledge they have gained. In this process, learners have the opportunity to digest the theoretical understanding sufficiently to create abstract thought, which they can then apply to future critical and analytical endeavors.

Foucault (1972) suggests that meaning does not exist in an unspoken intellectual understanding, but emerges in the process of the act of speech. The speech of storytelling situates meaning into examples of life, giving the listener an opportunity to make sense of the meaning in an accessible context. Through storytelling, teachers can take the opportunity for meaning one step further, by situating the meaning-making within the greater context of learning: 
Teachers do more than transmit meanings; they enact the role of social and moral agents of change; they uncover, reproduce, and produce forms of learning and social relations based on those often repressed memories, stories, and dreams that allow us to analyze and embrace schooling as part of a wider politics of solidarity, caring, and joy. (Giroux \& Freire, 1986)

The process of critical reflection does not always happen spontaneously.

Normally there is some experience, event, or prompt that inspires deeper consideration, or a new perspective. Fetherson and Kelly (2007) build upon the scholarship of Mezirow and Brookfield to understand how encounters with new ideas or experiences, "create a sense of dissonance or discomfort, [and] initiate a process of learning — an attempt to resolve the conflict between established patterns of thought, practice, or premise and the information and experience that presents a challenging alternative" (p. 269). McDonald (2009) speaks to this critical discomfort when sharing that, "Preeminent stories invariably relate to significant learning experiences — those characterized by surprising events which kindle disequilibrium in one's thinking, or moments of serendipitous improvisation, often 'ah ha!' moments, always genuine” (p. 181).

Perhaps most importantly, framing issues of marginalization within a story has the capacity to turn objects into subjects. When we are presented with objectified suffering, our tendency is to turn away - even when it is an issue that concerns us, we have the sense that no one is looking, and we can turn to more pressing (or less painful) concerns. When we become acquainted with an actual subject who is suffering, and it is a subject with whom we can connect either first or second hand, the issue becomes personal. We cannot turn away, because there is someone looking. Our humanity is connected to the suffering of another human being when that human being is visible to us (and even more so when we are also visible to that human being). Darder (2009) explains, "humility, 
anchored in a politics of love, provides the open-mindedness to listen to an adversary without stripping the person of dignity and respect” (p. 164). This capacity to welcome storytelling, even from — especially from — our adversaries, is a key to understanding how storytelling can mobilize action toward greater social justice.

As Senehi (2009) explains, "Stories encode and transmit everyday understandings of conflict and what to do about it" (p. 205). To impart the significance and importance of social justice issues, to personalize the subjects of social injustice, and encourage student action towards greater social justice, storytelling is frequently featured as an integral part of social justice education programming.

In summary, the following are examples of story-centric curricula that exemplify the use of story as central to the process of social justice education. These curricula combine informal stories, situated within historical context, with photographs and narrative from the subjects of the stories, with great effect. These exemplary programs include The Forgiveness Project (wwww.theforgivenessproject.com), which explores issues of forgiveness and restoration in the wake of incidents of extreme violence; Speaking Truth to Power (http://www.rfkcenter.org/sttp), an educational program of the Robert F. Kennedy Center for Justice and Human Rights that encourages agency and action toward social justice; and Teaching Tolerance (http://www.tolerance.org), a social justice project sponsored by the Southern Poverty Law Center. 


\section{Chapter 3}

\section{Methodology}

[T] he role of research in the field of peace education is paramount for advancing our ability to inform and generalize rather than prescribe, processes that enable students to think and act collectively towards greater peace and social justice. (Bajaj, 2008, p. 141)

In studying peace education, researchers might focus inwardly on peace education as a reflective practice and process; or focus outwardly on the curriculum and instruction of peace; or look outward even further to the social responsibility of public education to transform culture by promoting the understanding and practice of peace. My research encompasses all these dimensions in its exploration of how postsecondary educators use storytelling to build transformative agency toward social justice. The inward dimension is reflected in the transcendent qualities of love that build a pedagogy of love, the outward dimension is present in the modes of inquiry that can be utilized to address peace through building and sustaining democracy (Henderson \& Kesson, 2004), and the transformation of culture is seen in the increased awareness, voice, and agency that results from meaningful transactions with stories of social justice. This research study collected and analyzed narrative data in a grounded theory research process designed to investigate and articulate the relationship between storytelling and social change. Specifically, postsecondary social justice educators were asked to describe how they use storytelling as a pedagogical strategy to build awareness about the struggle toward social justice, and to ultimately empower students to engage in action toward social change.

This chapter introduces qualitative research methods and more specifically discusses the particular characteristics of a grounded theory methodology. Following this 
introduction, I justify the choice of a grounded theory design for my research study.

Within the framework of qualitative research, I then situate myself as the researcher, describing my identity and perspective, and acknowledging their influence in all aspects of the study. Lastly, I present the details of my research design.

\section{Qualitative Research Methods}

Qualitative research was embraced within the field of education during the 1960s as a necessary alternative to traditional research investigations, which were perceived as relying "too much on the researcher's view of education and less on the research participant's view" (Creswell, 2005, p. 42). Qualitative research, based in a constructivist epistemology, holds the view that meaning and knowledge are human constructions - in contrast with positivist epistemology, which comprises the belief that truth is scientifically observable in the world. By capturing the individual perspectives of research participants, educational researchers gained valuable insight into how people were constructing meaning and knowledge in relationship to myriad educational issues. This discovery radicalized the way research was conducted in the field, and also served to inspire educational researchers to acknowledge that their own views and perspectives were similarly influencing their interpretation of data, and the ways they were according significance to their findings.

Qualitative research encourages interpretive inquiry, where meaning-making is shaped by the perspectives and perceptions of the researcher (Piantanida \& Garman, 2009). Qualitative data defy post-positivistic beliefs of researcher neutrality and objective truth, and promote the idea that knowledge is subjective and contextual. Through this intrinsic interpretation, the researcher can be regarded as the artist of his/her research, 
creatively constructing meaning through the unique lens of personal understanding.

Glaser \& Strauss (1967) refer to the wisdom that researchers bring to their inquiry as theoretical sensitivity, which is the combination of individual personality characteristics and the researchers' capacity to develop insights, coupled with their foundational and disciplinary knowledge.

This research study follows the interpretive and critical traditions of knowledge building in qualitative inquiry. Interpretive inquiry is used to regard the social construction of meaning-making, while critical inquiry assists with determining both how transformation of understanding occurs in a general sense and also how this transformation of understanding empowers students to "become agents for social action" (deMarrais \& LeCompte, 1999, p. 3). DeMarrais and LeCompte describe the relationship between interpretive and critical theories in the context of the sociology of education, where interpretive theories serve as a bridge between theories of social transmission, which explain how traditions are reproduced between generations, and theories of social transformation, which explain how traditions are changed. Critical theories are the foundation of social transformation theories, and include feminist, postmodern, and poststructural perspectives.

Gibson (2007) describes the relationship between critical theory and grounded theory as having a "productive tension between the twin goals of emancipation and the production of a comprehensive social theory" (p. 436). A critical perspective provides context and substance to understanding how storytelling can empower postsecondary educators (and students) to transcend the constraints placed on them by the limitations of the dominant neoliberal educational agenda, driven by the underlying influences of the 
"imperialist white-supremacist capitalist patriarchy" (hooks, 1989, p. 50). Theory developed within the critical tradition seeks to educate people about the prevailing ideology of dominant and dominating influences, and to encourage people to advocate for social change that empowers all people and liberates the bonds of oppression.

\section{Grounded Theory}

Grounded theory was developed by Glaser and Strauss in 1967 to offer "a compromise between extreme empiricism and complete relativism by articulating a middle ground in which systematic data collection could be used to develop theories that address the interpretive realities of actors in social settings" (Suddaby, 2006, p. 634). Grounded theory is based within the theoretical perspectives of interactionism and pragmatism, and regards knowledge as arising through the action and interaction of selfreflective beings (Corbin \& Strauss, 2008). The two key concepts that identify grounded theory are the constant comparison of data, which is collected and analyzed simultaneously, and theoretical sampling, where the theory that emerges from the data determines all subsequent data collection (Glaser \& Strauss, 1967).

In considering various research designs, I realized that my primary interest is in engaging a process of discovery that explores and explains the powerful relationship between the nature of pedagogy and the capacity to mobilize social change. It became evident that my research was less about answering a single question than it was about a desire to understand the pedagogy of love, and within that, ways that postsecondary educators use storytelling as a tool for transformation and change. Clarke (2007) argues that in grounded theory research, "precisely what is to be studied emerges from the analytic process over time, rather than being designated a priori” (p. 347). Grounded 
theorists initiate research with general concepts to articulate the starting place, but these concepts do not necessarily indicate or even anticipate the outcome of the study. Charmaz (2006) describes the nature of grounded theory as

systematic, yet flexible guidelines for collecting and analyzing qualitative data to construct theories "grounded" in the data themselves. The guidelines offer a set of general principles and heuristic devices rather than formulaic rules. Thus, data form the foundation of our theory and our analysis of these data generates the concepts we construct. (p. 2)

I believe that grounded theory provides an appropriately flexible method to investigate the nature of the pedagogy of love, particularly because I am not entering into this research with a hypothesis to test, a treatment to evaluate, or an absolute truth to uncover. I believe the narratives collected for this study will reveal interesting and provocative perspectives, that those perspectives will generate valuable theory, and the emerging theory will benefit educators working toward greater social justice.

\section{Researcher Location}

In qualitative research, the self of the researcher is a central instrument of inquiry. Eisner (1991) describes the self as "the instrument that engages the situation and makes sense of it. It is the ability to see and interpret significant aspects. It is this characteristic that provides unique, personal insight into the experience under study" (p. 33). With the self acting in such a vital role in the research process, it is essential to engage in an indepth examination of the self to situate the researcher overtly within the inquiry. Corbin and Strauss (2008) share their realization that

to understand experience, that experience must be located within and can't be divorced from the larger events in a social, political, cultural, racial, genderrelated, informational, and technological framework and therefore these are essential aspects of our analyses. (p. 8) 
In the above quote, Corbin and Strauss (2008) emphasize the importance of understanding the complex identities of research participants, but the quote also serves to remind me that my own identity as a researcher has a tremendous influence on my research. To establish my standpoint as a researcher, I will identify myself within the social, political, cultural, racial, and gender-related parameters set forth above.

To begin, I am a white woman of privilege, who has benefited from a middleclass upbringing in an upper-middle-class community, within the United States of America. My privileged background has given me the benefits of an excellent education, confidence in my personal agency and capacity, and relative comfort from which to make deliberate choices about my life's direction and pursuits. These unearned privileges (McIntosh, 1990) have shaped my experiences of the world and in the world, including those experiences as a student and an educator, and continue to affect my personal and professional endeavors.

My interest in social justice is best framed by my identity as the daughter of a refugee from the Holocaust. Within the literature of survivorship, I am considered the flame holder for the legacy of my Jewish mother's exodus from Nazi Germany, as I have kept our story alive through my own activism with refugees and immigrants, my work championing the importance of human rights for diverse populations, and my role as violence-prevention and conflict-resolution educator. The depth of my commitment toward greater social justice has its roots in this history, has been awakened through my own observations and experiences of injustice, and has been fertilized by the stories I have heard over the past twenty-five years of activism. 
Central to my identity and location is the core belief that all human beings have value. Because of my standpoint as a woman, and because I believe the liberation of women is an essential step in the liberation of all oppressed groups, I consider this belief to be feministic. While a popular description of feminism is that it is the "radical" belief that women are people, my social justice mentor describes feminism as the radical belief that all human beings are of value (I. Ingham, personal communication, 2000). This radical belief is based on the premise that humans are intrinsically good, despite any and all actions that make them appear otherwise. ${ }^{3}$ This belief structure has enabled me to be an advocate for difficult dialogue, as a participant (e.g., between second-generation Holocaust survivors and children of Nazi war criminals) and also as a facilitator (with victims and offenders, and between groups experiencing intractable and/or ethnic conflict, e.g., warring Somali ethnic groups who have been resettled en masse as refugees in the United States). This belief has been a primary support for my continued work toward social justice in an era where the disparity between those who are afforded justice and those who are not continues to grow, seemingly without much notice or concern from the world at large.

Following Sir Francis Bacon's assertion that knowledge is power ${ }^{4}$, I come to this research with the belief that once social injustice has been identified and understood,

\footnotetext{
${ }^{3}$ This belief is supported by Marshall Rosenberg's idea that everyone shares a common set of universal human needs, and that all of our actions are efforts to have these needs met (Rosenberg, 1999). Oftentimes, however, the strategies we employ to meet those universal needs are twisted, causing us to hurt people in our attempts to have our needs met.

${ }^{4}$ This quote is attributed to Sir Francis Bacon, and I use it here to speak of power with as a collaborative force, as opposed to power over - which is a competitive force
} (Follet, 1918/1998). 
human beings experience a natural responsiveness toward action. I believe this responsiveness is most likely when those impacted by injustice are introduced as human beings worthy of concern (subjects), instead of part of the unwashed masses (objects), because human being are intrinsically empathetic. I have encountered many individuals who do not prioritize social justice, or who believe that meeting their own needs is more important than ensuring that others have their needs met, but, even against those odds, I remain convinced that the facts and feelings experienced through a process of loving praxis can and do engender compassionate action toward greater social justice.

\section{Research Design}

My research explores how storytelling fosters the goals of critical peace education. The question I pose is how postsecondary educators use storytelling to address issues of social change, and to inspire action toward social justice. This question is qualitatively framed and begs the collection of stories that explain if, how, and why postsecondary educators incorporate storytelling in their teaching as a way to work toward greater social justice. I started with a preliminary inquiry and, with the analysis of each new piece of data, the direction for further data collection was determined. Due to the organic nature of this research method, the research design can only approximate what will happen in the course of the project. Grounded theory researchers cannot predetermine the specific shape of the research process, or even anticipate the nature of the findings.

The data for this qualitative study have been generated from interviews with a diverse sampling of postsecondary social justice educators. While rich data could be generated from multiple sources (e.g., from students and from classroom observations), 
this study is focused on the work and experience of social justice educators, and uses their personal narratives as data. The reasons for this decision are both pragmatic, because of my access to postsecondary educators and my interest in hearing their stories, and theoretical, because of my desire to understand more about the specific pedagogical choices and strategies that postsecondary educators employ to increase students' understanding of social justice as well as their action toward social justice.

The interviews have generated narratives, which serve as the sole method of inquiry. Connelly and Clandinin (1990) describe narrative research as follows: "people by nature lived storied lives and tell stories of those lives, whereas narrative researchers describe such lives, collect and tell stories of them, and write narratives of experience" (p. 2). I collected personal-experience and teacher-story narratives (Connelly \& Clandinin, 1990). Personal-experience stories recount specific events, thereby providing opportunities for personal reflection and integration. Teacher-story narrative research focuses specifically on the stories of teaching that emerge within the field of education. I anticipated and found fluid relationships between these two types of stories, in that the narratives collected interweave stories of personal experience and stories of teaching. Narratives provide an opportunity to study "problems as forms of storytelling involving characters with both personal and social stories” (Webster \& Mertova, 2007, p. 4). Through critically analyzing the stories in our lives, we have the opportunity to recognize the myths that surround us and "are embedded in our social interactions" (p. 7).

In designing this research, I anticipated that narrative data from approximately eight to twelve postsecondary social justice educators would be collected through interviews, with the possibility of including alternative populations of respondents as a 
theory began to emerge ${ }^{5}$. The exact number of respondents could not be predicted with certainty, since grounded theory research continues data collection and analysis cycles until coherent theory emerges and theoretical saturation is reached.

Four respondents were interviewed as part of a pilot study, which served as the foundational data set for this study. All four of the pilot respondents were known professionally by the researcher, and represent a diverse sampling of identities. Of the four, three live and work in the United States, and one lives and works in Europe; three are female and one is male; two identify as homosexual and two identify as heterosexual; and two are faculty at postsecondary institutions and two work primarily as consultants to postsecondary and other educational institutions. The diverse identity of respondents provided a rich start to the study, and each respondent offered names of colleagues who might be appropriate as future respondents. The process of having study respondents recruit future subjects from among their acquaintances is called snowball sampling. Interviews were conducted in person, via Skype, or as email conversations, and elicited metacognitive reflections on teaching practices surrounding storytelling, and beliefs about how these practices facilitate social justice. In an effort to encourage creative reflection, a combination of three prompts were prepared to initiate the interview process, all of which are included in Appendix B of this paper. The first prompt is a semistructured interview protocol, which includes a series of questions that situate the respondent in terms of identity, practice, and philosophy. The second prompt is a list of scenarios to be read aloud to respondents, with the hope of generating metacognitive

\footnotetext{
${ }^{5}$ It might also benefit the emerging theory to include perspectives from students, educators operating outside of formal postsecondary education, random members of the population at large, or other as-of-yet undetermined populations.
} 
reflection on practice and the philosophical motivations of that practice. The third prompt is a device called story cubes (a set of dice that present a series of symbols the respondent can use to frame a storied response), which can encourage spontaneity and creativity in interview conversations.

The decision to use a variety of prompts resulted from my experience with the pilot study, which exclusively used a written protocol. In the course of that study, I found that, once respondents knew there was a protocol, they were anxious to know the questions in advance and answer each one in turn. These well-intentioned responses generated very linear and prescribed conversations instead of prompting more organic and expansive sharing. As a result, the prompts included in this study are more varied, and include abstract elements intended to encourage more free-flowing and reflective conversation. These prompts are the starting place for data collection, but the iterative nature of grounded theory research necessitates evolving questions, new angles for data generation, and innovative data collection methods to support emerging theory.

Respondents were selected from my professional contacts, and from the snowball sampling that occurred in the course of the pilot study. Additional recommendations of possible respondents from a broad range of perspectives were encouraged from existing contacts. I anticipated collecting and analyzing data from no more than three to four respondents before interviewing the next three to four, and so on until theoretical saturation had been achieved. I reserved the possibility of inviting some respondents to participate in a second interview, if it appeared they might be able contribute further to the emerging theory. 
The parameters for respondents were that they are educators who work with adults in postsecondary education, who identify themselves as social justice educators, and who are interested in exploring the nature of storytelling and social change. Study participants were given the choice to participate anonymously (through the use of pseudonyms of their choosing), or to participate as themselves (using their own names). Since these are professional educators speaking about their own work within the field of education, they may prefer to have their real names used in the study's findings, to lend credibility to the findings, to develop their own professional identity, and also to further their own scholarly contributions. Participants were given the opportunity to review any comments/data attributed to them before publication in any manuscripts that result from this study.

Interviews were recorded in digital audio files, which, once transcribed, were erased; or, if interviews were conducted via email, documentation of email correspondences was preserved as the transcription. Transcriptions were accompanied by memos, written by the researcher during the interview, immediately following the interview, and as part of the data analysis process. The transcriptions and memos constitute the data to be researched, and were mined for emergent theory to answer the questions guiding this project. All notes and artifacts from this project will be kept in a password-protected laptop computer, or will be locked in an office at Portland State University, for a minimum of three years after the completion of research. 


\section{Chapter 4}

\section{Results: The Data}

\section{Introduction}

This chapter introduces the data collection and analysis procedure followed in this grounded theory research, and illustrates the iterative and nonlinear process that is common to grounded theory studies. The four stages of coding in grounded theory research include initial coding, focused coding, axial coding, and theoretical coding. These stages are presented as a fluid continuum, which flows forward and backward until theoretical saturation has been reached. A running narrative of this research process is provided herein, and includes the tangible outcomes of the summative processes of focused coding and axial coding. A broad analysis of the data generated by this study, including excerpts from interview data combined with relevant citations from the literature of education and sociology, concludes this chapter and provides an invitation into the rich narratives of respondents.

\section{Data Collection and Analysis Procedure}

Kathy Charmaz (2006) describes initial sampling as a starting point for category development. The data generated by the pilot research project, Storytelling and Social Change, provided the preliminary data from which initial categories emerged for further exploration. The sample from the pilot study included four respondents, who were chosen because of the diversity they represented. All pilot respondents fit the parameters of the dissertation study, in that that they are all educators working with adults in postsecondary education, all identify themselves as social justice educators, and all are interested in exploring the relationship between storytelling and social change. Despite these 
similarities, their involvement in post-secondary education — as faculty, adjuncts, trainers, or consultants — varies, as do their definitions of social justice education. The social identities of the pilot respondents are also diverse: three live and work in the United States and one in Europe; three are female and one is male; and two identify as homosexual and two identify as heterosexual.

The pilot interviews were conducted with a prescribed protocol, which certainly influenced the content of the resulting conversations, but also managed to elicit interesting and unexpected themes in the course of those conversations. After transcribing the interviews and reading through the transcriptions, I began a line-by-line coding process. This type of coding helps to break data into segments, emphasize the actions of each segment, indicate areas of deeper meaning, contextualize the significance of each segment, start the process of comparing data with data, and identify any gaps that might exist within the data (Charmaz, 2006).

Concurrent with the line-by-line coding, I summarized points of interest and points of possible significance in correlating memos. These memos included in vivo codes from the data, block quotes from the transcripts, connections to themes in the literature, and some preliminary attempts to identify focused-coding categories.

The first group of respondents I interviewed after the pilot group, who will be referred to hereafter as the "first" group, emerged from a combination of names generated from participants in the pilot study, and from my own professional contacts whom I believed could contribute to the categories that were emerging through the focusedcoding process. Of the four respondents in the first group, all met the parameters of the dissertation study. All were adjunct or fixed-term faculty from Portland State University; 
they included three women and one man, three identified as white and one as NativeAfro-Caribbean American, and three identified as Americans and one as English.

Whereas the pilot interviews closely followed an interview protocol, the conversations with the first group of respondents were far less structured, with greater focus on encouraging respondents to share their stories of personal experience, and to elaborate and connect the ideas shared. The semistructured protocol served as a point of reference and ensured that each respondent had the opportunity to verbally consent to the study, agree to have their identity revealed in the study, and then situate themselves within the context of their identity. They were then asked whether they considered themselves to be social justice educators, which they all did; and they were asked to define their task as social justice educators. The remainder of each interview flowed organically from queries about how respondents use storytelling to affect social change.

Once the first round of interviews was transcribed, I conducted line-by-line coding, and created correlating memos that summarized points of interest and points of possible significance. At the end of the line-by-line coding process, I developed a list of focused codes that incorporated the pilot data as well as the data from the first round of interviews. I went back to the original transcripts and captured the in vivo codes and participant quotes that best illustrated the focused codes, and developed memos for each focused-code category. The focused code memos synthesized participant contributions with excerpts from the literature, along with my own preliminary thoughts and questions about the codes themselves. They also noted possibilities for theory that might emerge from these codes to answer my research questions. 
The second and third rounds of respondents were selected because of their capacity to contribute to the specific focused codes that were generated by analyzing the pilot data, in combination with the data from the first round. Purposeful sampling such as this, which seeks to gather data that will develop conceptual and theoretical categories, is called theoretical sampling and is an important hallmark of grounded theory research (Charmaz, 2006). Theoretical sampling for this study was conducted via Skype and through email conversations in an effort to reach theoretical saturation. Glaser (2001) defines theoretical saturation as different from simply seeing the same pattern again and again, but as "the conceptualization of comparisons of these incidents which yield different properties of the pattern, until no new properties of the pattern emerge" (p. 191). This goal can be reached through collecting new data from existing respondents, or by seeking new data from new respondents. Theoretical sampling for this study engaged new respondents with a new, and very specific protocol.

The following table lists the respondents associated with each phase of the study, and provides a sample of the diversity represented by their professional standing, geographic location, and their gender and racial identities. Narrative biographical information about each respondent is included in Appendix C, where respondents are situated within the larger context of their lives.

Table 1: Respondents

\begin{tabular}{|l|l|l|l|l|l|}
\hline Group & Name & Professional Status & Location & Gender & Race \\
\hline Pilot & Martina Emme & Ed Consultant & Germany & F & C \\
\hline Pilot & Roslyn Farrington & Fixed Term & Portland & F & A \\
\hline Pilot & Isbel Ingham & Adjunct & Eugene & F & C \\
\hline Pilot & John Lenssen & Consultant/Adjunct & Salem & M & C \\
\hline First & Sally Eck & Fixed Term & Portland & F & C \\
\hline First & Rachel Hardesty & Fixed Term & Portland & F & C \\
\hline
\end{tabular}




\begin{tabular}{|l|l|l|l|l|l|}
\hline First & Tom Hastings & Fixed Term & Portland & M & C \\
\hline First & Roberta Hunte & Adjunct & Portland & F & A \\
\hline Second & Kim Stafford & Tenured & Portland & M & C \\
\hline Third & Rosalie Gerut & Ed Consultant & Boston & F & C \\
\hline
\end{tabular}

\section{Focused Coding}

In the table below, the conceptual categories, or focused codes, that emerged in my analysis are named and followed by a brief summary of subthemes taken directly from the interview data and from the memos generated in response to the interview data. Select quotes from interview transcripts are also included to give a brief illustration of the basis for each category. The codes that emerged from my analysis have been used to guide the process of theoretical sampling, which has clarified areas for additional data collection to assist with reaching theoretical saturation in each of these areas.

Table 2. Focused Coding

\begin{tabular}{|c|c|c|}
\hline Category & Summary & Quotes from Transcripts \\
\hline $\begin{array}{l}\text { Social Justice } \\
\text { Educators }\end{array}$ & $\begin{array}{l}\text { What they are } \\
\text { Implicit understanding } \\
\text { versus explicit } \\
\text { identification }\end{array}$ & $\begin{array}{l}\text { To awaken students to think for themselves, } \\
\text { and to think critically (Ingham). } \\
\text { It's about interrupting that and creating } \\
\text { opportunities for students and faculty and } \\
\text { others involved in the learning process, to find } \\
\text { their voices, to challenge the system and to } \\
\text { change the system (Lenssen). } \\
\text { I think that I do social justice education, but I } \\
\text { don't know that I'd label myself as a social } \\
\text { justice educator (Farrington). }\end{array}$ \\
\hline
\end{tabular}




\begin{tabular}{|c|c|c|}
\hline $\begin{array}{l}\text { The Personal is } \\
\text { Political }\end{array}$ & $\begin{array}{l}\text { How identity matters in } \\
\text { social justice education } \\
\text { The role of self- } \\
\text { actualization } \\
\text { Personal reflection as } \\
\text { consciousness raising }\end{array}$ & $\begin{array}{l}\text { I think one of the first tasks of a social justice } \\
\text { educator, really, is to uncover, to reveal, to } \\
\text { question, to go deeper (Lenssen). } \\
\text { When we look at social change, and social } \\
\text { justice work, a huge part of it is in } \\
\text { understanding our identities, and understanding } \\
\text { where we have had privilege, where we have } \\
\text { had access (Eck). } \\
\text { I tell about how I'm racist, classist, sexist, } \\
\text { heterosexist, every day, and so they can begin } \\
\text { to witness it in themselves so they can feel } \\
\text { okay about talking about it (Farrington). } \\
\text { If we can talk about it, and practice compassion } \\
\text { for ourselves within it, we can do something } \\
\text { (Hunte). }\end{array}$ \\
\hline $\begin{array}{l}\text { Theories versus } \\
\text { Stories }\end{array}$ & $\begin{array}{l}\text { How/do theories teach } \\
\text { social change? } \\
\text { Stories as the living } \\
\text { history to support theory } \\
\text { Demystifying theory } \\
\text { Theories are stories }\end{array}$ & $\begin{array}{l}\text { We think that the ruling class knows better, } \\
\text { because...they know the theory...but they } \\
\text { don't know the stories. Now, the working class, } \\
\text { they have all the stories (Ingham). } \\
\text { I realized that my experiences... didn't add up } \\
\text { to any coherent picture compared to what this } \\
\text { (academic) could teach me (Hastings). } \\
\text { I've come to see peer-reviewed articles as } \\
\text { stories. You know, they are this person's story } \\
\text { about what the meaning of the literature is, and } \\
\text { what conclusions we can come to (Hardesty). }\end{array}$ \\
\hline $\begin{array}{l}\text { Relationship } \\
\text { Building through } \\
\text { Story Sharing }\end{array}$ & $\begin{array}{l}\text { Humanizing oppression } \\
\text { Validating experience } \\
\text { Building trust } \\
\text { Modeling vulnerability } \\
\text { and compassion (for self } \\
\text { and other) } \\
\text { Showing Concern/Interest }\end{array}$ & $\begin{array}{l}\text { A lot of the work that I do is about building } \\
\text { relationships in the classroom...because I think } \\
\text { that when we don't feel like we're alone, it } \\
\text { makes it far easier to have a sense of agency } \\
\text { (Eck). } \\
\text { Working in groups allows those opportunities } \\
\text { to share stories, to hear other people's stories. } \\
\text { It has two powerful impacts: it opens our eyes } \\
\text { and our hearts and our ears to the experiences } \\
\text { of other people, and it also allows us to kind of } \\
\text { turn the mirror back and see ourselves in a } \\
\text { different light, and to kind of revitalize our } \\
\text { stories (Lenssen). } \\
\text { After storytelling, the lighter side of life } \\
\text { became easier to get to (Emme). }\end{array}$ \\
\hline
\end{tabular}




\begin{tabular}{|c|c|c|}
\hline $\begin{array}{l}\text { Storytelling to } \\
\text { Normalize } \\
\text { Complexity }\end{array}$ & $\begin{array}{l}\text { Compound } \\
\text { view/compound eye } \\
\text { Embracing the } \\
\text { inevitability of conflict } \\
\text { Love grows through } \\
\text { conflict } \\
\text { Increasing } \\
\text { timelines/transforming } \\
\text { expectations }\end{array}$ & $\begin{array}{l}\text { In truth, structural violence is complex. Every } \\
\text { type of conflict is complex, it is layered, it is } \\
\text { multi-faceted, and to understand it we need to } \\
\text { be okay with the complex, and accept } \\
\text { complexity as par for the course for life } \\
\text { (Hunte). } \\
\text { There's all kinds of conflict that emerges in } \\
\text { social action...I believe that surfacing conflict } \\
\text { and being proactive around conflict is a great } \\
\text { leadership skill and a necessary leadership skill } \\
\text { (Lenssen). } \\
\text { If we can be more okay with the complex, than } \\
\text { also we can protect ourselves, protect - not } \\
\text { our innocence, but almost our idealism } \\
\text { (Hunte). }\end{array}$ \\
\hline $\begin{array}{l}\text { Storytelling as } \\
\text { Possibilizing }\end{array}$ & $\begin{array}{l}\text { Showing what's possible } \\
\text { through example } \\
\text { Counter stories/stories of } \\
\text { transformation } \\
\text { Creating opportunities for } \\
\text { students to see that } \\
\text { idealistic views are } \\
\text { already in } \\
\text { play/operationalized } \\
\text { Scaffolding to envision } \\
\text { something greater }\end{array}$ & $\begin{array}{l}\text { When you start to tell stories of people who } \\
\text { have and are changing the world, you can no } \\
\text { longer believe discouraging stories... So the } \\
\text { stories are critical (Ingham). } \\
\text { The counter stories bring a reality, and an } \\
\text { urgency, and also a sense of hope because } \\
\text { some of the stories are about creating new } \\
\text { community, or making change, or } \\
\text { empowerment (Lenssen). } \\
\text { And it was kind of amazing, looking up on the } \\
\text { board, at all of the ways that people can create } \\
\text { that ideal world, and to be aware that so many } \\
\text { of the brilliant ideas that they came up with are } \\
\text { actually happening in the world, in some small } \\
\text { way, and to me, that is somewhat heartening, } \\
\text { because it reminds you that this isn't so pie-in- } \\
\text { the-skyish (Hunte). }\end{array}$ \\
\hline $\begin{array}{l}\text { Stories as Creative } \\
\text { Art }\end{array}$ & $\begin{array}{l}\text { Poetic power of metaphor } \\
\text { Story as art } \\
\text { Art as voice } \\
\text { Voice as transformation }\end{array}$ & $\begin{array}{l}\text { I was just struck by the importance of words, of } \\
\text { creative words, of expressive words, in formal } \\
\text { structure like state government (Stafford). }\end{array}$ \\
\hline
\end{tabular}

\section{Axial Coding}

After initial coding and focused coding, the axial-coding process seeks to relate each code to the others through a combination of inductive and deductive thinking. Grounded theorists commonly emphasize causal relationships, and fit the elements into a 
basic frame of generic relationships to begin the process of building theory (Charmaz, 2006). Corbin and Strauss' (1990) coding paradigm provides a formal structure within which to develop an understanding of the interrelationship between the focused codes and their subcategories. Similar schemas are used in other qualitative methodologies, but this particular coding paradigm is most commonly used in grounded theory research.

Corbin and Strauss (1990) offer a coding paradigm that first names the phenomenon, and then identifies the causal conditions, context, intervening conditions, action strategies, and consequences. The data collected in this study, and the focused codes that resulted, best fit within the action-strategies portion of this model, and are contextualized by the various other elements that explain the strategies' presence, significance, and consequence. Using this model has clarified the significance of storytelling as a mechanism for social change, and has illustrated the larger context for emerging theory around loving praxis.

This coding paradigm frames the underlying phenomenon of this study as that of loving praxis. The study's purpose has developed into an inquiry about the nature of loving praxis, and a deeper understanding of how storytelling supports loving praxis in critical peace education. The context for this study is the backdrop of neoliberalism, which interferes with the practice of critical peace education by supplanting the democratic goals of greater social justice with the capitalistic creeds of economic domination. The intervening conditions for this study are critical peace education, and within that, social justice education, which are the domains in which the research has been conducted. The action strategy that is being studying is storytelling, and within that, the focused codes provide an exploration of how they lend themselves to the overarching 
phenomenon. Lastly, the consequences are the moments of transformation that occur, in the classroom, and in society at large, from the presence of loving praxis in the work of social justice.

Table 3. Coding Paradigm

\begin{tabular}{|l|l|}
\hline Phenomenon & Loving Praxis \\
\hline Causal Conditions & Disconnected and disempowered population without voice or agency \\
\hline Context & $\begin{array}{l}\text { Neoliberalism, standards-based education, structural violence, } \\
\text { systems of oppression }\end{array}$ \\
\hline Intervening Conditions & Critical peace education/social justice education \\
\hline Action Strategies & Storytelling \\
& $\circ \quad$ The Personal is Political \\
& $\circ$ Theories versus Stories \\
& $\circ$ Relationship Building through Story Sharing \\
& $\circ$ Storytelling to Normalize Complexity \\
& $\circ$ Storytelling as Possibilizing \\
\hline Consequences & Transformation and social change \\
\hline
\end{tabular}

\section{Theoretical Coding}

Building upon the coding paradigm developed during the axial-coding phase of analysis, the theoretical-coding section seeks to conceptualize "how the substantive codes may relate to each other as hypotheses to be integrated into a theory" (Glaser, 1978, pp. 72). After breaking the data into focused codes, theoretical coding works to weave "the fractured story back together" (p. 72) and give coherence to emerging theory. Another way to describe theoretical coding is to make overt the "implicit theoretical frame that organizes a given piece of work" (Charmaz, 2006, p. 65).

The theoretical framework that emerges from the data, which informs my theorybuilding, is based in critical theory and social constructivism. Storytelling, considered from these perspectives, appears to provide the opportunity for ideology critique, which inspires the transformation of student perspective, the maturation of student development, 
and the possibly of a proclivity to engage in activism toward social change. This theory will be explored at length in the following chapter.

\section{Analysis of Conceptual Categories}

The following section of this chapter explores the focused codes in greater depth, situating them within the diverse perspectives shared by respondents in the course of their interviews, and explicating those codes through comparison and discussion. Where possible, literature has been cited to contextualize these ideas within the canon of education, and to provide further insights into areas for possible theory building.

\section{Social justice educators.}

One of the parameters for participation in this study was that respondents identify themselves as social justice educators. This presented a slight challenge in that many of the participants were unfamiliar with the designation of social justice educator. I offer the following definition from Kumashiro (2009), a widely recognized educator and scholar in the field of social justice education, who explains that teaching toward social justice "means teaching students to think independently, critically, and creatively about whatever story is being taught, whether that is the dominant narrative or any number of alternative perspectives from the margins" (p xxv).

This definition provides an explanation of the goals of a social justice educator, which may not correspond exactly with the goals of respondents, but offers a starting point for discussion. While the idea of teaching for social justice has been commonplace in educational philosophy since at least the time of John Dewey (1930), the term social justice educator can pose some confusion in terms of whether it pertains to a particular discipline or disciplines, or whether it is constituted by a specific pedagogy or practice. 
Because I solicited the initial respondents from my own professional contacts, I was confident that they all met the broadly defined qualifications for participation, even if they only had an implicit sense of their identities as social justice educators.

In the course of each interview, respondents were asked whether they considered themselves to be social justice educators, and with some encouragement and explanation, they all agreed they were. They were then asked to define what it means to be a social justice educator and, not surprisingly, their responses varied, reflecting the diversity of their perspectives and subject areas of expertise. Despite the variations, there were many common themes in their descriptions of the tasks of a social justice educator, perhaps best characterized by the common desire to challenge students to develop a broader perspective, and within that, a stronger voice to speak their truth.

Isbel Ingham describes the particular challenge of a social justice educator to be that of making the world a bigger and better place. An educator's task to achieve that goal, she explains,

[i]s to awaken students, to assist them to think for themselves, and to think critically about the material they are being presented, and to take that to lead bigger lives. For them to understand the material they are being presented is kind of one-dimensional, and they need to make it two and three and even fourdimensional. And use it to make the world a bigger and better place.

Academic texts often neglect to provide broad perspectives, diverse voices, and in-depth analysis of the complexity that underlies systems of oppression. However, when educators impart critical-thinking skills and are able to encourage students to see issues within a broader context, students are able to recognize how systems advantage and disadvantage particular groups, and are better equipped to critically engage with issues of social justice. John Lenssen describes social justice education as an essential step in 
challenging students to deconstruct the structural violence (Galtung, 1969) that holds oppression in place. He speaks to the role of education as a socializing influence, and of the necessity for social justice education to challenge students to find their voices, and engage in the activism of democracy:

I strongly believe and understand that our schools are designed for white middle class people, and to maintain the current system of oppression. And so, social justice is about interrupting that and creating opportunities for students and faculty and others involved in the learning process, to find their voices, to challenge the system and to change the system. And that, for me is the key of social justice education. It's about understanding the dynamics, challenging them and changing them. So it is about an activism that goes beyond understanding.

While challenging the system in order to change it might be a commonly seen as part of the work of social justice educators, there are many ways to challenge and change, with multiple different perspectives on how to get the process started. Roslyn Farrington acknowledges the need for structural change, framing it as a process of saving the world, but rather than starting with activism in the world, she believes the first and most vital challenge for social justice educators is to deepen self-awareness, and to locate oneself within the existing and inequitable system of power and privilege as a means to help students see the world differently.

I think our job is to save the world, and we save the world by saving ourselves. And we also save the world by inspiring students to save themselves, and to save their world. And I think that's what our job is. For me it's been about recognizing about how I've been blind about my privilege in the world. And how having that insight changed how I walked in the world and how I related to everybody. And understand that students can grow up with that same level of blindness, because it's the culture we live in. And so, really, my job is to help them see the world through a different lens. And hopefully that will inspire them to be different.

Gaining a broader perspective about the world creates the opportunity for students to reflect on their own place in that world, and their own stories, voice, and agency within 
that. Kim Stafford speaks to the challenge of helping students find their own voice, and once found, of claiming and speaking their truth. He frames this task as a precursor to the freedom of speech that democracy requires in order to be functional.

I talk about the fundamental importance of people knowing how to exercise freedom of speech. My father used to say you can legislate freedom of speech, but you have to learn how to do it. Many people are silenced; many people silence themselves. Many important stories are not told, because we are afraid to tell them, or we don't know how to tell them. Or often, they are so important, they are paralyzing.

While some social justice educators emphasize an internal focus, an external focus, or a process that encompasses the spectrum between both, there is a general agreement within my data that the overarching challenge is to encourage students to develop a broader perspective, and a greater capacity to find and speak their voices as advocates for change. These are seen as key steps toward creating greater social justice, and ultimately, toward saving the world.

\section{The personal is political.}

When sharing stories about how they encourage students' interest in and understanding about social justice, almost all of the educators I spoke with stressed the importance of personal reflection as a means to locate one's self within the structure of social identity, as a mechanism to work toward self-actualization, and as a tool to raise consciousness - all as actions toward social change. I have coded this recognition as "the personal is political," to note the belief that a commitment to deepen self-awareness and a willingness to acknowledge one's role in society affects the political. This recognition was an integral part of the second wave of the feminist movement in the United States, where the personal is political originated as a cry to recognize the essential 
role that consciousness raising plays in creating personal change and, as a result, in creating social change and, as a result, in creating political change.

Aronowitz (1998) explains that, "Learning begins with taking the self as the first object of knowing" (p. 12), and describes critical consciousness as deriving from "the learner's capacity to situate herself in her own historicity, for example, to grasp the class, race, and sexual aspects of education and social formation and to understand the complexity of the relations that have provided this situation" (p. 14). In defining the tasks of a social justice educator, many respondents echo Aronowitz's sentiments, as they refer to the importance of the educator understanding her own identity within the social structure of privilege and oppression. John Lenssen articulates the significance of the relationship between self-knowledge and teaching social justice as follows:

I think one of the first tasks of a social justice educator, really, is to uncover, to reveal, to question, to go deeper - all of those. And, part of that task is for each person to know themselves, and how they are placed. And that means looking at assumptions, and biases, and language. Knowing cultural beliefs and looking for those contradictions - not only in the system but in ourselves - because most of us are not benefiting from the system, but we are taught to believe that somehow the system is working, even for those of us who have a real consciousness that it's not. There are ways that we unconsciously buy in and participate and, for those of us who have some position of authority, we actually recreate these systems of oppression that we are strongly opposed to.

This importance of self-understanding is echoed by Sally Eck, who specifically refers to the importance of knowing one's agent and target statuses within the broad arena of oppression theory, in order to be "able to hear the stories of others without shriveling, or being so angry that we can't participate.” She elaborates: 
When we look at social change, and social justice work, a huge part of it is in understanding our identities, and understanding where we have had privilege, where we have had access, where that privilege and access has padded us and our identities from experiencing the full wrath of those other parts of our identities, or confounded those, and made it more complex, and really getting at that.

When social justice educators do the work of understanding their own identities, they are better equipped to both model and facilitate the process for students. Roslyn Farrington describes her process for modeling self-awareness as a means to invite students into their own self-awareness - and ultimately, into a process of healing the harm that most everyone suffers within the larger system of oppression.

I start by telling my story. But I mainly do that to expose myself, so they feel safe to expose themselves. I really try to model what it means to be self-critical. So a lot of the stories that I tell about how I'm racist, classist, sexist, heterosexist, every day, and so they can begin to witness it in themselves so they can feel okay about talking about it. Because we don't want to talk about it, and if it just gets pressed down inside of us it never gets healed.

The process of self-disclosure, and the willingness to expose one's own process of being self-critical, can create an atmosphere of safety within the classroom that allows students to engage their own process of self-discovery within the learning community. Self-reflection can lead to self-discovery, which can lead to self-awareness, which then can lead to self-actualization - the state where one realizes the full potential of one's being (Maslow, 1943). Rachel Hardesty speaks to a similar process, where she frames her task as an educator as being to create "spaces in which people can self-actualize, without undue impediment." This means overtly acknowledging the constraints and impediments that exist for students in the world at large, and creating sufficient safety within the learning community for students to delve into a process of deeper self-understanding. 
Roberta Hunte eloquently describes her understanding of the connection between self-knowledge and personal agency in sharing, "I think that in beginning to understand my identity, I can understand the world. I can understand more about how I came to be where I am and how to leverage resources for my own advancement." She builds on the importance of modeling self-awareness and supporting students' self-actualization by bringing in the vital role of compassion as we unpack our stories - both for ourselves as agents and targets, and for our students as agents and targets.

I try to teach about these things from a perspective of, this is what's out there, and until we're able to talk about it, we can't do very much. But if we can talk about it, and practice compassion for ourselves within it, we can do something. We don't have to just stay in that, "I can't do a thing" space.

Being invited to talk about our experiences of justice, or lack thereof, empowers us to find our voices and speak our truths. Kim Stafford believes the foundation of democracy is "singing your own song," and emphasizes that "each person, the voice, the intelligence, the perspective of each person is required, and our collective authority as a nation requires the voice of everyone." When we recognize that the personal is political, we can access a very personal way to contribute to functional, or participative, democracy.

\section{Theories versus stories.}

Many respondents speak passionately about the role of theory, or lack thereof, in the process of social justice education. While some believe that strong theory is vital to build understanding of and mobilize activism around social change, others express disbelief that theory has a presence in the process of social change. Several respondents frame a dichotomy between theories and stories, as if they represent opposite and 
conflicting ways of negotiating knowledge - although one respondent creatively

describes theory as a type of storytelling that has been formalized within the culture of academia. While the discourse of critical peace education favors continuum thinking over dichotomous thinking, I have coded this category as a dichotomy to accurately represent the data, and also to invite integration.

The dichotomy of stories and theories is present in Christine Sleeter's foreword to SooHoo's work, Talking Leaves: Narratives of Otherness, where she justifies her use of stories as a means to make connection with readers, and differentiates its impact from the theories that are more common within academic discourse.

Often I am asked what prompted me to commit myself to social justice work, why I care. Although academic discourse helps to analyze and communicate many things, it is not the discourse I turn to when asked these kinds of questions. Instead, I tell stories. Through stories, I can bring readers or listeners into the world of emotion and imagery that gets lost in theory and data. (Sleeter, 2006, p. ix)

The idea of theory being unpersuasive, or even sterile, emerges within my interview data. Isbel Ingham speaks about the difference between theories and stories in her interview, and questions the value that theories bring to mobilizing processes of social change. She describes stories as being the motivating force for change, in that they illustrate how people have done what they have done, and inspire action in others.

Would you take a group of students and simply give them an academic text on the basics of nonviolent training, and then think that they could go out and do that? Without reading any stories? I don't know how you would do it without stories. You have to learn from what other people have done.

Isbel Ingham frames the dichotomy between theories and stories further within the context of class difference. In the quote below, she again suggests that theories in and 
of themselves cannot mobilize change, but that change is something that can result from the process of storytelling. Invoking Patricia Hill Collins's matrices of domination and intersectionality of oppression (2000), which address the interrelationship and impact of crisscrossing forms of oppressions, Isbel Ingham describes the task of a social change agent as being to facilitate exchange between the ruling and working class, bringing story — and its representation of reality — to theory builders.

We think that the ruling class knows better, because that's what we are told. But they don't know the stories. They know the theory, they know what they're supposed to do, but they don't know the stories. Now, the working class, on the other side, they have all the stories. And really, if the owning/ruling class had ever heard the stories of the working class, things would have to shift.

John Lenssen also recognizes the power of stories over that of theories, but shares how stories can bring a sense of reality to the integrity of theory building. "I think our stories move us beyond just the realm of the head, and that they touch our hearts and our emotions, and bring real living history to any of the theory we are talking about." Building upon this idea of story touching our hearts in ways that prompt practical changes in our understanding and use of theory, Roslyn Farrington offers Martin Luther King, Jr.'s vision of beloved community, as a means to shepherd in the realization of social justice.

Dr. King talked about beloved community, and he said, beloved community will require a qualitative change in our hearts as well as a quantitative change in our lives. And I think the storytelling is what inspires that qualitative change in our hearts. And so we have laws in place, but laws don't really change the hearts and minds of people. But if I touch your heart through storytelling, then you see me different, I see you different, and I'm forever affected by that.

Dr. King's vision of beloved community as joining the quantitative elements of theory and the qualitative experience of heart provides great inspiration for social change. 
Social justice educators, particularly those who operate within academia, have also found effective ways to bring the two together with their own vision and purpose. For example, Roberta Hunte uses several theories in her interview as a means to explain the purpose of peace education and the intellectual process engaged by a social justice educator who is negotiating conflict. She introduces Maire Dugan's idea of the nested foci paradigm (as cited in Lederach, 1997), which suggests that all issues within any conflict must be considered within the context of the systems in which the issues exist. She uses this paradigm to illustrate the value of theory in providing a framework by which to analyze conflict, as the task of social justice educators and conflict resolution scholars is to always keep structure in mind, and to think about how each little action links to the entire structure and contributes to structural change.

Tom Hastings also speaks to the value of theory as being a way to make meaning of action, and "to use theory to become a better activist." He shares, "I realized that my experiences — and I had some pretty deep experiential knowledge about community organizing, et cetera - all of that didn't add up to any coherent picture compared to what this (academic) could teach me." As a result of his own experience developing a greater sense of scholarship, he has become dedicated to acquainting students with theory as a persuasive way to prove the authenticity and efficacy of nonviolence.

In keeping with the idea of theory as a useful mechanism for developing greater understanding, Rachel Hardesty suggests that the theory-rich realm of academic writing, largely populated by peer-reviewed articles, is actually its own venue of storytelling. She shares, 
I've come to see peer-reviewed articles as stories. You know, they are this person's story about what the meaning of the literature is, and what conclusions we can come to. Immersing into a world of people's stories is kind of fun, because I don't have to take them so seriously, for a start. And can see them as metaphorical and not as truths, and really see the individual and compound views.

The idea of theories as stories is more than fun, and is not simply novel, as evidenced by the methodical manner Rachel Hardesty applies to her process. She describes how she uses theory to flesh out the scope of an issue, and to use that depth of consideration as a means to develop her own thoughts and positions on a given topic.

I'm interested in quite theoretical work that takes a very distant stance to an issue and may also be looking at a number of different cases and drawing universal themes. Because I suppose that's really the process of analysis that I use for stories, in that, here are all these different people, but what things are they saying that are the same, and what are the really different things they are saying, and how does that inform what I think I know about the subject?

Though theories themselves may not be the most effective vehicles to encourage students to engage with issues of social justice, theories situated in real life through stories, or even analyzed critically as a story of academic value, can be of great value to the process of learning. Once learning has occurred, most respondents agree that stories are more effective than theories for inspiring action, and for encouraging the qualitative change of heart that Dr. King spoke of as being a necessary precursor for real and lasting social change to occur.

\section{Relationship building through story sharing.}

In discussing the work of John Dewey, Schubert (2009) posits that a prerequisite to social justice is the presence of loving relationships, and explains "that loving relationships that strive for social justice can overcome harmfulness of an acquisitive society and provide the possibility of cultivating democratic and dialogic experience" ( $\mathrm{p}$. 
10). This quote supports the focused code of relationship building through story sharing that resulted from my interviews, and adeptly frames the nature of relationship as a counterhegemonic force of connection - one that creates the encouragement, voice, and agency that are necessary for participative democracy to function.

As they describe their roles as social justice educators, and share some of the methods they use to engage students' concern about issues of social justice, all the respondents in my study discuss the importance of relationship. They believe their relationships with students are the means by which to model respectful and accountable engagement, and many respondents speak about how they facilitate and encourage student relationships — with one another, and with their extended networks of connection. Respondents also talk about modeling specific relationship skills in the classroom, including vulnerability, and one respondent focuses on developing mentoring relationships with students as a means to support them in the difficult task of cultivating agency and activism around social change.

Roberta Hunte talks about building relationships between herself and the students in her classroom in an effort to ensure that they feel seen and heard. She tries to learn students' names, remember some of the stories they share about themselves, and tries to love each student by supporting them in their learning process as best she can. She tells her students that ending oppression begins in the way they relate to one another in the classroom. 
As a teacher I am constantly modeling [loving], but also encouraging my students to jump in there too, and to be responsible for themselves and for the group. So, for example, if we're going to be talking about Queer rights, how are we going to have that conversation in a way that's productive? Bearing in mind that we have people who are about this, and who are not. And that it's important for us to create a context that is, in some ways, more dynamic than what we see in the world. Even a dynamic of being able to talk about a lot of these structural things and not just put it as a republican or a democrat or a socialist - to talk beyond the labels. And to do so knowing that all sides, all groups are in the room together. Because whether we want to acknowledge it or not, we're all in the room.

Building respectful relationship can help educators and students feel safe engaging in complicated and contentious conversation, but even the relationship building itself can be an important buoy for students' sense of worth and agency. Sally Eck works to create relationships within each classroom experience, and believes that making space for people to connect in the classroom gives them the confidence to speak up, and ultimately the strength to speak out.

A lot of the work that I do is about building relationships in the classroom. And what I always say is that my secret goal is to have each other end up in each other's weddings and commitment ceremonies. And that does happen in my classes, and I really am proud of that. Because I think that when we don't feel like we're alone, it makes it far easier to have a sense of agency. I give breaks, really intentionally, so that the students will talk to each other. I sometimes shuffle my papers around for the first three minutes of class, so that they'll look at each other. I mean, just little things like that, so that people can know that they're not alone. I think that helps a lot, so that they can be vulnerable with each other.

Gaining confidence through relationship building helps students find their voices, which enables them to speak out against injustice. Taking the importance of relationships further still, Sally Eck shares that her real goal in interrupting oppression is to deepen relationships, because when we really know one another, and hear each other's stories of struggle, we are able to speak out in support of one another - even across differences: "I say that when we are doing an interruption, the point of doing this work is to examine the 
cultural lies, and the oppression that keeps us from connecting, and keeps us reifying and affirming oppression.”

The connection that Sally Eck speaks about is both key to relationship building and essential to deconstructing oppressions. Yet, Tom Hastings categorizes dominant culture in the United States as being a "culture of lone wolves" that makes connection in general, and group work in particular, very difficult for most students. He specifically creates assignments that involve group work, in a deliberate effort to teach students the skills of collaboration. Similarly, John Lenssen seeks to engage group work in his classes as a means to help students understand how differently people manage difficult situations, and as an opportunity for them to recognize diversity — including the chance to reflect on their own selves within a broader context than they typically have access to.

Having students work in groups - whether it's in class or in projects - gives a sense of what it means to be in a group, and also shows the different perspectives and different positions, the different ways that we are oppressed around issues of racism and sexism, and heterosexism, and classism. Working in groups allows those opportunities to share stories, to hear other people's stories. It has two powerful impacts: it opens our eyes and our hearts and our ears to the experiences of other people, and it also allows us to kind of turn the mirror back and see ourselves in a different light, and to kind of revitalize our stories.

Relationship building requires students to be vulnerable in the classroom, which is not a widespread expectation in the postsecondary experience. Sally Eck describes how she uses her own vulnerability to model for students what it looks like to be authentic in relationship with others.

I'm also very vulnerable in the classroom. And I use that to illustrate the ways that we can all be brave, and I really try to model that, and the ways that we all can have integrity, and I try to model that. And we really, I think that that example really helps serve the students, coupled with that foundational framework, and then some really concrete strategies. 
Both John Lenssen and Isbel Ingham speak to the difficulties of working toward social change without supportive relationships. John Lenssen suggests that taking time to build caring and engaged connections with others at the beginning of a movement or change effort is essential for success and sustainability. He expressively summarizes that, "there's an intimacy in this work that's necessary for social justice," and elaborates,

The work of social justice, whether it's antiracism or any other work, is hard as hell. You know, and it doesn't matter if you are coming, if you are one of the people most oppressed by that form of oppression, or you are an ally, it's hard as hell and allies have the opportunity of withdrawing when things get hard, or uncomfortable or unclear, and when you are in the midst of the oppression and things get hard or uncomfortable, you fall back into survival mode. So we lose a lot of people in this process because there hasn't been the upfront work of building community, building trust, building relationships across differences. So if we're working together, I need to know you and your experience, and how these issues impact you and where you are coming from. And I need to care almost as deeply about you as I care about me. And when I'm thinking about alliances across difference, they need to be that close and that connected. Some of us can be sustained by an abstract philosophy around human rights and oppression, but most of us sustain our work and our engagement in human rights and social justice through real life connections with people.

Reminiscent of Brown and Mazza's work on leadership in social change (1997), Isbel Ingham finds leadership for social change hard to develop, and even more difficult to sustain, because of the challenges inherent in the task. As a lifelong activist and educator, she sees the task of a social justice educator as supporting students to step into their voice and agency by continuing to cheer them on during the arduous process of community organizing around change. "I think (leadership is) about mentorship. Activists need mentors and supporters because it's so much harder now. People need someone behind them, patting them on the back and saying, 'You can do it,' over and over again." While the ways in which respondents discuss relationships vary, all of them speak to the importance of relationships in the work of social justice education. Martina Emme 
frames the importance of relationship in effecting change with the work of Martin Buber (1970), who differentiated between the objectified I-you relationship and the subjective and reverential relationship of I-thou. Similarly, Rachel Hardesty concludes her interview with a reference to the work of Nel Noddings (1984), who talks about caring and moral education, which supports the caretaker role of a social justice educator, whose job is to help students feel felt (Seigel, 2009).

John Lenssen explains the transformation that happens within social justice education as a direct result of the caring that is put into the relationships we build as educators and activists, and the connection we actively create in those relationships. He describes the sharing of stories as a key component to the connection within those relationships, as those stories allow us to care as deeply about each other's lives as we do about our own, and as a necessary ingredient in the recipe toward social justice.

My primary means of understanding is through connection, and part of that connection is storytelling. Part of that connection is engaging the struggle together and having that shared experience. Part of that connection is the living and breathing, and being in the homes and in the communities and living the story side by side — not just living my story, but living other, connecting with other people's stories in a very real way. Just using the word love, that's really what I'm talking about, needing to know your story, so that I care almost as deeply about your life and the life of your children as I do about my mine. That is a love connection that goes beyond just understanding. There's an intimacy in this work that's necessary for social justice.

That intimacy is something that many respondents sought to explain. Martina Emme describes engaged listening as an essential and transformation aspect of relationship building. In her experience, the rare pleasure of truly listening to another's story, and having them truly listen to hers, was an alchemical process for a better life. 
After storytelling, the lighter side of life became easier to get to - the nicer life, the better, not the easier or nice feelings of life. And before I always had the feeling I'm not allowed to enjoy life, see? And this is the change. I look at it in the very rare moments of this storytelling, in this circle, when real listening happens. It's not that the transformation process is right there, but it's like a seed and it grows, grows, grows. And for me, I have such a better feeling of what life could be after that experience.

Martina Emme goes on to describe that the relationships built through the sharing of story transform people's perspectives about structural violence, and how stories situate the urgency of social injustice in something tangible, or concrete.

I feel the need to help people understand they are part of the system, which is doing harm to others. And when there is this little moment of understanding, of opening up, then I am feeling good and something comes into the flow. And of course, you are absolutely right, storytelling is the door opener for this process. Otherwise you don't get it. Because it brings people right into the story - for example, very often we have discussions where people would say, "The society is..." It's very abstract when there is no personal story.

As relationships are built through the sharing of stories, students are transformed by the power of those relationships, which bolster and encourage greater understanding, voice, and agency. At the very least, relationships can provide us with knowledge about ourselves and the world around us, but at the most, they can provide us with the encouragement, connection, and agency to push forward toward a more participative democracy, and the greater social justice that results from and engaged citizenry.

\section{Storytelling to normalize complexity.}

Normalizing complexity is an in vivo code shared by Roberta Hunte ${ }^{6}$ to illustrate the importance of students recognizing that social justice issues are necessarily complex.

\footnotetext{
${ }^{6}$ She attributes this phrase to one of her academic mentors, Ben Anderson-Nathe, a faculty member in both Child and Family Studies and the School of Social Work at Portland State University.
} 
In an era where sound bites are used by the media and others to convey news, it is easy to get the (wrong) impression that issues are simple, and that there is a clear reckoning of right and wrong. Normalizing complexity speaks to desensationalizing the nature of conflict, and recognizing that right-and-wrong is not black-and-white, but rather a continuum of shades of gray. Kitchener and King (1990) speak to normalizing complexity in terms of student development, and articulate that, as students develop, they become more capable of engaging complex combinations of abstractions to creatively and effectively solve problems. The code of normalizing complexity represents the importance of understanding and even expecting complexity in addressing issues of social justice. This theme was found throughout my interviews, as respondents spoke to the need for social justice educators to impart the value, importance, and benefit of normalizing complexity in the stories shared through the media, in our own stories, in our relationships, and in the inevitable conflict that emerges in working toward social justice.

The simplistic messages and surface-focused stories of the mainstream media illustrate how to craft superficial renditions of our experiences. Isbel Ingham explains that part of her role as a social justice educator is to encourage critical thinking, and within that, to help students "understand the material they are being presented is kind of one-dimensional, and they need to make it two- and three- and even four-dimensional to make the world a bigger and better place." By delving into the depths of social issues, students gain the possibility of contributing to social change, and a better world.

Simplistic stories teach us that having a superficial understanding of any one issue is sufficient to be knowledgeable on that topic. While this poses a particular challenge to postsecondary education as a whole, it becomes even more problematic within the 
complexity that is inherent in issues common to peace education, primarily the struggle

for social justice. Rachel Hardesty speaks to the common phenomenon of students

arriving to classes with very little depth of understanding about the subject of the course,

and without any awareness of how superficial their knowledge is. She addresses the

importance of reflection and integration of their own stories about the world with other,

perhaps contradictory, stories of the world, as a means to build an informed and

democratic society.

$[\mathrm{P}]$ art of what I'm complaining about is that there is a difference between a deepseated inquiring interest and an impulsive attention to novelty - which may have been repeatedly sparked by a subject for them, but which they've never deepened. So I can feel a bit frustrated when they arrive without any sort of evidence having followed up on that sort of repeated impulsive spark that they've had. So a great deal of what I try to do in the class is to encourage that deepening. And, too, because I believe that people are actualized through deep integration of their own narratives of the world, the stories that we live with about the world and how it works are tremendously influential. So if they are not deep and considered, than I think we are a less rich society and a less stable society.

With a similar focus of creating a more rich and stable society, Kim Stafford describes how he uses his writing classes as an opportunity for students to delve more deeply into the complexity of their own story, and shares some devices he uses to encourage that deepening.

I've been accused of not teaching - just doing therapy. No, this is empowerment, this is a democracy of voices, this is stories being told to advance social understanding, engagement, and justice. That's what I'm trying to do. The first move in class is in that direction. And then people begin writing, and we help each other dig deeper - what haven't you told? If that were part one, what would be part two? What's the rest of this story? When you hear other people telling your stories, are you called to bring forth another dimension of your own story? So it's that kind of ongoing studio community, and making the stories of our witness. 
Delving into the depths of stories often reveals complexity, and within that complexity, conflict can be found. The inevitable presence of conflict in social justice work, both in terms of the structural violence that is addressed by the work, and in terms of the interpersonal struggle that results from the hardship of the work, is often too painful for people to endure for any sustained period. If we expect life to be easy, this work will certainly disappoint! If conflict is understood as a necessary — and even helpful - part of the process, then progress can be made toward proactive change.

Roberta Hunte elaborates on the idea of normalizing complexity in discussing the nature of structural violence, and in identifying the need for strength to endure the challenge and pain that is required to work toward change.

In truth, structural violence is complex. Every type of conflict is complex, it is layered, it is multi-faceted, and to understand it we need to be okay with the complex, and accept complexity as par for the course for life. I feel like the more that we can be okay with that, the more we can hang in in the tough conversations and work with the fact that we're not covering the kind of ground that we want to cover and headed for vacation, you know?

A cultural habituation toward the ease of vacation, and away from difficulty is certainly one of the obstacles to social justice. Achieving social justice requires effort and persistence, and it is not always fun. John Lenssen shares that one of the biggest challenges he faces in the work of social justice is in regard to the conflict that emerges within interpersonal and group dynamics. Conflict materializes in terms of leadership style, philosophical framework, and also around the social justice issues themselves. $\mathrm{He}$ posits that acknowledging conflict, and normalizing the complexity it poses, is an essential leadership skill in social justice work. 
So, as a group is working towards action there is a lot of conflict that emerges. And there are different perspectives, you know, who's going to lead, and traditional leadership or flattened leadership, or espousing one theory and acting a different way. So there's all kinds of conflict that emerges in social action, in real social action. I believe that surfacing conflict and being proactive around conflict is a great leadership skill and a necessary leadership skill, so that groups can come together and know each other personally, and learn about conflict through group dynamics.

Another part of the complexity respondents spoke about was the impatience with which we embark on efforts toward change. One-dimensional issues are indeed simple to solve, but multidimensional issues are necessarily complex — and often take time to resolve. Roberta Hunte shares her personal experience with the patience required in the complex aftermath of apartheid.

But that actually, the commitment to a cause may be much longer, and maybe our whole lives, you know. I think for me, like, South Africa was a big wake up to that. The way that things were presented was that once you get rid of Apartheid everything will be grand. And I've watched the disillusionment people have felt. And it's like, I feel almost like if we can be more okay with the complex, than also we can protect ourselves, protect - not our innocence, but almost our idealism. Those long-range ideals, ethics, vision, are still happening even in the moment.

Recognizing the inevitability of complexity in the work of social justice gives contributors the chance to sensationalize the issue at hand, instead of sensationalizing the drama of the work, or the workers. The nature of social justice work is necessarily complex and, as such, can require extensive time, effort, and energy for change to be effected. The concept of normalizing complexity is therefore vital for creating the agency that fuels movement toward social change. 
Storytelling as possibilizing.

Maxine Greene (2003) introduced the word possibilizing to the canon of critical pedagogy as a means to recognize the relationship between creative imagination and social change. If we can imagine the possibilities of a different tomorrow, we are emboldened to take action to create that change. Without the sense of possibility, and the hope that sustains our actions toward that possibility, discouragement prevails and inaction results. Levins Morales (1998) echoes the need for cultural work to infuse “people's imaginations with possibility, with the belief in a bigger future, is the essential fuel of revolutionary fire" (p. 4). The term possibilizing was chosen as a code because respondents unanimously refer to the importance of imagining the possibility of something different in order to instigate action toward change.

Isbel Ingham talks about the power of hearing stories about people who have changed and continue to change the world. Having one's discouragement transformed to hope gives students a renewed sense of possibility, and influences their resulting ideas and actions. The stories that inspire others are not limited to those of world-renowned heroes of social change, but include the stories of all of us in the course of our daily struggles and successes.

When you start to tell stories of people who have and are changing the world, you can no longer believe those discouraging stories. You can't. So, if you hear those stories you cannot be discouraged, but if you don't hear those stories, then you can be discouraged. So the stories are critical. You cannot be a social activist without the stories. It's impossible.

The storytelling project model (Bell, 2010) articulates the vital role of counter stories in the process of social change. Bell describes counter stories as those that provide both a contrast and a challenge to the hegemonic, or stock stories that are ubiquitous in 
mainstream society. John Lenssen describes counter stories in the following interview

excerpt.

So the counter stories are those stories that go against what is out there. The counter stories are the stories of interruption, or the stories of hope, and the stories of horrific oppression that is happening beneath the surface, that is happening psychologically, daily, in the lives of students and families in our community especially students of color, gay/lesbian/transgendered students, these are stories that are not really told. They're told in a very superficial way. So the counter stories bring a reality, and an urgency, and also a sense of hope because some of the stories are about creating new community, or making change, or empowerment. So those stories need to be told.

John Lenssen ties this notion of counter stories together with the idea of possibilizing in the following quote.

And how would I describe the relationship between storytelling and mobilizing student action? I don't really see them as separate. I see social justice work as always being about action, and so storytelling provides the layers and, you know, and sometimes the sense of urgency, or even the sense of what can be. A real strong feeling, "oh this is really possible."

This sense of possibility is something that Roberta Hunte actively seeks for her students by encouraging them to generate ideas about what an ideal, or socially just, world would look like. Many students experience the exercise of engaging their imagination as radical, but many of the ideas they generate create opportunities to share counter stories - real examples of how people have operationalized those ideals in the world. 
I did this exercise with my students where they had to imagine an ideal world. And they were like, why do we do this? We don't want to impose on other people. And I'm like they are imposing on us, because they are making it up - that's what city planners do. So I think we can manage for ourselves. But, what was really kind of fascinating about it was that they came up with these ideas about what they wanted, and then they had to think about what real world application would look like. And it was kind of amazing, looking up on the board, at all of the ways that people can create that ideal world, and to be aware that so many of the brilliant ideas that they came up with are actually happening in the world, in some small way, and to me, that is somewhat heartening, because it reminds you that this isn't so pie-in-the-skyish.

Other respondents share stories of how they use counter stories and possibilizing as a means to teach about democracy, and to encourage students to contribute to the participation necessary to keep democracy alive. Isbel Ingham encourages her students to get involved in public meetings as a way to possibilize their own involvement in issues of importance, and to provide a counter story to the stock stories of disempowerment that students are culturally immersed in.

And, for instance, I told a number of them about city council meetings that they could come listen to, and public forums on particular issues, and none of the students in my class - other than the really overt activists - had ever been to one of these. Maybe five or six went, and they were just astonished that they felt welcome, that their input was really valuable, and that just ordinary community members went. And it gave them a sense that, yeah, democracy really is participatory. They were very dissociated from that notion.

The sense of empowerment that is garnered through the possibility of participation can also be framed within the context of expanded perspectives. Rachel Hardesty suggests that the simple process of learning more about the diversity of perspectives in the world enables us to expand our own sense of what's possible, and as a result, gives us a greater capacity for imagining our own perspective. 
Even if it hasn't changed their point of view, they've understood why people hold other points of view. And I think that's a tremendous experience to provide people because, like I say, we can very easily tend to spend our time with like thinkers. So in that sense, as a teacher, one of one's responsibilities is to create the opportunity to see a breadth of perspective. That there is more than one way to know about something and that all of those ways of knowing contribute something to the truth, however we construct that in this minute. But the more perspectives we can hold in our minds at the same time, the more we know.

A broader perspective gives students a better sense of where their stories and voices fit into the larger discussion. Kim Stafford finds that once his students are more empowered to find their own voices and are encouraged, through the process of sharing their stories with classmates, to see that there is value in their stories of experience, they are prone to becoming more active in civic life. He describes his facilitation of their process as:

Very gentle, not intrusive, trying to create a forum for people to bring forth the difficult dimensions of their personal, family, and community experience. I think once we establish we're together to help each other do difficult work, then the writing that happens is not just therapy, as I've been accused of in my teaching, but it is empowerment. The democracy of voices, the stories being told to advance social understanding, engagement and justice, are what I'm trying to encourage. My feeling is that the writing, the saying out loud, the telling of the story long suppressed, is the catalyst for a more active life.

The active life that Kim Stafford speaks about, resulting from the empowered sense of agency to contribute to a functional democracy, can only happen if students know that it is possible. Stories are a compelling vehicle to convey what others have done, and to share what we ourselves have succeeded in, and to encourage movement toward positive social change. While the stories privileged by the corporate media typically focus the hopelessness of change, it becomes even more essential that social 
justice educators promote stories of possibility, stories of empowerment, stories of success to inspire all citizens, to make a difference in society.

\section{Stories as creative art.}

As respondents share about the integral role of storytelling in what they do as social justice educators, it is evident that storytelling not only changes people because of the content of the stories, but also because of the exchange that happens in the delivery of the story. Stories convey emotional and nonverbal aspects that speak volumes about how they have impacted the teller, whether they are the teller's own stories, or those about someone else. SooHoo (2006) explains that:

As listeners of the spoken, written, and silent stories, we hear differently what we've known before. The transformative power of story cannot be underestimated. We experienced a critical moment in every story; a place where each listener finds one's self within someone else's story. With magnetic force, the listener becomes inextricably entwined with the spin master. (p. 6)

While most interviews involve some exploration of how stories have been offered pedagogically, only a few address the artistry and delivery of the stories, and those that do, do so implicitly — sharing of examples without corresponding discussion or analysis. While the purpose of grounded theory research is to see what emerges from the data, focused coding can identify themes that are not recognized until later in the analysis process because of the implicit nature of the theme (Charmaz, 2006). The absence of an explicit discussion of creativity in the transcripts is not hindered by the subtle reference to the underlying theme of creativity, and has thus generated a focused code for further consideration.

The storytelling project (Bell, 2010) frames storytelling within the arts, and describes the arts as providing "a way to engage body, heart, and mind to open up 
learning and develop a critical perspective" (p. 17). Bell goes on to explain that “intellectual insight into broad patterns without sensory engagement can ultimately be distancing and disempowering" (p. 17), leaving target groups feeling unfelt and agent groups feeling unmoved. She emphasizes that, "the aesthetic experience of stories told through visual arts, theater, spoken word, and poetry, can help us think more creatively, intimately, and deeply about racism and other challenging social justice issues" (p. 17). The aesthetic experience can engage us emotionally in the importance of the issue, even if we do not have any rational stakes in being concerned.

SooHoo (2006) specifically addresses the power of spoken story, as compared with that of written story, weaving in the theme of magic that occurs when we connect with the impact of another human being's suffering. This suggests an increased value in the performative function of story, transforming our sense of concern and possibly engaging us more deeply in the struggle. She explains, "Writing could not capture the visceral punctuation of orally narrated stories, tight bodies, words caught in one's throat, eyes anxious and apprehensive. Writing is mediation. Thoughts and feelings must travel through pen, paper, or keyboard before touching another soul” (p. 6).

Kim Stafford, a poet and writer who teaches the art of writing stories, argues for the importance of an arts approach to storytelling, and describes the value that his poetry adds to an otherwise cerebral rendition of politics as usual. 
I was invited by John Kitzhaber to compose a poem for the inauguration. So yesterday, I was down in the House of Representatives in Salem, reading this poem as part of John Kitzhaber's inauguration. The event, of course, was extremely formal. All of the past governors came in, all of the supreme court justices, and you know, the state treasurer, all these people. And then the pastor, a fellow named Pastor Hardy from a church in Northeast, and I, the poet, were kind of the affective part of the whole event. And I was just struck by the importance of words, of creative words, of expressive words, in formal structure like state government. I was really honored to be asked, but at the same time, they really needed me.

Kim Stafford goes on to talk about the vital role that an arts-based approach to storytelling provides in terms of building a real democracy. Excerpted from a manifesto he presented to Dick Cheney, he recounts:

We live in a world in which a few people could destroy us all, but a few people can't save us. The math doesn't work that way. The only way we will be saved is for many people, and finally all people, to recognize and live by a sense of interdependence on earth. And this makes education and the arts, and childhood and music, the fundamental priorities of our time.

The creative arts, which are generally not incorporated into general postsecondary education, and are specifically not a part of critical peace education, provide unexpected power to move people beyond their logical presuppositions, and toward new and inspired possibilities of change. Change requires new ideas, and new ways of thinking about old ideas. By inviting creativity in the process of social change, we invite ourselves into the experience of the senses, and the transformation that new perspective affords.

The metacognitive reflections that constitute the narrative data from this study illustrate many diverse ways that postsecondary social justice practitioners use storytelling to address issues of social change and inspire action toward social justice. The rigorous process of coding and memo writing generated common themes in the data that explain the nature of social justice education, and contextualize the role and function 
LOVING PRAXIS

of storytelling within that. The insights that surfaced are helpful in explaining the nature of loving praxis, and contribute to a clearer understanding of the specific elements that facilitate its emergence. 


\section{Chapter 5}

\section{Discussion}

The literature on loving praxis is disparate and interdisciplinary, making it difficult to provide a solid backdrop for the results of this study. The following conceptual map proposes possible relationships between the various elements leading to and resulting from loving praxis. This map is a synthesis of diverse elements from the academic literature of the broadly defined field of education, and establishes loving praxis primarily as a contribution to the field of peace education. Because my interests lie with the role and action of the educator, and because I have constructed this exploration as a response to the problems of neoliberal education, I have included seven modes of inquiry (Henderson \& Kesson, 2004) that encourage wisdom-based curriculum choices as a means to build and/or sustain democratic societies. Song and Taylor (2005) suggest that a combination of these modes contribute "to a loving praxis of transformative education" (p. 141), echoing the intent of my own investigation. Beginning with Freire's (1970) definition of praxis, and expanding its scope by looking at it through the lens of Darder's explication of Freire's work as A Pedagogy of Love (2002), I propose that loving praxis comes into being when the transcendent qualities of love are present, and is then put into action through multiple strategies.

While this paper investigates storytelling as a method of loving praxis, there are certainly multiple ways through which educators might engage loving praxis. I have included consciousness-raising and dialogue as examples within this figure, but there are undoubtedly many strategies for employing loving praxis in the context of critical peace 
education - with the goal of ultimately transforming learners by facilitating a deeper

understanding of social justice, and a corresponding impetus to act toward its realization.

\begin{tabular}{|c|c|c|c|c|c|c|}
\hline \multicolumn{7}{|c|}{ Critical Peace Education } \\
\hline \multicolumn{7}{|c|}{ Using Modes of Inquiry } \\
\hline $\begin{array}{l}\text { Techné: } \\
\text { concrete } \\
\text { skills to } \\
\text { create }\end{array}$ & $\begin{array}{l}\text { Poesis: } \\
\text { soulful } \\
\text { attunement }\end{array}$ & $\begin{array}{l}\text { Praxis: } \\
\text { reflective } \\
\text { interplay } \\
\text { between } \\
\text { knowledge } \\
\text { and action }\end{array}$ & $\begin{array}{l}\text { Dialogos: } \\
\text { construction } \\
\text { of } \\
\text { understanding } \\
\text { through } \\
\text { multiple } \\
\text { perspectives }\end{array}$ & $\begin{array}{l}\text { Phronesis: } \\
\text { deliberative } \\
\text { and moral } \\
\text { reflection/ } \\
\text { decision } \\
\text { making }\end{array}$ & \begin{tabular}{|l} 
Polis: \\
fluid \\
interplay \\
between \\
political \\
and \\
ethical \\
issues
\end{tabular} & $\begin{array}{l}\text { Theoria: } \\
\text { contemplative } \\
\text { thinking, } \\
\text { envisioning } \\
\text { possibilities } \\
\text { and inquiring } \\
\text { for the } \\
\text { democratic } \\
\text { good }\end{array}$ \\
\hline \multicolumn{7}{|c|}{ Applying Transcendent Qualities of Love } \\
\hline Affec & tion & Compassion & Empath & Conn & ction & Justice \\
\hline \multicolumn{7}{|c|}{ Engaging Loving Praxis } \\
\hline \multicolumn{3}{|c|}{ Storytelling } & \multicolumn{2}{|c|}{ Consciousness Raising } & \multicolumn{2}{|c|}{ Dialogue } \\
\hline \multicolumn{7}{|c|}{ Resulting Transformation } \\
\hline \multicolumn{7}{|c|}{ Action Toward Social Justice } \\
\hline
\end{tabular}

Figure 1. Conceptual Framework for Dissertation Research

The research conducted within this study, the data, and the emergent theory, combine to offer a new explanation of loving praxis, and provide a model that situates storytelling inextricably within it. The data paint a picture of social justice education that supports the conceptual sketch of loving praxis, and move it to a much deeper and more comprehensive understanding. The data also suggest links to existing theories that explain and validate loving praxis as an integral part of postsecondary social justice education.

This chapter presents a running commentary of the way theory emerged from the data, and explains how it was articulated into a theory of loving praxis. Framing theorybuilding within the critical and interpretive traditions, I explain the various elements of the emergent theory and share a revised concept map of loving praxis that incorporates 
the new theoretical dimensions. Driving this theory is my understanding of storytelling as a method of ideology critique, facilitating the deconstruction of prevailing beliefs with attention to the concerns of social justice. The discussion of this theory answers the research question that shapes this dissertation, which asks how postsecondary social justice educators use storytelling to address issues of social change and to inspire action toward social justice.

\section{Theory Building}

The goal of grounded theory research is to construct and produce theory. The point and purpose of theory, however, is broadly understood and often contested by theorists themselves (Charmaz, 2006). In the context of the critical theory of adult learning, Stephen Brookfield (2001) explains that the purpose of theory, "is to generate knowledge that will change, not just interpret, the world" (p. 11), and suggests that a theory's validity is measured by its ability to inspire action toward such change.

Critical theory attempts to inspire change, while other theories are more inclined toward the development of new ways to understand concepts, or new ways to conceptualize the interrelationship of ideas. Brookfield (2001) offers five distinctive characteristics of critical theory, which distinguish it from other theories in particular, and positivist theory in general. First, it seeks to reconfigure the commodity exchange economy in order to create greater humanity and freedom for people. Second, critical theory seeks to provide people with the knowledge and understanding that will help them to deconstruct oppression. Third, critical theory breaks down the academic tradition of separating subject and object, and research and the focus of research. Fourth, it is normative in that, while criticizing society, its primary emphasis is on envisioning a more 
democratic world. Fifth, the verification of critical theory is challenged by its inability to measure success until social change has become manifest. In response to the necessary ambiguity posed by the fifth and final distinction, Brookfield offers that an indicator of validity for critical theory in adult learning might be "the extent to which adults believe that the theory captures their hopes and dreams" (p. 12).

This construct of critical theory falls into the category of interpretivist theories, which are also distinct from more traditional and positivist theories in academic research. Interpretive theories call for an "imaginative understanding of the studied phenomenon," (Charmaz, 2006, p. 126) and aim to, “conceptualize the studied phenomenon to understand it in abstract terms; articulate theoretical claims pertaining to scope, depth, power, and relevance; acknowledge subjectivity in theorizing and hence the role of negotiation, dialogue, understanding; [and] offer an imaginative interpretation" (p. 127). This understanding of theory acknowledges the interpretive, imaginative and subjective nature of interpretive theory building, which allows for the simultaneous presence of multiple and even contradictory realities, and within them, the provisional construction of truths.

Interpretive theorizing is linked to social constructivism, which extends constructivism by considering the role of other actors and cultural influences in the process of development. Social constructivism can also be understood as applying the assumptions of social constructionism to social settings by recognizing that groups construct knowledge for one another by creating shared culture — replete with shared meanings. By being immersed in this shared culture, individuals continually learn about the rules of conduct, including the values that attribute worth and dictate appropriateness. 
This perspective is consistent with that of critical theory, which also recognizes "identity to be socially and culturally formed" (Brookfield, 2001, p. 12).

Alasuutari speaks to the interpretive nature of theory building from a cultural studies perspective in his statement that, "[t]heories are...deconstructions of the way in which we construct realities and social conditions and ourselves as subjects in those realities" (1996, p. 382). Inherent within this statement is the recognition that both data and analysis are "created from shared experiences and relationships with participants and other sources of data" (Charmaz, 2006, p. 130). In other words, interpretivist theory exists within the view of the researcher. A constructivist approach recognizes that a significant part of understanding a theory is in becoming aware of how it is embedded in social, situational, positional, and relational contexts.

\section{My Theory of Loving Praxis: Storytelling as Ideology Critique}

After analyzing the data generated by this study, I propose that storytelling functions as a kind of ideological critique that serves as a critical element in the process of loving praxis. Ideology critique is a term used in critical theory to describe the process of uncovering prevailing ideologies in order to deconstruct their influence on society and impact on individuals. I argue this contention by showing how storytelling is used to radically alter worldviews and transform perspectives about the practices and structures that keep people in unconscious servitude and that hold systems of oppression in place. To explain this theory, I introduce the concept of ideology and the practice of ideology critique as a prologue to an analytical discussion of how the focused codes that emerge from the data explicate the process of ideology critique in the larger construct of loving praxis. 
Explaining ideology.

Althusser (1971), who was strongly influenced by the work of Gramsci, defines ideology as systematic thought control that is used to ensure that people at all levels of economic and social systems will believe the dominant system is fair and reasonable. Ideology exists within all of the various positions on the political spectrum, and within each informal and formal institution within society. Brookfield defines ideologies as

[B]roadly accepted sets of values, beliefs, myths, explanations, and justifications that appear self-evidently true, empirically accurate, personally relevant, and morally desirable to a majority of the populace, but that actually work to maintain an unjust social and political order. Ideology does this by convincing people that existing social arrangements are naturally ordained and obviously work for the good of all. (2001, p. 14)

An example of ideology is found in the beliefs that underlie neoliberal education, which is certainly germane to this study. A influential majority of the public have adopted the idea that neoliberal education is a superior form of education, and their views are promulgated by powerful public figures like Bill and Melinda Gates, and popular media exposés such as the film, Waiting for "Superman." These persuasive messages convince the public to blame schools for the problems of society rather than recognize the shortcomings of the neoliberal system.

Recognizing ideologies, and the pervasiveness of ideological influences, can be an effective pedagogical tool for educators to "interrogate and unmask the contradictions that exist between the mainstream culture of the school and the lived experiences and knowledge that students use to mediate the reality of school life" (Darder, Baltodano, and Torres, 2003, p. 13). Writing from the perspective of critical pedagogy, Darder, Baltodano, and Torres portray ideology as 
a starting point for asking questions that will help teachers to evaluate critically their practice and to better recognize how the culture of the dominant class becomes embedded in the hidden curriculum - curriculum that is informed by ideological views that silence students and structurally reproduce the dominant cultural assumptions and practices that thwart democratic education. (p. 13)

Ideology is also recognized within the literature on peace education, where the ideological concept of peace education employs a neo-Marxist critique of schooling to recognize the inevitability of formal education's reproduction of dominant culture's ideas and values, and suggests that true peace education requires both the critique of dominant ideologies, and the creation of opposing ideologies that challenge dominant perspectives.

\section{Ideology critique.}

Given the ubiquity of ideology, it is not a question of whether or not it underlies beliefs as much as how it does so. This is the nature of ideology critique, which Brookfield (2001) describes as "an activity springing from the Enlightenment conviction that living fully as an adult means acting on the basis of instincts, impulses, and desires that are truly our own, rather than implanted in us" (p. 16). Brookfield explains that ideology critique helps people understand how we learn what to believe, and where we learn what to believe - unveiling the influence of the formal and informal networks that frame ideological constructs and categories.

Ideology critique can be considered a formalized version of critical thinking, with the specific purpose of deconstructing ideologies serving to liberate people from unconscious influences. Mezirow (1991) refers to ideology critique as systemic critical thinking, and Brookfield (2005) further articulates ideology critique as a "critical distancing from, and then oppositional rearrangement with, the dominant culture" (p. 13), and names this process as the central learning task of adulthood. This form of critical 
thinking empowers educators and learners alike to recognize ideologies, and to understand how dominant and oppositional agendas are reinforced through their corresponding ideologies.

Hegemony is a helpful construct for understanding the controlling power that results from unexamined ideologies, and understanding hegemony is a useful precursor to deconstructing the influence of those ideologies. Hegemony is inherent to the ways people are influenced to accept social injustices as natural and unavoidable, even when they work against their own interests. Inevitably, hegemonies serve those in a position of power. Gramsci (1995) says, "Every relationship of hegemony is necessarily an educational relationship" (p. 157), because it convinces people to hold oppression in place instead of fighting against it. Hegemony describes the circumstances where control is achieved willingly through consensus, without requiring the use of force.

The concept of hegemony anticipates Foucault's (1980) writings on power, in which he argues that power works with more subtlety in contemporary society than it has in the past. He explains that we have moved away from sovereign power, which is characterized by outside control from a recognizable force, and toward disciplinary power, which is exercised from within ourselves, upon ourselves. Disciplinary power results from hegemony, which impels "people to learn and love their place" (Brookfield, 2001, p. 17).

The disciplinary powers that hold hegemony in place can be subverted by ideology critique, which reveals how we assume the values and beliefs that are learned through our interactions with the institutions of civil society and our own social networks. Brookfield (2001) explains that, "doing ideology critique involves adults learning to 
become aware of how ideology lives within them as well as understanding how it buttresses the structures of the outside world that works against them" (p. 16). Ideology critique can transform our understanding of the normal order of things into an understanding of the constructed realties designed to protect the interests of the powerful.

\section{Model of loving praxis}

To implicate storytelling as ideology critique within the framework of loving praxis, I offer the following model of loving praxis. This model illustrates the phenomenon of loving praxis as a process - one that might originate at any point within the cycle. The study conducted for this paper started with the actors - postsecondary social justice educators - and engaged them with questions that interrogated their actions. The conversations that ensued provided insight into this cycle of loving praxis, and the various elements that contribute to its progress toward the goal of social justice. 


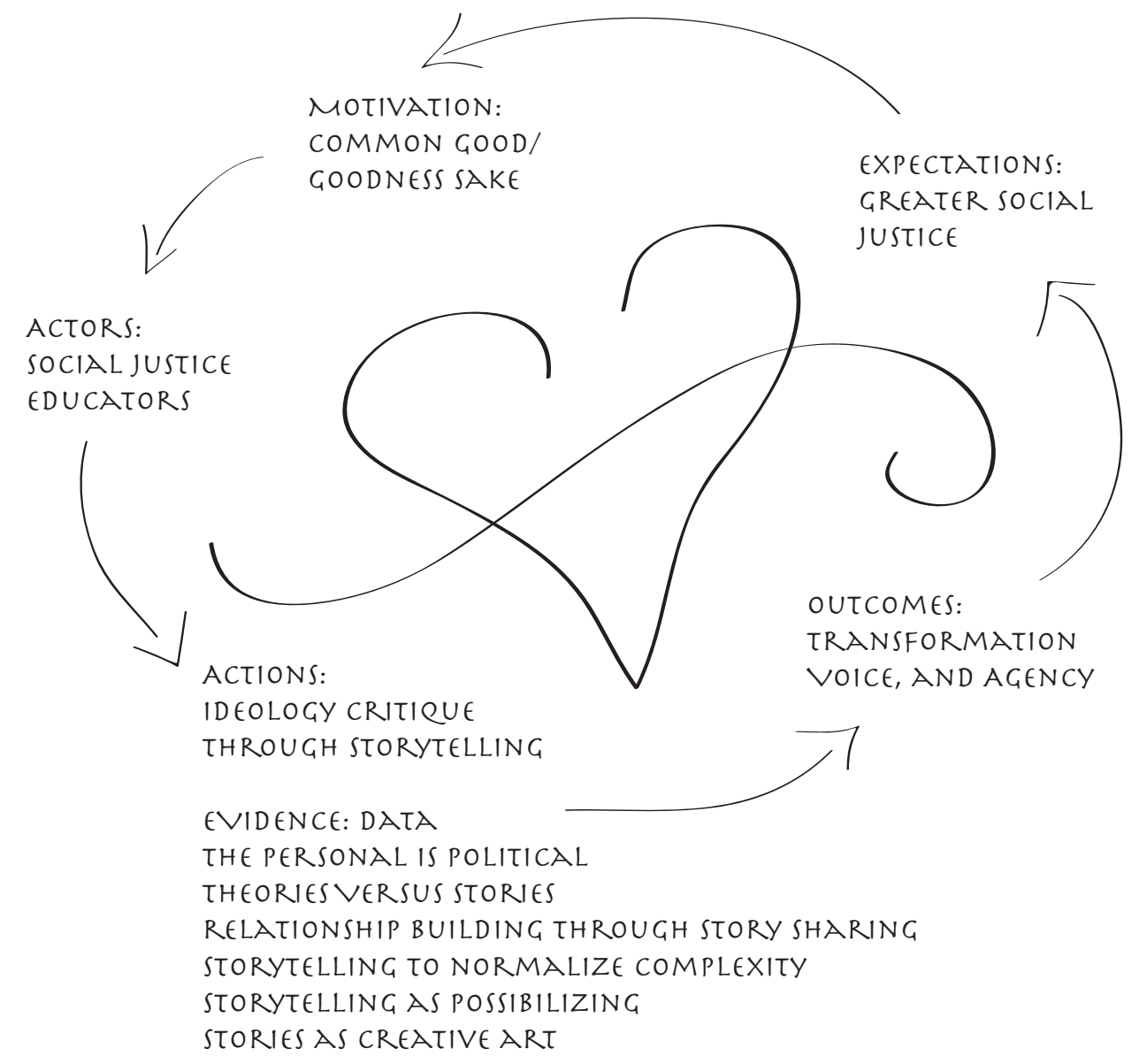

Figure 2. Schema of Loving Praxis as Theoretical Model

\section{Phenomenon: Loving praxis.}

The phenomenon of loving praxis is best described in Freirian terms, as a combination of loving in connection with our true vocation of being human, and praxis as "reflection and action upon the world in order to transform it" (Freire, 1970, p. 33). Loving praxis can also be regarded as consistent with Brookfield's (2001) explication of critical theory in adult education, which he describes as springing from a "distinct 
philosophical vision of what it means to live as a developed person, as a mature adult

struggling to realize one's humanity through the creation of a society that is just, fair, and compassionate" (p. 12). This vision of the developed and reflective self, who works toward the goal of social justice, echoes the essence of loving praxis.

Loving praxis moves beyond the sentimentality of love in favor of its radical roots in rebellion, where the nature of caring and connection with humanity gives voice to the need for change, and births action toward the possibility of a better world. In the following excerpt from Kalamu ya Salaam's (1979) poem, Revolutionary Struggle/Revolutionary Love, we are reminded that struggle can actually elicit this deeper sense of connection:

In short, if we do not share struggle, we can not share love. Love is a function of life and these anti-humans are constantly and consciously committed to oppressing, exploiting and killing us. During times of war and oppression, such as these are, there is no other love possible but serious and shared struggle. Every battle we "consciously" wage together will bring us closer and bind us more firmly, will increase our understanding of each other and the world. Revolutionary struggle brings with it revolutionary love.

Loving praxis is a manifestation of the kind of revolutionary love that emerges in response to, and often in spite of, the neoliberal constraints of capitalistic education. Loving praxis is inspired by the true vocation of being human that many postsecondary social justice educators (among others) are dedicated to realizing (Freire, 1970). To ground this transcendent phenomenon in practical terms, the following model is offered.

\section{Motivation: Common good/goodness sake.}

The motivations that inspire people to engage in the cycle of loving praxis, or to become social justice educators, or to take decisive action to create change in their learning communities, can come from any number of different prompts. As study 
respondents describe their processes of understanding how ideologies work, and what they did or do to deconstruct the hegemony that holds oppressions in place, many articulate their outrage at the injustices at work in the world, and how those experiences of injustice molded their dedication to creating change. This outrage in the face of injustice, and commitment to the creation of greater social justice, could be named a concern for the common good. Brookfield (2001) speaks of this as a, "desire to extend democratic socialist values and processes, to create a world in which a commitment to the common good is the foundation of individual well-being and adult development" (p. 21). Schubert (2009) chooses a comparable phrase in his effort to describe work toward social justice, and emphasizes how common good is realized through relationship.

In response to the what and the why of social justice, I selected an everyday phrase for goodness sake. The sake of goodness is, I contend, a highly defensible prerequisite for social justice. Another, equally or more important prerequisite is loving relationships....as a necessary and neglected dimension of social justice. (p. 3)

The sake of goodness can be considered as that which propels action toward social justice, and that which is realized in the practice of loving relationships. These are key elements in the model of loving praxis.

The sake of goodness, or the common good, can be easily forgotten in the course of a commodified reality. Marx's vision of the good society, which is one that values the common good, is instrumental in reorienting attention toward the importance of the common good. My data suggest that many postsecondary social justice educators have been motivated by circumstances, in their own lives and understandings of the world, to recognize the value of the common good, and are motivated by it to work toward the goal social justice. 
Actors: Postsecondary social justice educators.

Concern for the common good, for goodness sake, can motivate postsecondary educators to put social justice into action. Brookfield (2001) believes social justice education should be central to the task of all adult educators, and encourages educators to embrace the need for critical theory in postsecondary learning.

Given the centrality of hegemony to ideological analysis, a critical theory of adult learning should help us understand how adults learn to recognize hegemony in the beliefs and assumptions they live by, and the structures they live within. It should also examine how adults learn to contest hegemony individually and collectively by striving to replace it with a system of beliefs and practices that represents the interests of the majority. (p. 18)

Brookfield's (2001) contention that social justice should be included in all of adult education expands the understanding of social justice educators that emerged in my data, and that is addressed elsewhere in the literature. Nonetheless, locating responsibility for social justice within the broad field of adult education augments the potential audience for this study, and with it, the relevance of its scope.

\section{Action: Ideology critique through storytelling.}

According to my data, storytelling is regularly used as a method to engage students in a deeper critique of the world, and their own place within that world. The storytelling project model (Bell, 2010) provides a powerful theoretical framework by which to explain the role of story in ideology critique. It also offers support to educators and activists by providing a concrete way to understanding storytelling as a means to actualize social justice. The storytelling project model (Figure 3) emphasizes four types of stories that describe how people talk about race, and other issues of social injustice, 
and also charts the process toward change that can be achieved when these stories are critically analyzed.

The four types of stories in the storytelling project model include stock stories, concealed stories, resistance stories, and emerging/transforming stories (Bell, 2010). Stock stories dominate public discourse, and are told by the dominant institutions of society (i.e., schools, businesses, government, and media). Analyzing these stories helps students locate the underlying ideologies that shape our normative beliefs, practices, and values. Concealed stories exist alongside stock stories, and are often invisible to mainstream society. These are the stories of the dominated and marginalized groups; they tell the tales that decode the ways structural violence and oppression hold injustice in place. These stories need to be known and understood if we are to recognize the underlying ideologies of stock stories, and the hegemony created by their incessant retelling. Resistance stories exemplify the ways people have challenged injustice, including the stock stories that hold hegemonies in place. These stories inspire others to join in the hard work of social change, and contribute to the cultivation of imagination that creates hope and possibilizes the reality of social justice. Lastly, emerging/transforming stories directly "challenge stock stories, build on and amplify concealed and resistance stories, and create new stories to interrupt the status quo and energize change" (Bell, 2010, p. 25). These stories are the new stories that emerge as a result of submitting the stock and concealed stories to critical analysis and ideology critiques. The model shows that these stories have the potential for instigating action and change. It is important to note, however, that without mindful attention to continued ideology critique, one can easily get swept back into ubiquitous stock stories. 


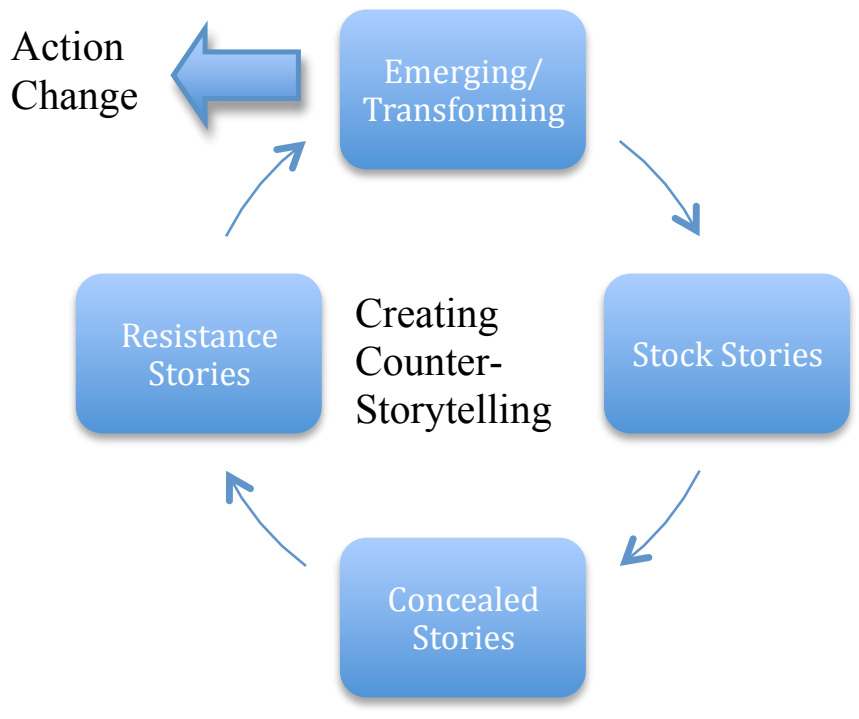

Figure 3. The Storytelling Project Model: Creating Counter-Storytelling

While counter stories have been used throughout history to engage change, the storytelling project model (Bell, 2010) explains how the process of counter storytelling unfolds, and what is possible when students are engaged in critical analysis, deconstruction, and reconstruction of stories. This process illustrates the ideology critique that is possible through story sharing, and that is described by the postsecondary social justice educators who participated in this study.

\section{Evidence: The data.}

The data generated in this study demonstrate a growing consensus about the vital role of storytelling within social justice education, and explain how postsecondary social justice educators use storytelling in their work. The data, and resulting focused codes, approximate a similar trajectory to the path illustrated by the storytelling project model, which clearly articulates the relationship between storytelling and ideology critique. 
The focused code, theories versus stories, addresses the question of whether stories are valuable in and of themselves. When stories are recognized as having value, either in concert with theories or as alternatives to theories, they can be explored as a viable and important strategy of loving praxis, and within that, as a method of ideology critique.

Relationship building through story sharing is an aspect of the storytelling project model that is not directly addressed in the visual of that model, but is a vital consideration in the explanation of the project (Bell, 2010). Bell describes the project, and the curriculum that results from it, as able only to exist within the context of relationship and community. She also elaborates on the project's reliance on the safety and strength that relationships afford participants, which make it possible for participants to risk the vulnerability that deconstructing and revealing concealed stories requires.

The storytelling project model (Bell, 2010) focuses on connecting narrative and the arts as a process. The focused code of stories as creative art introduces the value of engaging one's creativity in the process of ideology critique in order to imagine something that isn't yet known, or to realize something that hasn't been done before. Bell explains that the, "aesthetic experience of stories told through visual arts, theater, spoken work and poetry, can help us think more creatively, intimately and deeply about...social justice issues" (p. 17). These creative channels are increasingly recognized as central to the work of social justice, and are worthy of further study.

The personal is political speaks to the power of recognizing that one's own story is more real that than the stock stories, and that one's personal struggles are political. One's own struggles for justice are typically not acknowledged in the stock stories of 
dominant society, but rather in the concealed, and very personal, stories that emerge as people are allowed to speak their own truths.

Storytelling to normalize complexity illustrates the difficulties inherent in moving through the process of working toward social justice. Uncovering stock stories can be painful and challenging, revealing new dimensions of our agent and target statuses, and unearthing the concealed stories that embody our vulnerability. Complexity is also inherent in the resistance stories, in that they explicate the empowerment and change that occurs even in the most oppressive circumstances.

Storytelling as possibilizing exemplifies the power resistance stories have to pave the way for hope and change, and to inspire students with the actions and successes of those engaged in social change work, now and in the past. These stories embolden the voices and agency of those who hear them, and also help to inspire an imagining of what might be possible, beyond what is already known. Emergent/transforming stories result from this fresh perspective, as does the ability to envision new possibilities for the future. 


\begin{tabular}{|c|c|}
\hline $\begin{array}{l}\text { Storytelling Project } \\
\text { Model }\end{array}$ & $\begin{array}{c}\text { Data } \\
\text { Focused Codes }\end{array}$ \\
\hline 8 & 3 \\
\hline $\begin{array}{l}\text { Centrality of } \\
\text { Relationship }\end{array}$ & $\begin{array}{l}\text { Relationship Building } \\
\text { through Story Sharing }\end{array}$ \\
\hline 8 & 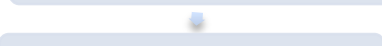 \\
\hline Arts Focus & $\begin{array}{c}\text { Stories as Creative } \\
\text { Arts }\end{array}$ \\
\hline 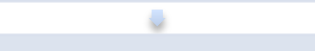 & 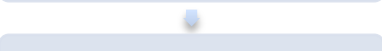 \\
\hline Stock Stories & Theories vs. Stories \\
\hline 8 & $\theta$ \\
\hline Concealed Stories & $\begin{array}{c}\text { The Personal is } \\
\text { Political }\end{array}$ \\
\hline 8 & 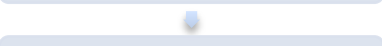 \\
\hline Resistance Stories & $\begin{array}{c}\text { Storytelling to } \\
\text { Normalize Complexity }\end{array}$ \\
\hline b & $\xi$ \\
\hline $\begin{array}{c}\text { Emergent/ } \\
\text { Transformation }\end{array}$ & $\begin{array}{l}\text { Storytelling as } \\
\text { Possibilizing }\end{array}$ \\
\hline
\end{tabular}

Figure 4. Focused Codes as Consistent with Bell's Storytelling Project Model to Establish Ideology Critique

\section{Outcomes: Transformation, voice, and agency.}

The outcome of loving praxis is that people are transformed and, as a result, have greater access to their voice and their agency as activists toward change (be it internally, externally, or both). The word transformation has been used ad nauseum, to the point that it has lost meaning, so I will define it by using Vygotsky's zone of proximal development (ZPD), and frame the process of transformation within the context of student development theory.

This study focuses on the role and function of social justice educators, and how they use storytelling as a method of loving praxis in critical peace education. Storytelling is a method of loving praxis, and it is a method of identity critique. It is also used by 
postsecondary social justice educators as a means by which to extend student learning by leading them through the process of self-discovery.

While Piaget believed that students should be taught at their appropriate developmental level (Wink \& Putney, 2002), Vygotsky argued that the learning process actually leads the process of development. Vygotsky states, "What the [student] can do in cooperation today he (sic) can do alone tomorrow. Therefore the only good kind of instruction is that which marches ahead of development and leads it” (1986, p. 188).

Vygotsky developed the ZPD as a way to articulate "the distance between the actual developmental level as determined by independent problem solving and the level of potential development as determined through problem solving under adult guidance or in collaboration with more capable peers" (Vygotsky, 1978, p. 86, emphasis in the original). I argue that the storytelling utilized by postsecondary educators serves as a more capable peer to students, providing them with a more critical and complex understanding of the world — and particularly the ideologies of the world that hold hegemony in place, and interfere with the common good.

The purpose of Vygotsky's ZPD was to emphasize the relationship between instruction and development (Chaiklin, 2003). Piaget noted that as students progressed through the developmental stages of learning, their perspectives shifted from having an egocentric focus to being more contextualized within their environment (Fosnot, 1996). Consistent with student development theory, the use of storytelling as ideology critique in postsecondary education increases the likelihood that students will recognize that their worldviews are limited, and in need of [re]vision. This recognition is what Perry (1970) identified as progress through epistemological development from the stage of dualism, 
where students don't question what they are presented with; toward multiplicity, where students begin to question the absolute nature of truth; to relativism, where students are able to evaluate truths within the context of evidence.

\section{Expectations: Social justice.}

The goal of loving praxis, and within that, critical peace education, is to create greater social justice. In this model, the expectation is that students will inevitably move toward social justice when the concealed stories of "others" are unearthed and examined. The expectations of the model could be considered as the end result of the model or, alternately, the expectation of achieving greater social justice might prompt initiation of the cycle of loving praxis.

The overarching goal of this model is social justice, for two main reasons. Social justice will, I believe, necessarily result from the other steps in the process because it is a natural outgrowth of those steps. When educators are motivated by the common good to engage students in ideology critique, designed to encourage voice and agency, social change is taking place and social justice is underway. And while movement toward social justice can be difficult to quantify, and was not measured in this study, the educators interviewed were clear that their expectations of social justice encourage hopefulness in students, which then creates a sense of possibility for valuing the common good, which then starts the cycle of loving praxis anew. 


\section{Chapter 6}

\section{Conclusions}

The purpose of this study is to gain a deeper understanding and appreciation of loving praxis as a framework that serves critical peace education in its efforts to create social change. The research conducted has explored the guiding question of how postsecondary social justice educators use storytelling, a method of loving praxis, to address the need for social change and inspire action toward social justice. The data from this study comprise a wealth of metacognitive reflection from a diverse sampling of postsecondary social justice educators who share their ideas, insights, and practices for teaching toward social change.

This research study is grounded in critical theory, which emerged from the Frankfurt School of Social Research and is recognized as the intellectual tradition that has had the greatest impact and influence on adult education research and theorizing in the past two decades (Brookfield, 2005). Horkheimer claims that the main goal of critical theory "is man's [sic] emancipation from slavery" (1975, p. 246), which hints at critical theory's Marxist and revolutionary roots, and reveals the political power inherent in its critique. Brookfield (2001) stresses the importance of recognizing these radical roots in adult learning, urging us to remember that the critical theory's intent is for its critique to serve as a catalyst for revolutionary social change. Brookfield ties these Marxist principles of revolution together with the transformative goals of adult learning when he explains critical theory as deriving, "from a distinct philosophical vision of what it means to live as a developed person, as a mature adult struggling to realize one's humanity 
through the creation of a society that is just, fair, and compassionate" (p. 12). This

philosophical vision is the basis for loving praxis.

The argument for the importance of this research is located within the crisis of neoliberalism, where the tenets of democratic education are being challenged by an educational agenda that favors standards-based learning and employment training over the critical and analytical thinking skills required for democracy to flourish. Without broad recognition that education is most valuable when it helps students engage in critical and analytical thinking, educational systems bow to public demand - and that public is currently being led to believe that capitalistic values trump democratic values or, perhaps worse, that capitalistic values are democratic values. Brookfield describes the crisis in terms of exchange values:

Although it is the use value of learning that adult learners and adult educators keep in mind, it is the exchange value that policy makers and purse holders consult when determining whether programs should be funded and how they should be evaluated. A transformative adult learning experience such as going to college and finding one's worldview radically altered becomes converted into a qualification that can be exchanged for higher salary and status. (Brookfield, 2001, p. 11)

As a result, the exchange value of learning in adulthood (job success) overshadows its use value (meaning, perspective, recognition of interdependence), and adult learners are subsequently shortchanged of the opportunity to develop their critical consciousness. In this climate it becomes all the more imperative to understand the extent to which social justice educators are swimming against the neoliberal tide in order to teach students how to find voice and agency so that they might become active contributors to democracy. This research project is intended to provide support and 
validation for the work social justice educators can do, and are already are doing, to create enlivened and radical change in their communities.

The major results of this study locate storytelling within a larger process of loving praxis, and explain how postsecondary social justice educators engage story as an action that contributes to the process of social justice. The power of storytelling is explained in terms of its correlation to the process of ideology critique, which facilitates both critical thinking and critical consciousness. The steps in the resulting model outline how, by valuing the common good, social justice educators are motivated to take action through storytelling. The outcome they are working toward is that of supporting transformation, voice, and agency within students as a means to inspire them toward the creation of greater social justice in their worlds. The sense of possibility cultivated by this process re-engages the cycle by validating the value of and hope for the common good.

\section{Validity and Limitations of Study}

Validity and reliability in constructivist grounded theory research are typically measured by replicability of the study. However, given the emergent construct of grounded theory studies, and the interpretive nature of the data analysis process, Corbin and Strauss (1990) qualify that "grounded theory is reproducible in the limited sense that it is verifiable" (p. 15). This acknowledges that, though the results might not be reproduced, they can be verified through a careful consideration of comparable data.

I believe this study could be easily verified if postsecondary social justice educators were engaged in similarly directed conversations. Postsecondary social justice practice has broad consistencies, despite the many variations in the field. Even though my 
process of analysis was highly interpretive, I believe that the data and my findings approximate common themes that would also emerge in a larger study.

As interpreted by Brookfield (2001), critical theory's perspective is that an "important measure of theory's validity... is its capacity to inspire action" (p. 11). In support of this, the critical theory of adult learning further specifies that validity is "the extent to which adults believe that the theory captures their hopes and dreams" (p. 12). The colleagues who have read the draft versions of my discussion have unanimously expressed deep appreciation for its ability to both articulate and validate the importance of loving praxis as a viable process of effective social change.

The limitations of this study pertain mostly to constraints of time and resources. It would have been interesting to work with a larger data sample, and to deliberately include respondents who represented broad geographic diversity, and greater diversity in their professional standing as tenured, tenure-track, fixed-term, adjunct, or consultant. Diversity in these areas might have given greater insight into how the environment and status of the educator encourage or discourage creative practices in social justice education, or shape different perspectives on social justice education overall.

In addition, it would have been interesting to augment the interview data with classroom observations, to quantify and qualify educator practices, as well as assess student responses to particular strategies. Survey data and/or focus groups from the students of study respondents could also provide valuable data to support study findings any emerging theory. This would have qualified the perspectives of respondents, and codified their responses within the consistent contexts of researcher observation and reported student experience. 


\section{Significance of Research}

The significance of this study is its attention to the powerful alchemy that stories bring to the transmuting process of social justice education. By recognizing how stories serve as ideology critique in the greater context of loving praxis, this study both illuminates and validates the work in which social justice educators are engaged. Levins Morales (1998) stresses the value of possibilizing, normalizing complexities, and the central role of building relationships with self and others in the following quote and, in doing so, anticipates many of the themes that emerge in my data. She describes the importance of social justice education as the

capturing of imagination, the restoration of wholeness and a sense of dignity; the nitty-gritty of how to bring complexity into places where we are offered simplistic and shallow explanations, and how to strip artificial complication from the straightforward; how to name and reclaim, over and over, the connections we are taught to ignore, the dynamics we are told do not exist. (pp. 4-5)

Embracing these elements as a vital part of social justice education further underscores Brookfield's (2001) challenge to adult educators to recognize the prevalence of ideology at play within our selves, our lives, and in the institutions of civil society; and to prepare adult learners for the vital task of defying ideologies that do not support the common good.

Motivated by a concern for the common good, social justice educators working to bring about social change can and do encourage the development of students' humanity through the creative process of telling, hearing, reading, and sharing stories. Maxine Greene (1994) speaks to her goal that learning communities will 
...pulsate with the plurality of conceptions of what it is to be human... We want them to be full of the sounds of articulate young people, with ongoing dialogues involving as many as possible....And we want them to care for one another... and to stir wide-awakeness; a renewed consciousness of possibility. (p. 25)

This quote addresses the aliveness present when the humanity of students is seen and acknowledged by educators, and when the multiplicity of human experiences is accepted and honored. Witnessing each others' humanity, especially through dialogue with people different from ourselves, fosters compassion and builds the argument of the common good. The way these dialogues generally manifest is through the telling of stories, but only if we listen. When we do, the possibilities for social justice within this environment are endless.

I strongly believe in the tremendous value of quality research that supports the goals of social justice, particularly in the current culture of neoliberalism. In particular, I believe that the current climate makes significant and essential any and all studies that emphasize the value of multiple perspectives expressed in their most fundamental form — that of story. These are the studies that encourage the development of student voice, and remind students of the possibilities inherent in their personal agency, especially when it is directed toward achieving greater social justice.

Cai and Sims Bishop (1994) share that, "Voices from the heart, once heard, can change other hearts" (p. 68). This is illustrative of the power of sharing authentic stories, and their ability to transform the hearts of all involved. As Trin Minh-ha (1989) shares, "The story depends upon every one of us to come into being. It needs us all, needs our remembering, understanding, and creating what we have heard together to keep on coming into being" (p. 119). As we come into being, our change of heart is illustrated by 
the transformation and expansion of perspective that student development theory articulates, and that so many of my study respondents echo in their own voices. The change of heart, or transformation that engenders concern for the common good - and justice for all — is the compelling nature of loving praxis.

\section{Recommendations}

The results of this study describe loving praxis as a vibrant phenomenon, and offer a dynamic model that reveals how social justice educators can engage students in a process of transformation that leads to greater social justice. Numerous ideas for future research were generated by this study, including more in-depth explorations of the topics that emerged, as well as more measurement-oriented studies of the process of loving praxis. The recommendations I offer focus on the following possibilities: exploring the relationship between creativity and social change; testing the newly-developed model of loving praxis; and applying the model of loving praxis to specific social justice issues, and to particular methods of social justice education.

As I was analyzing the data from this study, the focused code of stories as creative art generated a lot of curiosity in me about the relationship between creativity and social change - an exciting topic, but beyond the scope of the study. This topic has its own body of literature, and there are multiple academic disciplines and practical fields taking leadership in its development. I had preliminary conversations with several practitioners in this area, and everyone was enthusiastic about contributing to a future study of creativity and social change. It would be particularly interesting to pursue the nature of this relationship, and to situate it within the broader context of loving praxis. 
My model of loving praxis emerged as a result of my interpretation of the educator narratives generated by the study, but it would be interesting to test its accuracy and validity by either sharing it with a broad sample of social justice educators for comment, or conducting a similar study with a larger group of social justice educators to confirm the model's validity. While I believe this model could be replicated in a larger study, it would be interesting to test that hypothesis, and solicit additional information and feedback about the nature of loving praxis in general, and the efficacy of this particular model of loving praxis.

One of the questions that came up during the course of designing and conducting this research was how to measure movement toward social justice. Because this seemed like a particularly challenging task, I developed a research question and overall design that did not try to measure social change. I sought instead to assess the practice of social justice educators, and chose to do this through their own reflective narratives. An interesting subsequent study could measure the student transformation that results from social justice education, and to both quantify and quantify that change. It occurred to me that one way to measure that change would be to quantify progress within the model of loving praxis that emerged in the course of this study.

The idea of measuring social change, or even students' movement toward a social justice orientation, caused me to think about how to apply the model of loving praxis to specific social justice issues, and particular methods of social justice education. It would be fascinating to quantify what changes occur among U.S. students who have been socialized in a racist society, after they were exposed to stories about the Civil Rights Movement of the 1960s, and after being taught to deconstruct and critique the ideologies 
that hold the legacy of racism in place within social institutions. It would also be fascinating to see how those changes compare with the changes of German students who have inherited an unconscious underlayment of anti-Semitism (evidenced by the rise of neo-Nazism in Germany) experience after being exposed to stories about the Holocaust, and after being taught to deconstruct and critique the ideologies that preserve antiSemitism in Germany — and that encourage xenophobia throughout much of Europe.

\section{Conclusion}

In recognizing the relationship between storytelling and ideology critique in social justice education, this study illustrates how stories can reveal the existence of ideologies, explain how they impact society when they are unquestioned, and model how developing voice and agency can generate stories that inspire others to engage in democratic participation. When social justice educators introduce ideology critique, and especially if they allow it to unfold organically as students share and respond to stories, students have the opportunity to recognize the importance of deconstructing ideologies and taking action to create change.

Speaking about youth, but addressing a common need for students of all ages, Greene (2009) plaintively notes that, "If situations cannot be created that enable the young to deal with feelings of being manipulated by outside forces, there will be far too little sense of agency among them" (p. 139). The awareness that allows us to recognize ideology, and our ability to examine the hegemony that results from it, is the first step toward creating social change. Hegemony remains in place until we realize that we need to take action toward change. 
Greene (2009) notices that, "only when we envisage a better social order do we find the present one in many ways unendurable, and hence stir ourselves to repair it" (p. 141). Imagining a better world may seem like an easy task, but it is one that takes critical and analytical thinking skills, a sense of hope about what the future holds, and a capacity for creative vision. Antonia Darder (2009) describes the task of critical pedagogy as being one that "cultivates imagination and seeks to create opportunities to insert students into new and unfamiliar contexts so they can grapple with the cognitive dissonance and ambiguity, which is intrinsic to a highly diverse society" (p. 164). In gaining comfort with the unknown and unfamiliar, students have the opportunity to expand their consciousness and, through that, cultivate their imagination.

Emily Dickinson (1960) wrote, “The Possible's slow fuse is lit by the Imagination" (p. 689). In response to Dickinson's poem, Maxine Greene (1995) explains that the

fuse may be slow because of the ways in which the imaginative capacity has been ignored. In the many education reports that have appeared in recent years, imagination plays no part. In plans for cooperative work among teachers and professors, the stress is on pragmatic issues: standards, disciplines, benchmarks, approaches to assessment. (para. 1)

The need for imagination is perhaps at the heart of the neoliberal crisis in education. And the solution is perhaps rooted in the presence of loving praxis. Greene (2009) writes that "[i]magination, moreover, is enriched and stimulated through live encounters with others, through exposure to diverse vantage points and unfamiliar ways of looking at the world" (p. 142). This echoes the standpoint of loving praxis, which is rooted in the plurality of perspective and within the context of relationship. 
Paolo Freire (1994) speaks to a similar need for poetic imagination to be pragmatically applied to social concerns, and directed to adult educators so that they can show students that, "the lovelier world to which they aspired was being announced, somehow anticipated in their imagination" (p. 39). The sense of possibility that is generated from an enlivened imagination is possibly the force that John Dewey (1954) imagined would enable humanity to break through "the crust of conventionalized and routine consciousness" (p. 183), to create the change needed to work toward greater social justice.

The theory of loving praxis that is explicated in this study describes a process with the potential to transform student perspectives about the nature of injustice, engage student concern for those issues of injustice, and motivate students to use their voices to prompt action toward greater social justice. Storytelling is presented as a method of loving praxis, and as a means to effectively engage ideology critique. But one of the most powerful effects that storytelling offers is its ability to illustrate what is possible when voice and agency are engaged, and when people are willing and able to step up to the task of democracy. This sense of possibility is a refreshing dose of hope in a time when the prevailing messages of our culture speak of hopelessness, and is a welcome clue about how to cultivate the imagination needed to create a more just tomorrow.

I believe this study provides a strong foundation for diverse and fascinating subsequent studies, many of which I hope to conduct myself. It also provides a platform for a well-substantiated theoretical model with which to engage future projects. In the process of this research my own practice as a social justice educator has grown immeasurably, and it is my expectation that other social justice educators will also learn 
from my research. Finally, I hope this work will embolden postsecondary educators, and educators in general, to value the importance of the work they do, to validate the contributions they make to change the world, and to recognize that loving praxis is a legitimate and effective road toward the goal of social justice. I hope that educators will be willing to embark on a journey of loving praxis, will relish in the imagination that is generated in its wake, and will celebrate the possibilities for social change that are realized as a result. 


\section{References}

Abilock, D. (2005). Six Promising Approaches to Civic Engagement. CLSA Journal, 29(1), 8-11.

Alasuutari, P. (1996). Theorizing in qualitative research: A cultural studies perspective. Qualitative Inquiry, 2(4), 371-384.

Althusser, L. (1971). Lenin and philosophy. New York, NY: Monthly Review Press. Aronowitz, S. (1998). Introduction. In P. Friere, Pedagogy of freedom (pp. 1-19). Lanham, MD: Rowman \& Littlefield.

Bajaj, M. (Ed.) (2008). Encyclopedia of peace education. Charlotte, NC: Information Age Publishing, Inc.

Bell, L. (2010). Storytelling for social justice: Connecting narrative and the arts in antiracist teaching. New York, NY: Routledge.

Boulding, E. (2000). Cultures of peace: The hidden side of history. Syracuse, NY: Syracuse University Press.

Brookfield, S. (1986). Understanding and facilitating adult learning. San Francisco, CA: Jossey-Bass.

Brookfield, S. (2001). Repositioning Ideology Critique In A Critical Theory Of Adult Learning. Adult Education Quarterly, 52(1), 7-22.

Brookfield, S. (2005). The power of critical theory: Liberating adult learning and teaching. San Francisco, CA: Jossey-Bass.

Brown, C., \& Mazza, G. (1997). Healing into action: A leadership guide for creating diverse communities. Washington, DC: National Coalition Building Institute. Buber, M. (1970). I and thou. Thou. New York, NY: Scribner. 
Burns, R., and Aspeslagh, R. (1983). Concepts of peace education: A view of western experience. International Review of Education, 29(3), 331-330.

Cai, M., \& Sims Bishop, R. (1994). Multicultural literature for children: Towards a clarification of the concept. In A. Dyson \& C. Genishi (Eds.), The need for story: Cultural diversity in classroom and community (pp. 57-71). Urbana, IL: National Council of Teachers of English.

Certeau, M. (1984). The practice of everyday life. Berkeley, CA: University of California Press.

Chaiklin, S., (2003). The zone of proximal development in Vygotsky's theory of learning and school instruction. In: A. Kozulin, B. Gindis, V. S. Ageyev, \& S. M. Miller (Eds.), Vygotsky's educational theory in cultural context (pp. 39-64). Cambridge, UK: Cambridge University Press.

Charmaz, K. (2006). Constructing grounded theory: A practical guide through qualitative analysis. Thousand Oaks, CA: Sage Publications.

Clarke, A. (2007). Feminisms, grounded theory, and situational analysis. In S.Nagy Hesse-Biber (Ed.), Handbook of feminist research: Theory and praxis (pp. 345370). Thousand Oaks, CA: Sage Publications.

Coles, R. (1989). The call of stories: Teaching and the moral imagination. Boston, MA: Houghton Mifflin Company.

Collins, P. H. (2000). Black feminist thought: Knowledge, consciousness and the politics of empowerment. Boston, MA: Unwin Hyman.

Connelly, F., \& Clandinin, D. (1990). Stories of experience and narrative inquiry. Educational Researcher 19(5), 2-14. 
Corbin, J., \& Strauss, A. (1990). Grounded theory research: Procedures, canons, and evaluative criteria. Qualitative Sociology, 13(1), 3-21.

Corbin, J., \& Strauss, A. (2008). Basics of qualitative research: Techniques and procedures for developing grounded theory ( $3^{\text {rd }}$ ed.). Thousand Oaks, CA: Sage

Cranton, P. (1994). Understanding and promoting transformative learning. San Francisco, CA: Jossey-Bass.

Creswell, J. (2005). Education research: Planning, conducting, and evaluating quantitative and qualitative research. Upper Saddle River, NJ: Pearson Education International.

Cruikshank, J. (1998). The social life of stories: Narrative and knowledge in the Yukon Territory. Lincoln, NE: University of Nebraska Press.

Dale, M. (2004). Tales in and out of school. In D. Liston \& J. Garrison (Eds.), Teaching, learning and loving: Reclaiming passion in educational practice (pp. 65-79). New York, NY: RoutledgeFalmer.

Darder, A. (2002). Reinventing Paulo Freire: A pedagogy of love. Boulder, CO: Westview Press.

Darder, A. (2003). Teaching as an act of love. In A. Darder, M. Baltodano, \& R. Torres (Eds.), The critical pedagogy reader (pp. 497-510). New York, NY: RoutledgeFalmer.

Darder, A., Baltodano, M., \& Torres, R. (Eds.). (2003). The critical pedagogy reader. New York, NY: RoutledgeFalmer. 
Darder, A. (2009). Imagining justice in a culture of terror: Pedagogy, politics, and dissent. In S. Macrine (Ed.), Critical pedagogy in uncertain times: Hope and possibilities (pp. 151-166). New York, NY: Palgrave MacMillan.

deMarrais, K., \& LeCompte, M. (1999). The way schools work: A sociological analysis of education (3rd ed.). New York, NY: Addison Wesley Longman.

Dewey, J. (1930). Education and democracy. New York, NY: The Macmillan Company. Dewey, J. (1954). The public and its problems. Athens, OH: The Swallow Press.

Diaz Soto, L. (2005). How can we teach peace when we are so outraged? A call for critical peace education. Taboo: The Journal of Culture and Education, 9(2), 9196.

Dickinson, E. (1960). The Gleam of an heroic act. In T. Johnson (Ed.), The complete poems (pp. 688-689). Boston, MA: Little Brown.

Eisler, R. (2004). Education for a culture of peace. In R. Eisler, R. Miller (Eds.), Educating for a culture of peace (pp. 11-41). Portsmouth, NH: Heinemann.

Eisler, R., and Miller, R. (Eds.). (2004). Educating for a culture of peace. Portsmouth, NH: Heinemann.

Eisner, E. W. (1991). The enlightened eye: Qualitative inquiry and the enhancement of educational practice. New York, NY: Macmillan.

Ellsworth, E. (1989). Why doesn't this feeling empowering? Working through the repressive myths of critical pedagogy. Harvard Educational Review, 59(3), 299324.

Fetherson B., \& Kelly, R. (2007). Conflict resolution and transformative pedagogy: 
Grounded theory research project on learning in higher education. Journal of Transformative Education 5(3), 262-285.

Fishman, G., \& McLaren, M. (2005). Rethinking the Gramscian and Freirean legacies: From organic to committed intellectuals or critical pedagogy, commitment, and praxis. Cultural Studies <-> Critical Methodologies, 5(4), 425-446.

Follett, M. P. (1918/1998). The new state. University Park, PA: Penn State Press.

Fosnot, C. T. (1996). A psychological theory of learning. In C. T. Fostnot (Ed.) Constructivism: theories, perspectives, and practice (pp. 8-33). New York, NY: Teachers College Press.

Foucault, M. (1972). The archeology of knowledge. New York, NY: Pantheon Books. Foucault, M. (1980). Power/knowledge: Selected interviews and other writings. $1972-$ 1977. New York, NY: Pantheon.

Fowler, F. (2004). Policy studies for educational leaders: An introduction (2nd Ed.). Upper Saddle River, NJ: Pearson Education, Inc.

Freire, P. (1970). Pedagogy of the oppressed. New York, NY: Seabury Press.

Freire, P. (1994). Pedagogy of hope. New York, NY: Continuum.

Fromm, E. (1956). The art of loving. New York, NY: Harper.

Galtung, J. (1969). Violence, peace, and peace research. Journal of Peace Research, 6(3), $141-158$.

Gates, B. E. (2006). Where is the moral in citizenship education? Journal of Moral Education, 35(4). Retrieved from http://www.informaworld.com/smpp/content?content=10.1080/030572406010256 
Gibson, B. (2007). Accommodating critical theory. In A. Bryant and K. Charmaz (Eds.), The SAGE handbook of grounded theory (pp. 436-453). Thousand Oaks, CA: Sage Publications.

Giroux, H. (2010). Lessons from Paulo Freire. Chronicle of Higher Education, 57(9), p. B15-B16.

Giroux, H. (2009). The attack on higher education and the necessity of critical pedagogy. In S. Macrine (Ed.), Critical pedagogy in uncertain times: Hope and possibilities (pp. 11-26). New York, NY: Palgrave MacMillan.

Giroux, H., \& Freire, P. (1989). Introduction. In D. Purpel, The moral and spiritual crisis in education: A curriculum for justice and compassion in education. Granby, MA: Bergin and Garvey Publishers, Inc.

Glaser, B. G. (1978). Theoretical sensitivity. Mill Valley, CA: The Sociology Press.

Glaser, B. G. (2001). The grounded theory perspective: Conceptualization contrasted with description. Mill Valley, CA: The Sociology Press.

Glaser, B. G., \& Strauss, A. L. (1967). The discovery of grounded theory: Strategies for qualitative research. Hawthorne, NY: Aldine.

Gramsci, A. (1995). Further selections from the prison notebooks: Antonio Gramsci (D. Boothman, Ed., Trans.). Minneapolis, MN: University of Minnesota Press.

Greene, M. (1994). Multiculturalism, community and the arts. In A. Dyson \& C. Genishi (Eds.), The need for story: Cultural diversity in classroom and community (pp. 11-27). Urbana, IL: National Council of Teachers of English.

Greene, M. (1995). Metaphors and responsibility. On Common Ground: Partnership and the Arts, 5. Retrieved from http://www.yale.edu/ynhti/pubs/A18/greene.html 
Greene, M. (2003). In search of a critical pedagogy. In A. Darder, M. Baltodano, \& R. Torres (Eds.), The critical pedagogy reader (pp. 97-112). New York, NY: RoueledgeFalmer.

Greene, M. (2009). Teaching as possibility. In S. Macrine (Ed.), Critical pedagogy in uncertain times: Hope and possibilities (pp. 137-149). New York, NY: Palgrave MacMillan.

Haavelsrud, M. (1981). On the substance of disarmament education. In M. Haavelsrud (Ed.) Approaching disarmament education. Guildford, UK: Westbury House. Hardiman, R., \& Jackson, B (1992). Racial identity development: Understanding racial dynamics in college classrooms and on campus. In M. Adams (Ed.), Promoting diversity in college classrooms: Innovative response for the curriculum, faculty, and institutions (pp. 20-37). San Francisco, CA: Jossey-Bass.

Harris, I., \& Morrison M. (2003). Peace education. Jefferson, NC: McFarland \& Company, Inc.

Henderson, J. G., \& Kesson, K. R. (2004). Curriculum wisdom: Educational decisions in democratic societies. Upper Saddle River, NJ: Pearson Education hooks, b. (1989). Talking back: Thinking feminist, thinking black. London, UK: Sheba. hooks, b. (1994). Teaching to transgress: Education as the practice of freedom. New York, NY: Routledge.

hooks, b. (2000). All about love: New visions. New York, NY: William and Morrow Company, Inc.

hooks, b. (2006). Toward a worldwide culture of love. Shambala Sun, July, 58-63, 90. 
Horkheimer, M. (1975). Critical theory: Selected essays. New York, NY: Continuum. (Original work published 1937).

Hursh, D. (2004). Undermining democratic education in the USA: The consequences of global capitalism and neoliberal policies for education policies at the local, state and federal levels. Policy Futures in Education 2(3/4), 607-620.

Iceland, J. (2006). Poverty in America: A handbook. Berkeley, CA: University of California Press.

Kitchener, K. S., \& King, P. M. (1990). The reflective judgment model: Ten years of research. In M. L. Commons, C. Armon, L. Kohlberg, F. A. Richards, T. A. Grotzer, \& J. D. Sinnott (Eds.), Adult development, Vol. 2: Models and methods in the study of adolescent and adult thought (pp. 63-78). New York, NY: Praeger.

Knowles, M. (1970). The modern practice of adult education: Andragogy versus pedagogy. New York, NY: Association Press.

Kozol, J. (1992). Savage Inequalities: Children in America's schools. New York: HarperPerennial.

Kumashiro, K (2009). Against common sense: Teaching and learning toward social justice (2nd ed.). New York, NY: Routledge.

Lederach, J. P. (1997). Building peace. Washington, DC: United States Institute of Peace. Levins Morales, A. (1998). Medicine stories: History, culture and the politics of integrity. Cambridge, MA: South End Press.

Liston, D., \& Garrison, J. (Eds). (2004). Teaching, learning and loving: Reclaiming passion in educational practice. New York, NY: RoutledgeFalmer. 
Lulofs, R., \& Canh, D. (2000). Conflict: From theory to action (2nd Ed.). Needham Heights, MA: Allyn and Bacon.

Lynd, S., \& Lynd, A. (1966). Nonviolence in America: A documentary history. Indianapolis, IN: Bobbs-Merrill.

Mahrouse, G. (2006). (Re)producing a peaceful Canadian citizenry: A lesson on the free trade of the Americas Quebec city summit protests. Canadian Journal of Education 29(2), 436-453.

Maslow, A. H. (1943). A theory of human motivation. Psychological Review, 50(4), 370396.

McDonald, D. (2009). March of the not-so-perfect penguins: Storytelling as pedagogy. Kappa Delta Pi Record, 45(4), 180-183.

McIntosh, P. (1990). White privilege: Unpacking the invisible knapsack. Independent School Magazine, 49(2).

Mezirow, J. (1991). Transformative dimensions of adult learning. San Francisco, CA: Jossey-Bass.

Minh-ha, T. (1989). Woman, native, other: Writing postcoloniality and feminism. Bloomington, IN: Indiana University Press.

Morrison, M. (2008). Elise Boulding and peace education. Encyclopedia of Peace Education. Retrieved from http://www.tc.edu/centers/epe/entries.html

Murdoch, I. (1971). The sovereignty of good. New York, NY: Schocken.

Nastase, A. (1983). The culture of peace and peace education. International Review of Education, 29(3), 391-401. 
LOVING PRAXIS

National Commission on Excellence in Education. (1983). A nation at risk: The

imperative for educational reform: A report to the Nation and the Secretary of

Education, United States Department of Education. Washington, DC: U.S.

Government Printing Office.

Newman, A. (2009, December 28). Advertising — for marketers, love is in the air. New York Times, p. B3.

Noddings, N. (1984). Caring: A feminine approach to ethics and moral education. Berkley, CA: University of California Press.

Nussbaum, M. (1990). Love's knowledge: Essays on philosophy and literature. New York, NY: Oxford University Press.

O’Neil, R.M. (2005). Academic Freedom: Past, Present, and Future beyond September 11. In P. Altback, R. Berdahl, \& P. Gumport (Eds.), American Higher Education in the Twenty-First Century: Social, Political, and Economic Challenges (2nd ed.) (pp. 91-114). Baltimore: The Johns Hopkins Press.

Palmer, P.J. (1998). The courage to teach: Exploring the inner landscape of a teacher's life. San Francisco, CA: Jossey-Bass.

Perry, W. G. (1970). Forms of intellectual and ethical development in the college years. New York, NY: Holt, Rinehart and Winston.

Piantanida, M., \& Garman, N. B. (2009). The qualitative dissertation (2nd ed.). Thousand Oaks, CA: Corwin.

Plummer, K. (1995). Telling sexual stories: Power, change, and social worlds. London: Routledge. 
Reardon, B. (1999). Educating the educators: The preparation of teachers for a culture of peace. Peace Education Miniprints No. 99. Retrieved from ERIC database, ISSN $1101-6418$.

Roosevelt, G. (2006). The Triumph of the market and the decline of liberal education: Implications for civic life. Teachers College Record, 108(7), pp. 1404-1423.

Rosenberg, M. (1999). Nonviolent communication: A language of compassion. Del Mar, CA: PuddleDancer Press.

Rossiter, M. (2006). Radical mutuality and self-other relationship in adult education. In S. Merriam, B. Courtenay, and R. Cervero (Eds.), Global issues in adult education: Perspectives from Latin America, Southern Africa, and the United States (pp. 387-398). San Fransisco, CA: Jossey-Bass.

Rukeyser, M. (1973). Kathe Kollwitze. In J. Goulianos (Ed.), By a woman writ (p. 374). New York, NY: Bobbs Merrill.

Saltman, K. (2009). Schooling in disaster capitalism: How the political right is using disaster to privatize public schooling. In S. Macrine (Ed.), Critical pedagogy in uncertain times: hope and possibilities (pp. 27-54). New York, NY: Palgrave Macmillan.

Schubert, W. H. (2009). Love, justice, and education: John Dewey and the Utopians. Charlotte, NC: Information Age Publishing, Inc.

Senehi, J. (2009). Building peace: Storytelling to transform conflicts constructively. In D. Sandole, S. Byrne, I. Sandole-Staroste, \& J. Senehi (Eds.), Handbook of conflict analysis and resolution (pp. 201-214). New York, NY: Routledge. 
Senehi, J., Flaherty, M., Kirupakaran, C., Kornelsen, L., Matenge, M., \& Skarlata, O. (2009). Dreams of our grandmothers: Discovering the call for social justice through storytelling. Storytelling, Self, Society, 5(2), 90-106. doi: $10.1080 / 15505340902837366$

Siegel, D. (2009). The healing power of emotion: Affective neuroscience, development and clinical practice. New York, NY: WW Norton \& Company.

Sleeter, C. (2006). Foreward. In S. SooHoo, Talking leaves: Narratives of otherness ( $p$. $i x-x)$. Cresskill, NJ: Hampton Press, Inc.

Song, J., \& Taylor, P. (2005). Pure blue sky: A soulful autoethnography of chemistry teaching in China. Reflective Practice: International and Multidisciplinary Perspective, 6(1), 141-163. doi: 10.1080/1462394042000326842

SooHoo, S. (2006). Talking leaves: Narratives of otherness. Cresskill, NJ: Hampton Press, Inc.

Suarez, D. (2006). Educational professionals and the construction of human rights education. Comparative Education Review, 51(1), 48-70.

Suddaby, R. (2006). From the editors: What grounded theory is not. Academy of Management Journal 49(4), 633-642.

United Nations (2006). Plan of action: World programme for human rights education, first phase. United Nations Educational, Scientific and Cultural Organization. http://unesdoc.unesco.org/images/0014/001478/147853e.pdf

Weiler, K. (1991). Freire and a feminist pedagogy of difference. Harvard Educational Review 61(4). Cambridge, MA: Harvard Education Publishing Group. 
Vygotsky, L. S. (1978). Interaction between learning and development (M. Lopez-

Morillas, Trans.). In M. Cole, V. John-Steiner, S. Scribner, \& E. Souberman (Eds.), Mind in society: The development of higher psychological processes (pp. 79-91). Cambridge, MA: Harvard University Press.

Vygotsky, L. S. (1986). Thought and language. Cambridge, MA: MIT Press.

Webster, L., \& Mertova, P. (2007). Using narrative inquiry as a research method: An introduction to using critical event narrative analysis in research on learning and teaching. London, UK: Routledge.

Williams, B. (1993). Shame and necessity. Berkeley, CA: University of California Press.

Wink, J. \& Putney, L. (2002). A vision of Vygotsky. Boston, MA: Allyn and Bacon.

ya Salaam, K. (1979). Revolutionary struggle: Revolutionary love. The Black Scholar 10(8,9). Currently found in Chicken Bones: A Journal for Literary \& Artistic African-American Themes. Retrieved from http://www.nathanielturner.com/revstrugglerevluv.htm 


\section{Appendix A}

\section{HSRRC Approvals}

\section{胥 Portland State}

Human Subjects Research Review Committee

$\begin{array}{ll}\text { Post Office Box } 751 & 503-725-4288 \text { tel } \\ \text { Portland, Oregon 97207-0751 } & 503-725-3416 \text { fax } \\ & \text { hsrrc@lists.pdx.edu }\end{array}$

November 17, 2010

To: Amanda Byron

From: Mary Oschwald, HSRRC Chair

Re: Approval of your application titled, "Loving Praxis in Critical Peace Education: A Grounded Theory Study of Storytelling" (HSRRC Proposal \# 101532).

Dear Amanda,

In accordance with your request, the Human Subjects Research Review Committee has reviewed your proposal referenced above for compliance with DHHS policies and regulations covering the protection of human subjects. The committee is satisfied that your provisions for protecting the rights and welfare of all subjects participating in the research are adequate, and your project is approved. Please note the following requirements:

Changes to Protocol: Any changes in the proposed study, whether to procedures, survey instruments, consent forms or cover letters, must be outlined and submitted to the Chair of the HSRRC immediately. The proposed changes cannot be implemented before they have been reviewed and approved by the Committee.

Continuing Review: This approval will expire on November 17, 2011. It is the investigator's responsibility to ensure that a Continuing Review Report (available in ORSP) of the status of the project is submitted to the HSRRC two months before the expiration date, and that approval of the study is kept current.

Adverse Reactions: If any adverse reactions occur as a result of this study, you are required to notify the Chair of the HSRRC immediately. If the problem is serious, approval may be withdrawn pending an investigation by the Committee.

Completion of Study: Please notify the Chair of the Human Subjects Research Review Committee (campus mail code ORSP) as soon as your research has been completed. Study records, including protocols and signed consent forms for each participant, must be kept by the investigator in a secure location for three years following completion of the study.

If you have questions or concerns, please contact the HSRRC in the Office of Research and Sponsored Projects (ORSP), (503) 725-4288, 6th Floor, Unitus Building, 4th \& Lincoln.

Cc: Ramin Farahmandpur 
Human Subjects Research Review Committee

$\begin{array}{ll}\text { Post Office Box } 751 & 503-725-4288 \text { tel } \\ \text { Portland, Oregon 97207-0751 } & 503-725-3416 \mathrm{fax}\end{array}$

Portland, Oregon 97207-0751 $\begin{aligned} & \text { 503-725-3416 fax } \\ & \text { hsrrc@lists.pdx.edu }\end{aligned}$

May 13, 2010

To: Amanda Byron

From: Nancy Koroloff, HSRRC Chair

Re: Approval of your application titled, "Storytelling and Social Change " (HSRRC Proposal \# 101294).

Dear Amanda,

In accordance with your request, the Human Subjects Research Review Committee has reviewed your proposal referenced above for compliance with DHHS policies and regulations covering the protection of human subjects. The committee is satisfied that your provisions for protecting the rights and welfare of all subjects participating in the research are adequate, and your project is approved. Please note the following requirements:

Changes to Protocol: Any changes in the proposed study, whether to procedures, survey instruments, consent forms or cover letters, must be outlined and submitted to the Chair of the HSRRC immediately. The proposed changes cannot be implemented before they have been reviewed and approved by the Committee.

Continuing Review: This approval will expire on Mav 13.2011. It is the investigator's responsibility to ensure that a Continuing Review Report (available in ORSP) of the status of the project is submitted to the HSRRC two months before the expiration date, and that approval of the study is kept current.

Adverse Reactions: If any adverse reactions occur as a result of this study, you are required to notify the Chair of the HSRRC immediately. If the problem is serious, approval may be withdrawn pending an investigation by the Committee.

Completion of Study: Please notify the Chair of the Human Subjects Research Review Committee (campus mail code ORSP) as soon as your research has been completed. Study records, including protocols and signed consent forms for each participant, must be kept by the investigator in a secure location for three years following completion of the study.

If you have questions or concerns, please contact the HSRRC in the Office of Research and Sponsored Projects (ORSP), (503) 725-4288, 6th Floor, Unitus Building, 4th \& Lincoln.

Cc: Robert Gould 


\section{Human Subjects Research Review}

Post Office Box 751

Portland, Oregon 97207-0751
$503-725-4288$ tel

503-725-3416 fax

hsrre@lists.pdx.edu

March 11, 2011

To: Amada Byron

From: Mary Oschwald, HSRRC Chair

Re: HSRRC renewal of approval for your project titled, "Storytelling and Social Change" (HSRRC Proposal \# 101294)

As part of the Committee's continuing review, the Human Subjects Research Review Committee has reviewed your above referenced project for compliance with Department of Health and Human Services policies and regulations on the protection of human subjects.

The Committee is satisfied that your provisions for protecting the rights and welfare of all subjects participating in the research are adequate. Your project is renewed and this approval will expire on 5/13/2012. Please note the following policies:

1. If the project continues beyond the expiration date, the investigator needs to submit a Continuing Review Report form two months before the expiration date. The form is available at www.rsp.pdx.edu/compliance human.php and in the Office of Research \& Sponsored Projects.

2. To add this project's continuing review to the HSRRC/IRB meeting agenda, please refer to the HSRRC/IRB meeting schedule. Submit the report, and the required number of copies, by the submission deadline that is approximately two months before the project's expiration date. The HSRRC/IRB needs two months to do a continuing review of the project, so it is extremely important that you meet the committee's submission deadline.

3. If this project finishes before the expiration date, please contact the HSRRC administrator so that the file can be closed and records updated. It is the investigator's responsibility to keep the approval status current. If the project's approval expires while the project is active, the investigator must complete a new application and submit it for a new HSRRC review. In addition, any data collected after the expiration date cannot be used in the research. Please don't let this happen!

If you have questions or concerns, please contact the HSRRC in the Office of Research and Sponsored Projects (ORSP), 503-725-4288, Unitus Building, 6th Floor, 4th and Lincoln Streets. 


\section{Appendix B}

\section{HSRRC Application Proposal}

\section{Investigator's Assurance}

See attached.

\section{Project Title \& Prospectus}

Storytelling as Loving Praxis in Critical Peace Education: A Grounded Theory Study of Postsecondary Social Justice Educators, is a dissertation that will be submitted for partial fulfillment for the degree of Doctor in Education.

As national interest and commitment toward social justice issues in education have steadily decreased over the past decades, it is increasingly vital to understand how the educational process in general, and educators in particular, can mobilize students to become active contributors to a functional democracy. This research project instigates an inquiry into how educators in postsecondary education engage student concern and action toward social change, and specifically toward greater social justice.

This research project will engage a grounded theory methodology, and will collect narrative data from approximately 8-12 postsecondary social justice educators. The exact number of respondents cannot be predicted with certainty, since grounded theory research continues data collection and analysis cycles until coherent theory emerges, which is known as reaching theoretical saturation. Four respondents were interviewed in a prior study (HSRRC101294), all of who were known professionally by the researcher, and a snowball sample of additional candidates was collected for this resulting study. Some respondents might be invited to participate in a second interview, if the researcher believes additional data can support the goal of theoretical saturation.

Interviews will be conducted in-person or via Skype, and some combination of three prompts will be offered to initiate the interview process, all of which are included in the appendices of this application. The first prompt is a semi-structured interview protocol, the second prompt is a list of scenarios that will be read aloud to respondents, and the third prompt are Story Cubes (which present a series of symbols that the respondent can use to frame a story/response). These prompts are the starting place for data collection, but the iterative nature of grounded theory research necessitates evolving questions, new angles for data generation, and innovative data collection methods to support emerging theory.

\section{Exemption Claim for Waiver of Review}

\section{$\mathrm{N} / \mathrm{A}$}

\section{Subject Recruitment}

Respondents will be selected from my professional contacts, and from the snowball sample that emerged in the course of my prior (pilot) study. Additional recommendations 
of possible respondents will be welcome from existing contacts. I am seeking to interview 8-12 respondents over the course of the project, collecting and analyzing data from a group of 3-4 respondents before interviewing the next 3-4, and so on. Some respondents might be invited to participate in a second interview, if the researcher suspects that they can contribute further to the emerging theory.

The parameters for potential respondents are that they are educators who work with adults in postsecondary education, who identify themselves as social justice educators, and who are interested in exploring the nature of loving praxis.

\section{Informed Consent}

See attached.

\section{First-Person Scenario}

For subjects choosing an in-person interview:

I received an email from Amanda Smith Byron at Portland State University, inviting me to participate in an in-person or Skype interview about my use of loving praxis in my role as an educator. I agreed to participate in an in-person interview and responded to her email. Amanda wrote back within two days, and suggested several days when we could meet. I suggested that we meet at my office (or at a coffee shop of my choosing) on a day in the following week. On the appointed day, I met Amanda and she asked whether I wanted to use my own name or a pseudonym of my choosing. I told her my choice, and she said that she would offer me the opportunity to review any comments/data attributed to me in her resulting manuscript(s). We sat for approximately an hour, and I answered a series of questions about my use of storytelling as a social justice educator. It was an interesting conversation, and I left with a fresh perspective on my identity as an educator, and a new appreciation for the role and importance of storytelling as a function of loving praxis in critical peace education. I received an email from Amanda the next day, thanking me for participating in her research project.

For subjects choosing a Skype interview:

I received an email from Amanda Smith Byron at Portland State University, inviting me to participate in an in-person or Skype interview about my use of storytelling in my role as an educator. I agreed to participate in a Skype interview and responded to her email. Amanda wrote back within two days, and suggested several days and times when we could meet. We agreed upon on a day and time in the following week. On the appointed day, I spoke with Amanda via Skype and she asked whether I wanted to use my own name or a pseudonym of my choosing. I told her my choice, and she said that she would offer me the opportunity to review any comments/data attributed to me in her resulting manuscript(s). We spoke for approximately an hour, and I answered a series of questions about my use of loving praxis as a social justice educator. It was an interesting conversation, and I left with a fresh perspective on my identity as an educator, and a new appreciation for the role and importance of storytelling as a function of loving praxis in critical peace education. I received an email from Amanda the next day, thanking me for 
participating in her research project.

\title{
VII. Potential Risks and Safeguards
}

While I don't anticipate any major or minor physical, social, psychological, employment, legal, economic, coercive, or other risks to subjects, the nature of human communication can stimulate discomfort. I will make it clear that subjects are in control of the interview process and can terminate the interview at any point, should they feel any discomfort with the conversation. Furthermore, while the data collected is not sensitive data, participants will have the opportunity to review any comments/data attributed to them before the manuscript(s) are finalized.

\section{Potential Benefits}

The potential benefits of participation for the participants include the fruits that come from thinking critically about their teaching practice, and from having the importance of their role as social justice educators recognized and affirmed. The interview will invite educators into a reflective and evaluative process surrounding their own teaching practice, which may elicit greater insight about their roles as educators, and may generate new ideas for achieving their educational goals. In addition, the interview process itself may validate the subjects' sense of value, and may recognize the importance of their contributions to greater social justice.

\section{Confidentiality, Records \& Distribution}

Study participants will be given the choice to participate anonymously (through the use of pseudonym of their choosing), or to participate as themselves (using their own names). Since these are professional educators speaking about their own work within the field of education, they may choose to have their real names used in my findings to lend credibility to my research, and to develop their own professional identity and further their scholarly contribution. Participants will also be given the opportunity to review any comments/data attributed to them in any final manuscripts that result from this study.

Interviews will be recorded in digital audio files, which will be destroyed once transcripts are completed. All interview transcripts, notes, and artifacts from this project, will be kept in my password-protected laptop, or in my locked office at Portland State University, for a minimum of three years after the completion of the research.

\section{Appendices}

\author{
1.Email Script \\ 2.Informed Consent \\ 3. Interview Protocol \\ 4. Scenario \\ 5. Story Cubes
}


Storytelling and Social Change

Email Script

Dear [prospective subject's name]:

My name is Amanda Smith Byron, and I am both a faculty member in the Graduate Program in Conflict Resolution at Portland State University, and a doctoral student in the Graduate School of Education. I am beginning a study entitled, Storytelling as Loving Praxis in Critical Peace Education: A Grounded Theory Study of Postsecondary Social Justice Educators, and would like to invite you to participate.

You are being asked to take part because of your work as a social justice educator. As part of the study, I am interested in your opinions and attitudes about how storytelling can be used to encourage students to take action toward greater social justice. I am hopeful that the information I collect will help us better understand storytelling as a strategy for mobilizing activism, and as an essential method of loving praxis in transformative education. If you decide to participate, you will be asked to participate in either an in-person or Skype interview process, which involves answering questions about your understanding and experience of the relationship between storytelling and social justice, and your own experiences as a social justice educator. It should take approximately an hour to complete. There is a possibility you will be invited to participate in a second interview, of similar length, to contribute additional perspectives to the data.

As a result of this study, you may experience some inconvenience, and the conversation has the potential to generate some aggravation about the lack of social justice in the world today. However, I assure you that you are welcome to stop the process at any time if you find yourself in any discomfort whatsoever. While you personally may not receive any direct benefit from taking part in this study, the study may help to increase knowledge that may help others in the future.

Any information obtained in connection with this study that can be linked to you or identify you through scholarly publication, can either be kept confidential through the use of pseudonym of your choosing, or can bear your own name for your professional advancement. You will have an opportunity to make that choice before commencing the interview process. You will be given the opportunity to review any comments/data attributed to you before any resulting manuscript(s) are finalized. All information gathered will be stored in a locked faculty office at Portland State University.

Participation is entirely voluntary. Your decision to participate or not will not affect your relationship with the researcher or with Portland State University in any way. If you decide to take part in the study, you may choose to withdraw at any time without penalty. Please keep a copy of this letter for your records.

If you have concerns or problems about your participation in this study or your rights as a research subject, please contact the Human Subjects Research Review Committee, Office of Research and Sponsored Projects, 600 Unitus Bldg., Portland State University, (503) 725-4288 / 1-877-480-4400. If you have questions about the study itself, contact Amanda Smith Byron at (503) 725-9170 or abyron@pdx.edu.

Sincerely, Amanda Smith Byron Core Faculty, Graduate Program in Conflict Resolution 
Doctoral Student, Graduate School of Education

Portland State University

Loving Praxis in Critical Peace Education: A Grounded Theory Study of Storytelling and Action Toward Social Justice in Postsecondary Education

Informed Consent

You are invited to participate in a research study conducted by Amanda Smith Byron from Portland State University, Graduate School of Education. In Storytelling as Loving Praxis in Critical Peace Education: A Grounded Theory Study of Postsecondary Social Justice Educators, the researcher hopes to learn about the relationship between storytelling, as a strategy of loving praxis, and the mobilization of student action toward greater social justice. You were selected as a possible participant because of your work as a social justice educator.

If you decide to participate, you will be asked to participate in either an in-person or Skype interview process, which involves answering questions about your understanding of the relationship between loving praxis and social justice, and your own experiences as a social justice educator. It should take approximately an hour to complete. There is a possibility you will be invited to participate in a second interview, of similar length, to contribute additional perspectives to the data.

While participating in this study, it is possible that you may experience some inconvenience, and possibly some aggravation about the lack of social justice that exists in the world. I assure you that if you experience any discomfort at all, you are welcome to stop the study at any time, without any negative consequences. And while you may not receive any direct benefit from taking part in this study, the study may help to increase knowledge that may help others in the future.

Any information that is obtained in connection with this study and that can be linked to you or identify you through scholarly publication can be kept confidential through the use of a pseudonym of your choosing, or can bear your own name for your professional advancement. You will have the opportunity to make that choice before the interview commences. You will be given the opportunity to review any comments/data attributed to you before any resulting manuscript(s) are finalized. The information gathered will be kept in a locked faculty office at Portland State University.

Your participation is voluntary. You do not have to take part in this study, and it will not affect your relationship with Portland State University. You may also withdraw from this study at any time without affecting your relationship with Portland State University.

If you have concerns or problems about your participation in this study or your rights as a research subject, please contact the Human Subjects Research Review Committee, Office of Research and Sponsored Projects, 600 Unitus Bldg., Portland State University, (503) 725-4288 / 1-877-480-4400. If you have questions about the study itself, contact Amanda Smith Byron at (503) 725-9170 or abyron@pdx.edu.

Your signature indicates that you have read and understand the above information and agree to take part in this study. Please understand that you may withdraw your consent at any time without penalty, and that, by signing, you are not waiving any legal claims, rights or remedies. The researcher will provide you with a copy of this form for your own records. 
LOVING PRAXIS

Signature

Date 
LOVING PRAXIS

Storytelling as Loving Praxis in Critical Peace Education: A Grounded Theory Study of Postsecondary Social Justice Educators

Interview Protocol

1. What is your name, or if you wish to keep your personal identity confidential, please choose a pseudonym for yourself.

2. What is your social identity? How do you define your standpoint? From what perspective do you speak?

3. Do you consider yourself to be a social justice educator? If so, why and/or how?

4. Is this something you explicitly call yourself, or is it something implicit about what you do? Why do you think?

5. What do you understand the task(s) of a social justice educator to be?

6. What strategies do you use to engage students' concern about social justice, and particularly social injustice?

7. How do you encourage students to become involved in working toward greater social justice?

8. How do you use storytelling in your classroom or educational setting?

9. What do you think storytelling contributes to the process of social change?

10. How do you encourage student storytelling?

11. How would you describe the relationship between storytelling social change?

12. Is there anything else you'd like to share about this topic?

13. Is there anyone you can recommend to be interviewed? 
Storytelling as Loving Praxis in Critical Peace Education: A Grounded Theory Study of Postsecondary Social Justice Educators

$\underline{\text { Scenarios }}$

If your learning goal for the class was to introduce nonviolent social change, and you wanted students to understand how it works, what are some strategies you might use to do so?

In the course of teaching a class, a student joins the class discussion by saying that no one can be trusted, and the only way to bring about change is to be large and in charge - to have more money and guns than the other guys. What would you do?

If you noticed that the values and ideas of dominant culture were being reproduced in your classroom discussion, and you wanted to encourage alternative voices/perspectives, what would you do?

If you had a student approach you after class, and tell you that you were favoring minority voices over majority voices, and that - as a representative of the majority $-\mathrm{s} / \mathrm{he}$ felt judged and silenced in your classroom, and in the liberal college environment overall, how would you respond? 
Storytelling as Loving Praxis in Critical Peace Education: A Grounded Theory Study of Postsecondary Social Justice Educators

Story Cubes

Rory's Story Cubes ${ }^{\circledR}$ game contains nine $19 \mathrm{~mm}$ cubes with iconic images created to spark the imagination.

\section{9 cubes}

\section{4 images}

10 million combinations

The visual and kinesthetic nature of Rory's Story Cubes ${ }^{\circledR}$, along with the simplicity of design and game-play, make it accessible to engage with for all ages and abilities.

Rory's Story Cubes are a simple and effective means for inspiring creative thinking and problem solving. Participants toss the dice, examine each of the nine face-up images and let them guide the conversation or story. The nine dice, each with an image on six sides, hold a total of 54 images. This means that with every roll, there are over 10 million combinations for you to use as the inspiration for your story.

For distance participants, an i-phone/i-pad application is available to play with. 


\section{Appendix C}

\section{Description of Study Participants}

Sally Eck is a Senior Instructor in Women, Gender and Sexuality Studies at Portland State University. In addition to teaching full time, she organizes the Feminist Pedagogy, Diversity and Social Justice Education Symposium, is an active Committee member on the Women's Resource Center Advisory Board, serves on the Women, Gender and Sexuality Studies Governing Board, is a campus and community workshop facilitator, and is the advisor to the Women, Gender and Sexuality Studies Student Steering Committee. Sally's scholarly agenda includes feminist pedagogy and a practical application of feminist consciousness and activism in our everyday lives. More specifically, she is passionate about teaching interrupting oppression as a means for deepening our commitment to community and relationship.

Martina Emme is a founding member of One by One, an organization committed to transforming the legacies of conflict, war, and genocide through facilitated dialogue, public presentations, art exhibits, and educational forums. Since 1996, Dr. Emme has facilitated dialogue groups with descendants of the Third Reich and descendants of the Holocaust. She is a lecturer at the University of Applied Science in Berlin, and has also taught at the University of Potsdam, Academy for Health and Social Affairs, and the Technical University, both in Berlin.

Roslyn Farrington has been a faculty member in Portland State University's Women's Studies Department since 2002. She holds a Master's Degree in Education, a B.A. in English, and Certificates in Women's Studies and Black Studies. Her courses include Intro to Women's Studies Sophomore Inquiry; bell hooks; Living for Change; 
Women Writing and Memoir; Contemporary Women Writers; Women, Love \& Selfcare; Women, Writing \& Personal Transformation; and Women of Color in the U.S. Roslyn spent five years as the Executive Director of the Oregon Commission for Women, and is the founder of All About Community, a consulting business dedicated to building the beloved community, one person, one organization, one community at a time. Roslyn is also the founder and teacher of a spiritual community called The Beloved Sangha. Roslyn's mission, based on the philosophy of Dr. Martin Luther King, Jr., is to build Beloved Community - community based on unconditional love, where all people have a voice.

Rosalie Gerut is the daughter of Holocaust survivors from Vilne, Lithuania and Lodz, Poland, and is also a founding member of One By One, an organization committed to transforming the legacies of conflict, war, and genocide through facilitated dialogue, public presentations, art exhibits, and educational forums. Her lifetime pursuits have been in the areas of music and psychology, where she is dedicated to finding methods of healing from trauma. In 1993 she volunteered to attend a special meeting that brought together descendants of the Holocaust and the Third Reich. During this intensely moving gathering, she found a way to overcome the suffering of her people together with people from the other side who were looking to regain their humanity. Together they formed One by One, Inc. and have been working ever since, bringing together people polarized by war, genocide and conflict to pursue tikkun olam ("repairing the world") together. Rachel Hardesty has taught about education subjects since 1984, and her activism around criminal justice inspired a research agenda related to the death penalty in Oregon. Her interest is in restorative and non-violent responses to extreme violence. She runs a 
Compassionate Listening Project with those entangled in the death penalty system, is a trained mediator and facilitator of victim-offender meetings, and facilitates Circles of various kinds (in particular healing, talking, learning). She is also an adjunct instructor at Capella University where she works in the public safety department as a course facilitator, subject matter expert writing courses and dissertation mentor. From 20082010 she was the chair of the Teaching Committee for the American Society of Criminology. She is a lifetime member of the capital defenders group of Oregon Criminal Defense Lawyers Association, and her research interests include restorative androgogies, online education, restorative justice, and the death penalty.

Tom H. Hastings is full-time faculty for the graduate program in Conflict Resolution at Portland State University and part-time faculty in the Portland Community College Peace and Conflict certificate program. He is on the Governing Council of the International Peace Research Association, past co-chair of the Peace and Justice Studies Association (and current board member), and on the Academic Advisory Board of the International Center on Nonviolent Conflict. He directs PeaceVoice, a program of the Oregon Peace Institute, and has written several books and many articles about nonviolence and other peace and conflict topics. He is a former Plowshares resister and a founding member of two Catholic Worker communities, and currently lives in Whitefeather Peace House.

Roberta Hunte graduated with her Masters in Conflict Resolution from PSU in 2006 and is a Doctoral Candidate with the Arthur V Mauro Centre for Peace and Justice Studies at the University of Manitoba in Winnipeg, Canada. Her research explores the experiences of African American tradeswomen in the building trades as they overcome 
structural and cultural barriers. Roberta is an adjunct instructor with Portland State in the Graduate Program in Conflict Resolution, the Child and Family Studies Program, and in the University Studies Department. She is originally from Virginia and has lived in South Africa and Canada.

Isbel Ingham teaches social justice courses at Portland State University, including Participating in Democracy, Introduction to Social Justice, Social Liberation, Feminism and Conflict Resolution, and Facing History. Her personal experience as an activist coupled with her professional experience as a counselor, mediator, and diversity trainer, supply her with an abundance of stories that support her teaching. For thirty years she has led support groups that seek to dismantle oppression, in particular racism, sexism, classism and homophobia. She is particularly interested in the sociology of educational equity, and recycling and reuse campaigns that strive to reclaim environmental harmony. As the grandmother of seven, Isbel immerses herself in community, and works to create a sustainable and just world for all.

John Lenssen is a consultant working with schools, universities, governmental agencies, and non-profits on issues of cultural competency, leadership, conflict resolution, and organizational change. $\mathrm{He}$ is also an adjunct faculty member at the University of Oregon and Lewis and Clark College, teaching graduate level courses on leadership, equity, and cultural competency. He was formerly the leader of the Access and Equity Team and coordinator of the Safe and Drug Free Schools Program at the Oregon Department of Education, and also served as an administrator in the Educational Opportunities Program at Oregon State University and the Office of Minority Affairs at the University of Washington. He is an associate with Stir Fry Seminars and Consulting 
in Berkeley, California, Education and Training Consultants, Inc., in Oregon, and Workplace Solutions in New York.

Kim Stafford is the author of a dozen books of poetry and prose, and the director of the Northwest Writing Institute and the William Stafford Center at Lewis \& Clark College, where he has taught since 1979. He holds a Ph.D. in medieval literature from the University of Oregon, and has worked as a printer, photographer, oral historian, editor, and visiting writer at a host of colleges and schools. His book, Having Everything Right, won a citation for excellence from the Western States Book Awards in 1986. Stafford has received creative writing fellowships form the National Endowment for the Arts, a Governor's Arts Award for his contributions to Oregon's literary culture, and his work has been featured on National Public Radio. 